University of Rhode Island

DigitalCommons@URI

Open Access Dissertations

2015

\title{
A Numerical Study of the Circulation, Ecology and Biogeochemistry on the Southern New England Shelf
}

Shuwen Zhang

University of Rhode Island, shuwen_zhang@my.uri.edu

Follow this and additional works at: https://digitalcommons.uri.edu/oa_diss

\section{Recommended Citation}

Zhang, Shuwen, "A Numerical Study of the Circulation, Ecology and Biogeochemistry on the Southern New England Shelf" (2015). Open Access Dissertations. Paper 396.

https://digitalcommons.uri.edu/oa_diss/396

This Dissertation is brought to you for free and open access by DigitalCommons@URI. It has been accepted for inclusion in Open Access Dissertations by an authorized administrator of DigitalCommons@URI. For more information, please contact digitalcommons-group@uri.edu. 
A NUMERICAL STUDY OF THE CIRCULATION, ECOLOGY AND BIOGEOCHEMISTRY ON THE SOUTHERN NEW ENGLAND SHELF BY SHUWEN ZHANG

A DISSERTATION SUBMITTED IN PARTIAL FULFILLMENT OF THE REQUIREMENTS FOR THE DEGREE OF DOCTOR OF PHILOSOPHY IN OCEANOGRAPHY 


\section{DOCTOR OF PHILOSOPHY DISSERTATION}

OF

\section{SHUWEN ZHANG}

APPROVED:

Dissertation Committee:

Major Professor $\quad$ Lewis M. Rothstein
Susanne Menden-Deuer
David Bengtson
Dave Ullman
Nasser H. Zawia
DEAN OF THE GRADUATE SCHOOL

UNIVERSITY OF RHODE ISLAND

2015 


\begin{abstract}
This Ph.D. dissertation presents a process-oriented study with two primary objectives: 1) to obtain a physical understanding of the impacts of local and remote forcing, including basin-scale natural climate variability, on the interannual variability of along-shelf transport and water properties of the Middle Atlantic Bight (Chapter 1); 2) to explore the impacts of physical processes on the seasonal variation of phytoplankton biomass in Rhode Island coastal waters (Chapter 2). To achieve the two objectives, we apply a numerical modeling approach employed by the Regional Ocean Modeling System (ROMS) together with substantive analyses of both in-situ and remote observations.

Chapter 1 focuses on the interannual-to-decadal variability of along-shelf transport and water properties of the Middle Atlantic Bight (MAB). A suite of process oriented numerical experiments is designed for separating local and remote forcing in order to explore their contributions to the interannual-to-decadal variability of along-shelf transport. Results show that the low-frequency variability is dominated by remote forcing from the open boundaries of the region. The penetration of the Labrador Current into the region contributes to a significant increase of along-shelf transport in the winters of 2009 and 2010. By contrast, the anticyclonic mesoscale eddies associated with the Gulf Stream have a negative impact on the along-shelf jet, and in certain cases even reverse the alongshelf transport. The along-shelf transport is also found to possess a decadal transition, i.e. weaker during 2004-2008 but stronger during 2009-2013.
\end{abstract}


Chapter 2 focuses on the mechanisms controlling the seasonal variation and spatial distribution of phytoplankton biomass in Rhode Island (RI) coastal waters. We first apply an Empirical Orthogonal Function (EOF) analysis to a nine-year monthly chlorophyll-a dataset in order to determine the spatial/temporal structure of the signal. The first EOF mode shows that the spatial variations of chlorophyll-a are in phase from the RI coast to the outer shelf, and the temporal variations are dominated by the strong seasonal cycle characterized by a broad peak during the fall-winter months (October to March). The spatial distribution of chlorophyll-a indicates that the phytoplankton biomass decreases with distance offshore as the water depth increases. To understand the mechanisms controlling the abovementioned features, we first set idealized onedimensional (1-D) numerical experiments, using a physical-biological model (ROMSNPZD), to isolate advective processes. Results show that the fall-winter bloom is initiated by enhanced vertical turbulent mixing, which results from the combined effects of the increased surface momentum forcing and surface cooling, bringing nutrients up into the euphotic zone. The extensive mixing also has a counteractive effect on the fall-winter bloom as phytoplankton are carried below the euphotic layer. A three-dimensional (3-D) experiment is then conducted to validate the key conclusions drawn from 1-D simulations from which we find that results from the 3-D experiment are qualitatively in agreement with those from the 1-D experiments. 


\section{ACKNOWLEDGMENTS}

I am sincerely grateful to my advisor, Dr. Lew Rothstein, for his guidance, patience and encouragement. Thank you to Dr. Susanne Menden-Deuer, Dr. David Bengtson, Dr. David Ullman and Dr. James Opaluch for serving on my core committee and providing valuable advice. A special thank you goes to Dr. Yiyong Luo, who volunteered his much appreciated time and expertise for this work. I am appreciative to many scientists from GSO, WHOI and Rutgers University for insightful discussions on this work.

Funding for my research was received from Department of Energy, Rhode Island STAC Collaborative Research Grants and NSF Rhode Island EPSCoR, for which I am very grateful. Moreover, many thanks to GSO Alumni Awards for generously supporting my conference trips.

I thank all of my friends and loved ones from home and school for keeping company with me also guiding me even when you didn't realize you were. I owe a special thank you to my husband Kun Gao, for his ceaseless selflessness. Words fall short of describing the extent of the support that he lent to me as well as the contributions that he made during this journey. 


\section{DEDICATION}

To my dearest parents and my husband. 


\section{PREFACE}

This dissertation is written in manuscript format and consists of two scientific journal articles. The first chapter has been submitted to Continental Shelf Research and is under revision. The second chapter is in preparation and will be submitted to Estuarine, Coastal and Shelf Science. 


\section{TABLE OF CONTENTS}

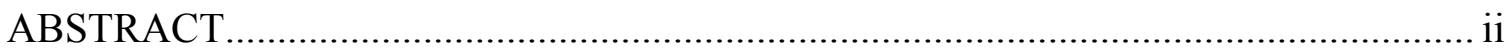

ACKNOWLEDGMENTS ................................................................................ iv

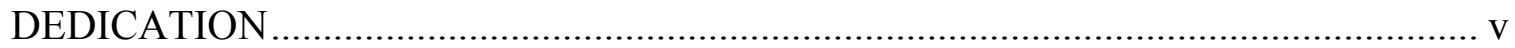

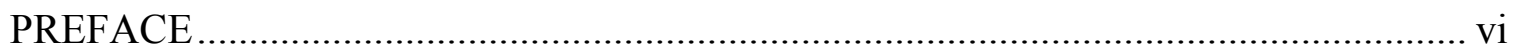

TABLE OF CONTENTS ................................................................................... vii

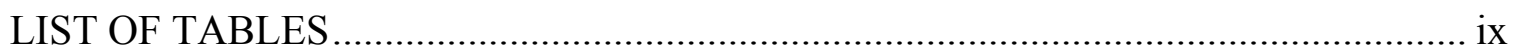

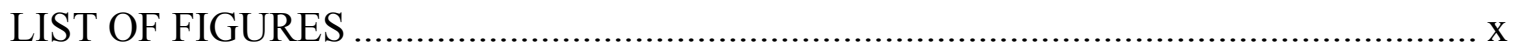

Chapter 1 A Numerical Investigation of the Interannual-to-Decadal Variability of the

Along-shelf Transport in the Middle Atlantic Bight..................................................... 1

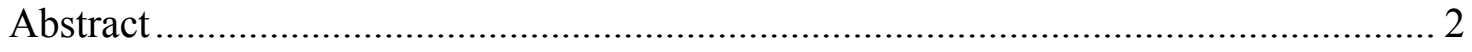

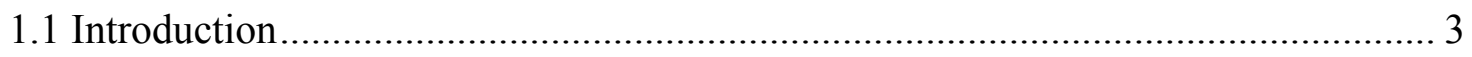

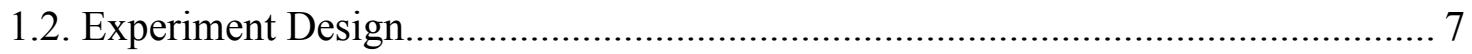

1.2.1. Experiment REAL ........................................................................ 7

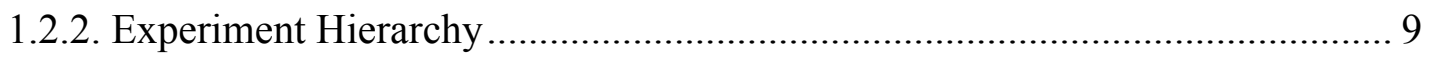

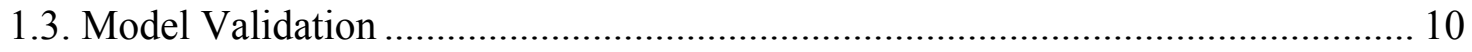

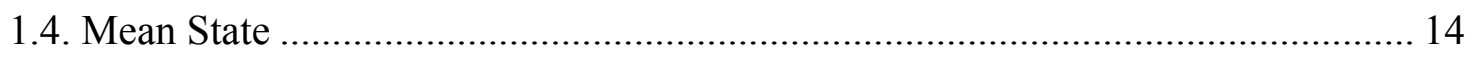

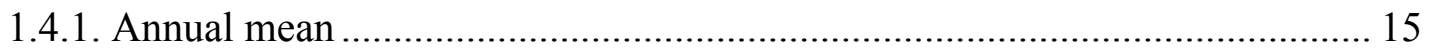

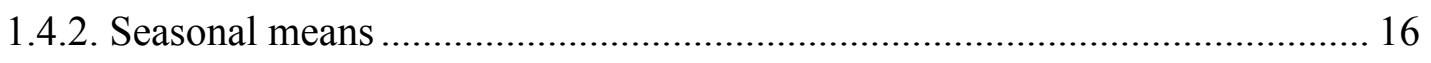

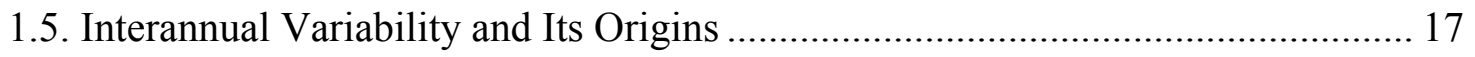

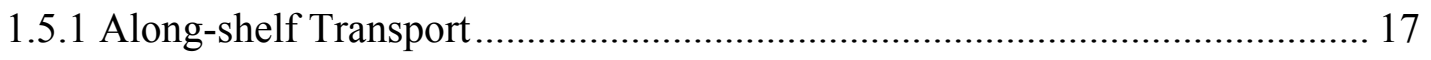

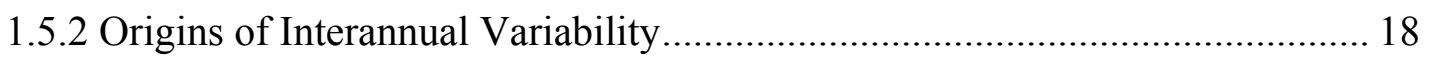

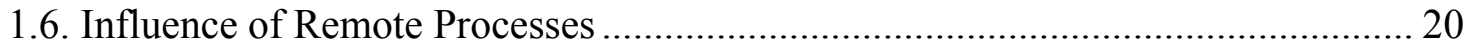




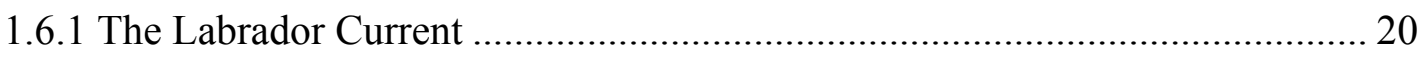

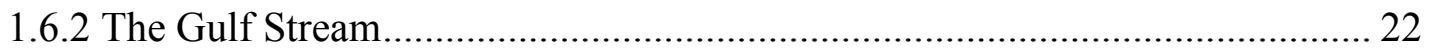

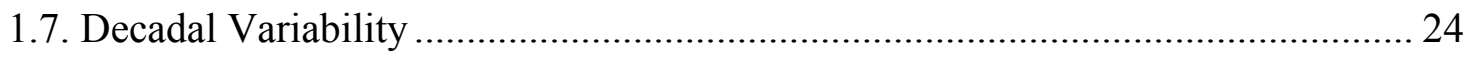

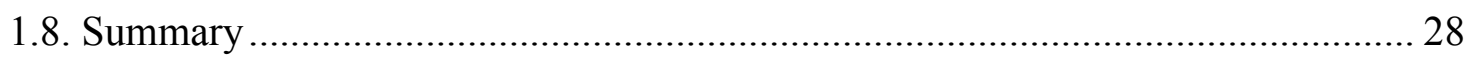

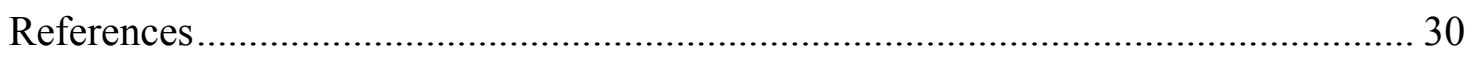

Chapter 2 Physical Controls on Phytoplankton Blooms in Rhode Island Coastal Waters 55

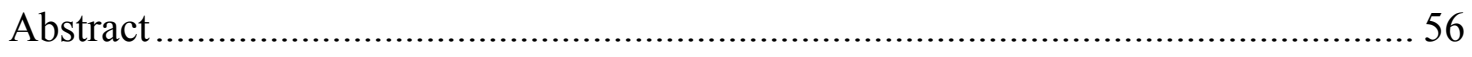

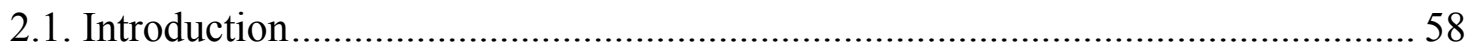

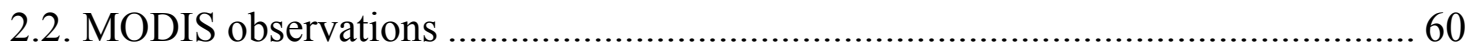

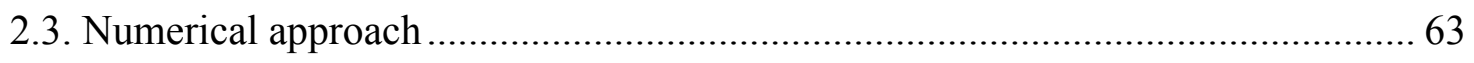

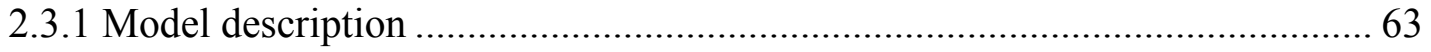

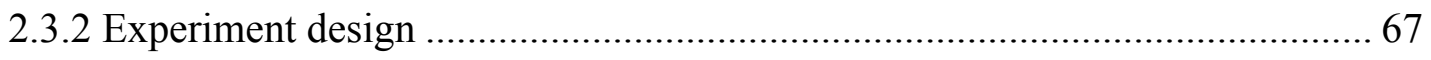

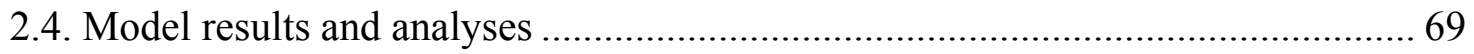

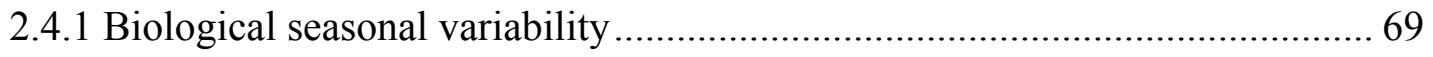

2.4.2. Mechanisms responsible for the fall-winter phytoplankton bloom ................ 72

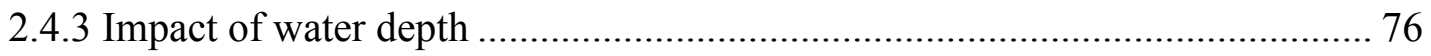

2.4.4 Results from the three-dimensional experiment ............................................ 78

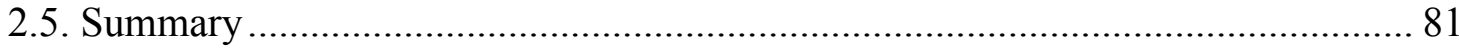

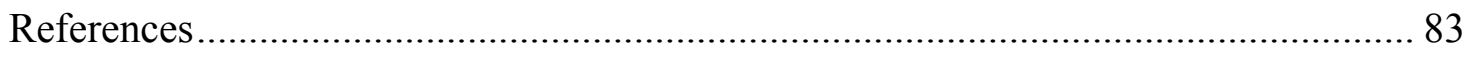

Appendix A: Model sensitivity to biological parameters ......................................... 106

Appendix B: Choice of background turbulent diffusivity ……................................... 110 


\section{LIST OF TABLES}

1-1 Hierarchy of experiments conducted in this study.

1-2 Comparison between modeled and observed (Lentz, 2008a) along-shelf volume transport at six cross-shelf transects within the MAB. The standard deviations are listed in parenthesis. The coastal endpoints of each transect and the water depth at

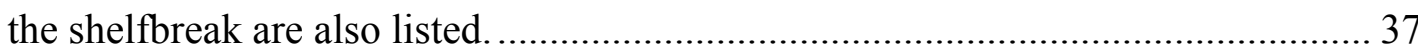

2-1 Biological parameters used in this study and the ranges in previous studies. 87 


\section{LIST OF FIGURES}

1-1 Map of the Northeast U.S. continental shelf/slope region and the regional-scale ROMS model domain (black box). The primary geographical features are the Scotia Shelf (SS), the Gulf of Maine (GoM), Georges Bank (GB), the Middle Atlantic Bight (MAB) and Cape Hatteras (CH). The 50, 100, 1000 and $3000 \mathrm{~m}$ isobaths are represented by black contours. Principal circulation features are equatorward flow of shelf and slope waters and poleward flow of the Gulf Stream; a warm core ring is also depicted (Based on http://www.nefsc.noaa.gov/ecosys/ecology/Oceanography/). The three selected cross-shelf sections discussed in the text are marked as $T_{1}, T_{2}$ and $\mathrm{T}_{3}$ 38

1-2 Comparison of depth-averaged currents between the model (blue arrows) and observations (red arrows); the southern New England shelf area is highlighted and inserted in the lower right corner. Thick, light-grey lines indicate six cross-shelf transects from the coast to the shelfbreak; their corresponding locations are listed in Table 1-2. Black dashed lines are the two satellite tracks, along which the SSHA data are sampled. The 50, 100, and $1000 \mathrm{~m}$ isobaths are also shown.

1-3a The comparison between the model solutions for seasonal mean temperatures (left column) and the climatology produced by Linder et al. (2006) (right column) at middepth (40-55 m) in (a) winter, (b) spring, (c) summer, and (d) fall. Black line indicates $100 \mathrm{~m}$ isobath.

1-3b As in Figure 1-3a, but for salinity......

1-4 Hovmöller diagrams of satellite-observed (upper panel) and model-simulated (lower panel) cross-shelf transect of SSHA along (a) Track-126; (b) Track-50 from Jan 
2004 to Dec 2013. The black solid line and the dash line indicate the 1000 and 3000

$\mathrm{m}$ isobaths, respectively.

1-5 Mean-state surface velocity from experiment REAL. The shaded area denotes the region where the along-shelf average is obtained. The 50,100, 1000, and $3000 \mathrm{~m}$ isobaths are also shown.

1-6 Mean-state along-shelf (a) velocity (represented by the colors; negative values indicate southwestward direction); (b) salinity (34.5 PSU isohaline is highlighted by black contour); (c) temperature $\left(10^{\circ} \mathrm{C}\right.$ isothermal is highlighted by black contour) in the southern New England shelf/slope area (shaded area in Figure 1-5). 44

1-7 Cross-shelf distribution of the along-shelf momentum budget terms: (a) the Coriolis force, (b) the PGF, (c) the viscosity and (d) the nonlinear advection terms. 45

1-8 Cross-shelf distributions of the along-shelf velocity (represented by the colors; negative values indicate southwestward direction) and 34.5 PSU isohaline (black contour, indicating the shelfbreak front) averaged in the southern New England shelf/slope area in (a) February, (b) May, (c) August, and (d) November. 46

1-9 Time series of the along-shelf transport cross $T_{1}$ transect in different experiments: (a) REAL, WIND and SURF; (b) REAL and OBCs; (c) REAL, UPSTREAM and OFFSHORE. 47

1-10 Mid-depth (50m) distribution of (a) 10-year averaged winter temperature (color) and surface velocity (vectors) and (b) temperature anomaly for the 2009 winter (color) and surface velocity (vectors) from experiment REAL. (c) and (d) are for salinity. The 50,100, 1000, and $3000 \mathrm{~m}$ isobaths are also shown. 48 
1-11 Comparison between the winter-averaged physical fields in the climatological state (left) and in 2009 (right) along the northeastern boundary of the model domain. (a)(b): temperature, with $4^{\circ} \mathrm{C}$ and $8^{\circ} \mathrm{C}$ isothermals highlighted; (c)-(d) salinity, with 34 and 35 PSU isohalines highlighted; (e)-(f) along-shelf velocity, with the negative values indicating a southwestward current.

1-12 (Left Column) Monthly mean surface velocity (vectors) and current speed (color) for (a) 2004 October, (b) 2005 September and (c) 2007 July. (Right Column) Daily snapshots of gridded AVISO SLA on (d) Oct 6, 2004, (e) Sep 18, 2005 and (f) Jul 1, 2007. The 50, 100, 1000, and $3000 \mathrm{~m}$ isobaths are shown in all figures. 50

1-13 Cross-shelf distributions of the along-shelf velocity (represented by the colors; negative values indicate southwestward) and the potential density (represented by the black contours) along $\mathrm{T}_{1}$ section in (a) October 2004, (b) September 2005 and (c) July 2007.

1-14 Time series of the along-shelf transport integrated between 50 and $300 \mathrm{~m}$ from experiment REAL (black heavy lines) and experiment OBCs (black dashed lines) along (a) $\mathrm{T}_{1}$, (b) $\mathrm{T}_{2}$ and (c) $\mathrm{T}_{3}$. The transport anomalies (black thin lines) are calculated by subtracting OBCs from REAL. The five-year averaged along-shelf transports during 2004-2008 (2009-2013) are represented by the blue (red) lines in (a)-(c). Positive values indicate southwestward flow. The shaded areas denote winter months, which are December, January, February and March............................... 52

1-15 The winter (Dec-Mar) NAO index defined by Hurrell (1995), obtained from the NOAA National Weather Service Climate Prediction Center (http://www.cpc.ncep.noaa.gov/products/precip/CWlink/pna/nao.shtml). The blue 
area denotes smoothed values from a 5-year moving average (the mean of the five years preceding and including the data point). The moving average is often applied to remove the large year-to-year variability and to emphasize the longer term and more slowly varying changes of climate. Though a moving average can be of any length less than the length of the entire record, five years is commonly chosen because it emphasizes the decadal variability associated with changes in the regional and global atmospheric and oceanic circulations but maintains details of the timing and amplitude of decadal changes. 53

1-16 The spatial distribution of the SSH anomaly during 2004-2008, which is obtained by subtracting the 10-year averaged SSH from its average of 2004-2008, is represented by the colors. The climatological mean locations of the Gulf Stream North Wall from Taylor (2011) are denoted by the black dots. The 10-year averaged $35 \mathrm{~cm} \mathrm{SSH}$ from experiment REAL is highlighted by the white contour, and the annual averaged $35 \mathrm{~cm}$ SSH during 2004-2008 (2009-2013) are represented by the red (blue) contours. The $100 \mathrm{~m}$ and $1000 \mathrm{~m}$ isobaths are shown by thin black lines. 54

2-1 Surface chlorophyll-a concentrations averaged from the nine-year (2004-2012) MODIS dataset. Black contours are isobaths from $40 \mathrm{~m}$ to $80 \mathrm{~m}$ in $10 \mathrm{~m}$ interval. The black frame indicates the study area for the EOF analysis. The two black dots indicate two locations that are representative of the inner $(40 \mathrm{~m})$ and outer $(80 \mathrm{~m})$ shelf, respectively. 88

2-2 Anomalous spatial eigenfunctions (upper panel) and time-varying amplitudes (upper) for Mode 1 from the EOF analysis of the 9-year MODIS observations. The gray transparent areas indicate the fall-winter months (October to March). 89 
2-3 EOF mode1 monthly- and spatially- averaged chlorophyll-a concentration in the study area (upper) and surface wind speed (lower) during January 2004-December 2012. The gray transparent areas indicate the fall-winter months (October to March).

2-4 Climatological monthly chlorophyll-a concentrations at two locations (indicated in Figure 2-1) at depths of $40 \mathrm{~m}$ and $80 \mathrm{~m}$, respectively. The error bars are the standard deviation of the mean in each month.

2-5 Bathymetry of the three-dimensional model domain. Black contours are isobaths from $40 \mathrm{~m}$ to $80 \mathrm{~m}$ in $10 \mathrm{~m}$ intervals. The black rectangle denotes the Rhode Island coastal region, which is the average area for the model-simulated chlorophyll and turbulent diffusivity. The black line indicates the cross-shelf transect that is discussed in the text.

2-6 Annual cycle of surface chlorophyll concentrations in the five 1-D experiments H40H80. The water depths used in these experiments are indicated in the figure. Note the $\mathrm{x}$-axis indicates one year from July 1st through June 30th 93

2-7 Time-depth distributions of N, P, Z and D during one year for experiment H40 (water depth is $40 \mathrm{~m}$ ) 94

2-8 Same as Figure 2-7, but for experiment H80 (water depth is $80 \mathrm{~m}$ ). 95

2-9 Time-depth distributions of the phytoplankton budget terms over the course of a climatological year. (a) DPT: the local changes of the phytoplankton with time; (b) BIO: the sum of phytoplankton growth, zooplankton excretion/egestion and phytoplankton mortality; (c) DIF: the physical effects of vertical diffusion on phytoplankton. See equation (2) in the text. 96 
2-10 Time-depth distributions of: (a) phytoplankton growth rate (U); (b) the MichaelisMenten curve as a function of nitrate concentration $\mathrm{f}(\mathrm{N})$ and; (c) the photosynthesislight (P-I) relationship f(I) during a climatological year. 97

2-11 Climatological surface (a) momentum forcing (solid - wind speed; dashed - wind direction, zero degree is eastward) and (b) net heat flux $\left(\mathrm{W} \mathrm{m}^{-2}\right)$.

2-12 Time-depth distributions of (a) velocity along the wind direction; (b) velocity cross the wind direction; (c) temperature; (d) turbulent diffusivity coefficient during a climatological year.

2-13 Winter-averaged (November-March) profiles of (a) turbulent diffusivity $\left(k_{v}\right),(\mathrm{b})$ turbulence kinetic energy (TKE), (c) turbulence length scale $(l)$.

2-14 Time-averaged (November-March) profiles of (a) current velocities (sold - the velocity along the surface wind direction; dashed - the velocity cross the surface wind direction) and (b) vertical shear. 101

2-15 Time-averaged (November-March) profiles of the phytoplankton budget terms. The solid lines are the DIF terms and the dashed lines are the BIO terms (see Equation 2 in the text). 102

2-16 Surface chlorophyll fields in (left column) the three-dimensional model simulation and (right column) the MODIS observations for four typical months. The black box in the right column indicates the model domain. 103

2-17 (a) Monthly mean and standard deviation of the surface chlorophyll and (b) monthly mean of the turbulent diffusivity at $15 \mathrm{~m}$ depth spatially averaged within the Rhode Island coastal region (indicated by the black box in Figure 2-5) 104 
2-18 Cross-shelf distributions of (left column) the turbulent diffusivity and (right column) the phytoplankton biomass along the transect shown in Figure 2-5.

2-A1 Parameter sensitivity derived from a series of 1-D sensitivity experiments. The histogram represents maximum normalized RMSD for each parameter with respect to the control simulation (experiment H40 in the main text; see Table 2-1 for parameter names, units and control values). For a given parameter, the blue/red bars indicate the maximum normalized RMSD after decreasing/increasing the control value by $50 \%$, respectively.

2-A2 Annual cycle of the surface chlorophyll concentrations in the sensitivity experiments. Black solid lines indicate the result from the control simulation; black/grey dashed lines are the results from the experiments in which the biological parameters are increased/decreased by $50 \%$, respectively. Note the $\mathrm{x}$-axis indicates one year from July 1st through June 30th. 112

2-A3 Annual cycle of temperature at three depths (red $1 \mathrm{~m}$; blue $6 \mathrm{~m}$; magenta $28 \mathrm{~m}$ ) from: (a) one-year mooring dataset, black dots indicate historic observation at this location; (b) with $\mathrm{k}_{\text {back }}=1 \times 10^{-5} \mathrm{~m}^{2} \mathrm{~s}^{-1}$; (c) with $\mathrm{k}_{\mathrm{back}}=1 \times 10^{-4} \mathrm{~m}^{2} \mathrm{~s}^{-1}$; (d) with $\mathrm{k}_{\mathrm{back}}=1 \times 10^{-3} \mathrm{~m}^{2} \mathrm{~s}^{-1}$ 113 


\section{CHAPTER 1}

A Numerical Investigation of the Interannual-to-Decadal Variability of the Alongshelf Transport in the Middle Atlantic Bight

by

Shuwen Zhang ${ }^{1}$, Yiyong Luo ${ }^{1}$ and Lewis M. Rothstein ${ }^{1}$

Submitted to Continental Shelf Research

${ }^{1}$ Graduate School of Oceanography, University of Rhode Island, Narragansett, RI 02882. 


\begin{abstract}
A numerical simulation using the Regional Ocean Modeling System (ROMS) indicates that there is significant interannual-to-decadal variability of along-shelf transport and water properties over the Middle Atlantic Bight (MAB) from 2004-2013. To examine the relative contribution from local atmospheric forcing versus remote, oceanic open boundary forcing to such low-frequency variability, we implement a suite of process oriented numerical experiments. Results show that the interannual variability is dominated by remote forcing from the open boundaries of the region rather than by local atmospheric forcing. The penetration of the Labrador Current into the region contributes to a significant increase of along-shelf transport in the winters of 2009 and 2010. By contrast, the anticyclonic mesoscale eddies associated with the Gulf Stream decrease the background along-shelf jet and, in certain cases, even reverse the along-shelf transport. In addition, the along-shelf transport appears to have a decadal transition, i.e., weaker during 2004-2008 but stronger during 2009-2013.
\end{abstract}




\subsection{Introduction}

The Northeast U.S. continental shelf/slope region encompasses an area of approximately $260,000 \mathrm{~km}^{2}$ from the Scotia Shelf in the north to Cape Hatteras in the south, covering the Gulf of Maine/Georges Bank (GoM/GB) and the entire Middle Atlantic Bight (MAB). The MAB shelf is widest off southern New England, extending over $200 \mathrm{~km}$ seaward from shore, and is relatively narrower off Cape Hatteras where the shelfbreak is approximately $30 \mathrm{~km}$ from shore (Figure 1-1).

The primary water masses of this region are the relatively cold and fresh Shelf Water and the warm and saline Slope Water. The boundary between these two water masses occurs in a narrow transition region referred to as the shelf/slope front (Mountain, 2003). Associated with this front is a narrow, southwestward flowing baroclinic jet that, to leading order, is in geostrophic balance. The front/jet system itself is part of the basinscale, buoyancy-driven coastal current system originating as the East Greenland Current from the north, and ultimately being entrained into the Gulf Stream near Cape Hatteras. Along its path, the front/jet system is modified by various factors, including freshwater runoff and offshore recirculation, and experiences a substantial decrease in volume transport (Loder et al., 1998).

Quantifying the along-shelf transports and cross-shelf exchanges of the shelfbreak region have been long-standing research topics (e.g., Beardsley et al., 1981). A mass and salinity balance in the MAB indicates that approximately three quarters of the water that passes south of Nantucket leaves the shelf by the time it reaches Delaware and a third of the water that is lost is replaced by the more saline waters of the upper slope (Biscaye et al., 1994). Clearly, these transport change must involve a considerable amount of cross- 
shelf exchanges of mass, heat, freshwater, and nutrients. But how these transport changes are accomplished and which processes are responsible for various portions of the exchange has not yet been satisfactorily documented. Intensive in-situ studies since the 1970s have been carried out using moorings and hydrographic surveys at various locations during different time periods (NESDE, Beardsley and Flagg, 1976; NSFE, Beardsley et al., 1985; SEEP-I, Walsh et al., 1988; SEEP-II, Biscaye et al., 1994; and CMO/PRIMER, Dickey and Williams, 2001), all with the common goal of understanding the dynamics of the front and the critical shelf and slope exchange processes. The hydrography of the shelfbreak region has been described in a number of syntheses, the latest of which is produced by Linder and Gawarkiewicz (1998) and Linder et al. (2006). A difficulty common to all these efforts is how to interpret the episodic and discontinuous observations to form a statistically significant description of the frontal structure accounting for the influence of onshore and offshore front fluctuations.

High spatial resolution and temporally continuous numerical simulations of ocean state variables have become important additional tools for obtaining a better understanding of the shelf/slope circulation and for quantifying its variations. Chen et al. (2001) employed the Finite-Volume Community Ocean Model (FVCOM), configured as a three-dimensional model covering the region from New Jersey to the Nova Scotia shelf, to examine the climatological circulation and its seasonal transition over the GoM/GB. Chen and He (2009) employed the Regional Ocean Modeling System (ROMS) to produce a three-dimensional hindcast of the MAB and GoM during 2004-2008. A more detailed study focusing on the mean state of shelfbreak circulation and the total water transport across the $200 \mathrm{~m}$ isobath over the MAB was reported in their succeeding paper 
(Chen and He, 2010). However, neither the abovementioned climatology or the four-year numerical simulations are sufficient for addressing the interannual variability of the shelfbreak front/jet system that might occur in response to local forcing and/or basinscale natural climate variability.

There is growing evidence that interannual variations in the Northeast U.S. continental shelf/slope region must be linked to processes on a much larger scale, since the entire area is located within a western boundary 'confluence zone', with the subpolar gyre and Labrador Current/Scotia Shelf waters moving southwestward, and the subtropical gyre and the Gulf Stream moving northeastward (Beardsley and Flagg, 1976). A revealing view of the variability in the region suggests that the Gulf Stream, the slope sea, as well as the GoM/GB and MAB shelf are all impacted by variations in the atmospheric circulation over the subpolar regions (Flagg, 2006), dominated by the North Atlantic Oscillation (NAO). One of the more striking periods in the recent record is the 1990s; Drinkwater et al. (2002), Pershing et al. (2001), and Greene and Pershing (2003) all have posited that the large drop in the winter NAO index in 1996, and the associated changes in atmospheric forcing over the Labrador Sea, were responsible for a cold/fresh Labrador Slope Water flux into the slope sea, up onto the Scotian Shelf and through the Northeast Channel into the Gulf of Maine in 1998. Rossby and Benway (2000) suggested that the behavior of the Gulf Stream south of New England was linked to the Labrador Slope Water that flowed into the slope sea around the Tail of the Grand Bank, and Rossby et al. (2005) illustrated an $\sim 100 \mathrm{~km}$ southward shift of the Gulf Stream axis beginning in mid-1995, peaking in 1998 before recovering to a more northerly position in 2000. In addition, recent studies reveal that there is a significant correlation between 
near-surface transport in the Gulf Stream and the NAO index (Rossby et al., 2010), as well as between Gulf Stream associated warm-core rings and the state of the NAO (Chaudhuri et al., 2009). The only study of the correlation between the local along-shelf transport off southern New England and the NAO was conducted by Luo et al. (2013) using a regional circulation model that was focused on the period 2004-2009. This study found that the along-shelf transport near the shelfbreak is negatively correlated with the NAO index, with a lag of 13 months. However, their 6-year simulation resulted in a less than compelling statistical argument.

In this study, we aim to advance our understanding of the interannual variability of the MAB shelf/slope circulation and water properties by extending the numerical modeling approach employed by Luo et al. (2013). Specifically, we extend the regional model domain in Luo et al. (2013) to include the influence of the Gulf Stream as well as increasing the length of the simulation to a decade. With this, our objective is to further investigate the interannual variability of along-shelf transport and water properties of the $\mathrm{MAB}$, and to better understand the underlying physical mechanisms controlling such interannual variability.

The rest of this chapter is organized as follows. The numerical model configuration, a realistic simulation from 2004-2013 and a suite of process-oriented numerical experiments are described in Section 2, followed by model verification in Section 3. The mean state of the shelf/slope system during the decade under investigation is discussed in Section 4. Analyses of the interannual variability of the along-shelf transport and its origins are presented in Section 5, and the underlying physical mechanisms are presented in Sections 6. The decadal variation of along-shelf transport during the 10-year 
simulation and plausible mechanisms are explored in Section 7. Finally, Section 8 summarizes the results and the important findings of this study.

\subsection{Experiment Design}

\subsubsection{Experiment REAL}

Our numerical simulations use the Regional Ocean Modeling System (ROMS). ROMS is a free-surface, hydrostatic, terrain-following, primitive equations ocean model widely used by the scientific communities for estuarine, coastal and basin-scale ocean applications. The algorithms that comprise ROMS computational nonlinear kernel are described in detail in Shchepetkin and McWilliams (2005). Our regional-scale ROMS implementation is bounded by Cape Hatteras to the south and the Scotia Shelf to the north, covering the GoM/GB and the entire MAB (black box in Figure 1-1), with a constant $5 \mathrm{~km}$ horizontal resolution. The topography is derived from the 1 arc-minute ETOPO1 Global Relief Model of Earth's surface and the bathymetry ranges from 10 to $5000 \mathrm{~m}$ within our model domain. There are 30 terrain-following levels in the water column with the highest resolution of $0.33 \mathrm{~m}$ near surface and the lowest resolution of $485.3 \mathrm{~m}$ at depth.

The open boundary conditions are provided by a global eddy-resolving numerical solution produced by the Hybrid Coordinate Ocean Model/Navy Coupled Ocean Data Assimilation (HYCOM/NCODA, http://hycom.org/dataserver/glb-analysis). HYCOM/ NCODA provides three-dimensional ocean state variables with $1 / 12^{\circ}$ resolution in both longitude and latitude, with 32 vertical layers. The output used for this study spans from January 2004 to December 2013; a monthly climatology for each variable (velocity, temperature and salinity) is used as boundary conditions for the model's spin-up. An 
interior relaxation procedure was required in order to remedy a well-known ROMS problem with Gulf Stream separation at Cape Hatteras (John Wilkin, personal communication). For this we relaxed ROMS tracers and baroclinic velocities in the deep Slope Sea below $3000 \mathrm{~m}$ towards the HYCOM solution with a 3-day time scale so that the Gulf Stream pathway is constrained to the appropriate position. The cause of this problem with ROMS is beyond the scope of our study.

Free surface and depth-averaged velocities are specified using the method of Flather (1976) with external sub-tidal values taken from HYCOM/NCODA plus five tidal constituents $\left(\mathrm{M}_{2}, \mathrm{~N}_{2}, \mathrm{~S}_{2}, \mathrm{O}_{1}, \mathrm{~K}_{1}\right)$ from the global ocean tides model TPXO7.2 (http://volkov.oce.orst.edu/tides/TPXO7.2.html). The tidal input provides needed tidal mixing, hypothesized as an important element of the regional circulation. In addition, a quadratic drag formulation is employed for bottom stress with the value of the quadratic bottom drag coefficient as $7.5 \times 10^{-3}$, and the Mellor-Yamada Level 2.5 turbulence closure scheme is chosen for vertical mixing (Mellor and Yamada, 1982).

The local surface forcing is derived from the National Oceanic and Atmospheric Administration (NOAA) National Centers for Environmental Prediction North America Regional Reanalysis (NCEP/NARR), which has spatial and temporal resolutions of 32 $\mathrm{km}$ and 3 hours, respectively. All of the atmospheric components (winds, air temperature, air pressure, relative humidity, rainfall rate, short and long wave radiations) are averaged into daily intervals, spanning from January 01, 2004 to December 31, 2013. Bulk formulae are used for the computation of the surface momentum, sensible and latent heat fluxes. To further constrain the spatial pattern of the net surface heat flux, a thermal relaxation term is implemented following He and Weisberg (2002): 


$$
K_{H} \frac{\partial T}{\partial Z}=\frac{Q}{\rho C_{p}}+c\left(T_{o b s}-T_{m o d}\right)
$$

where $K_{H}$ is a vertical diffusivity coefficient, Q is the net heat flux, and $\rho$ and $C_{p}$ are the seawater density and specific heat capacity, respectively. The relaxation coefficient $c$ is set as $0.8 \mathrm{~m} \mathrm{day}^{-1}$, and the model simulated sea surface temperature $T_{\text {mod }}$ is subtracted from $T_{o b s}$, which is the daily blended cloud-free sea surface temperature obtained from the Jet Propulsion Laboratory Multi-scale Ultra-high Resolution Sea Surface Temperature (JPL MUR-SST, http://mur.jpl.nasa.gov/).

Fresh water outflow is incorporated using the United States Geological Survey (USGS, http://www.usgs.gov/water/) stream gauge climatological datasets from seventeen major rivers. These are, from north to south, St. Johns River, St. Croix River, Penobscot River, Kennebec River, Androscoggin River, Merrimac River, Neponset River, runoff from Narragansett Bay (including Taunton River, Blackstone River, Pawtuxet River), Pawcatuck River, Connecticut River, Housatonic River, Hudson River, Delaware River and Potomac River.

The model is initialized with January climatological conditions, and the barotropic and baroclinic time steps are 2.5 and 75 seconds, respectively. The model is first spun up with monthly climatological forcing for 2 years, and then integrated with the surface and open boundary forcing from January 2004 to December 2013 to produce the targeted tenyear dataset. We label this experiment as REAL in Table 1-1.

\subsubsection{Experiment Hierarchy}

In addition to the above-described REAL experiment, we have also performed five parallel sets of experiments with ROMS to examine the response of the oceanic 
circulation and along-shelf front/jet system to various external forces, including local surface forcing and remote forcing both from upstream and offshore open boundaries (Table 1-1). For all of the experiments, the first two-year spin-up periods are exactly the same as REAL, while the difference is described in the following.

Experiment WIND investigates the influence from surface winds, so we change the atmospheric wind components to their 10-year climatology with monthly variations.

Experiment SURF aims to examine the combined impacts from surface momentum and buoyancy fluxes, therefore all of the atmospheric components, as well as SST relaxation, are changed to their 10 -year climatology with monthly variations.

Experiment $\mathrm{OBCs}$ is designed to test the effects from the open boundary conditions. Consequently, the model is integrated with the monthly climatology of all the open boundary conditions but still keeps the 10-year surface forcing with interannual variations.

The final two experiments are designed to further investigate the impacts from upstream and offshore forcing, respectively. Experiment UPSTREAM keeps the upstream open boundary as climatology while changing the offshore open boundary to respond to the 10-year interannual variability. Experiment OFFSHORE keeps the offshore open boundary as climatology while the upstream open boundary is forced by the 10 -year interannual variability.

\subsection{Model Validation}

For the purpose of model validations we compare our most realistic results (experiment REAL) with three different observational datasets. 
A direct comparison of mean depth-averaged shelf currents at 27 locations over the MAB between the model and the observations is presented in Figure 1-2. The observations are from Lentz (2008a) in which he obtained the time series of the depthaveraged currents longer than 200 days. The model results are derived from experiment REAL in which the mean currents are averaged from 2004-2013. Consistent with the observations, the model shows that the depth-averaged mean along-shelf currents at all sites are approximately along isobaths and increase with water depth over the shelf from $\sim 3 \mathrm{~cm} \mathrm{~s}^{-1}$ on the inner shelf to more than $10 \mathrm{~cm} \mathrm{~s}^{-1}$ in $100 \mathrm{~m}$ water depth. While differences in both speed and direction exist for each pair of comparisons, the model overall does a highly satisfying job, with the RMSEs of the speed and the direction being less than $1 \mathrm{~cm} \mathrm{~s}^{-1}$ and $10^{\circ}$, respectively. These differences could be attributed to the model resolution and topographic smoothing, especially for one site off the Maryland coast.

Next, the model simulated along-shelf volume transport is compared at six crossshelf transects with those reported by Lentz (2008a) (Table 1-2). The volume transports are obtained by numerically integrating each cross-shelf transect, which is indicated by the thick light-grey lines in Figure 1-2. Overall, the along-shelf transport estimates decrease from Cape Cod to North Carolina, consistent with the idea that shelf water is continually entrained into the offshore shelfbreak frontal jet from north to south over the MAB, characterized as a so-called 'leaky pipe' by Lozier and Gawarkiewicz (2001). The relatively low along-shelf volume transport off Georges Bank is mainly due to the Gulf Stream warm-core rings that induce shelf-water entrainment, and the higher transport off southern Cape Cod is caused by the outflow from the Gulf of Maine through the Great 
South Channel. This occurs more frequently here than over the MAB (Chaudhuri et al., 2009).

We next sampled the mid-depth $(40-55 \mathrm{~m})$ model temperature and salinity to obtain their seasonal cycle over the entire MAB plus the Georges Bank continental shelf/slope region, and compared that with the climatologies constructed by Linder and Gawarkiewicz (1998) and Linder et al. (2006). This comparison is presented for four three-month seasons: winter (Jan-Feb-Mar), spring (Apr-May-Jun), summer (Jul-AugSep), and fall (Oct-Nov-Dec); Figures 1-3 a, b respectively. The model generally captures thermohaline features well. There is a large seasonal variation in the cross-shelf thermal gradient with the largest value near the $100 \mathrm{~m}$ isobath (black contours in Figure 1-3a), corresponding to the position of the shelfbreak front. In winter, the shelf water temperatures increase offshore by virtue of surface cooling throughout the region. Surface heating starts to warm shelf water during the spring and leads to the development of a shallow seasonal thermocline over the mid-depth. During summer, cross-shelf thermal gradients are found in two regions with cold water located on the shelf. One is located to the southeast of Georges Bank, resulting from the intensified anti-cyclonic circulation around the bank transporting relatively cold, fresh water from the western Gulf of Maine and across the Northeast Channel. The other region spreads from the southern New England shelf over the Delaware/ Maryland shelf, and is the residual cold winter water that remains under the shallow seasonal thermocline, the so-called 'cold pool', that persists from May through October (Houghton et al., 1982; Lentz, 2008b). The mid-depth temperature of the cold pool area is higher from model simulations than it 
from the historical climatology produced by Linder et al. (2006), in which the majority of stations were collected during a longer period of 1990-2002.

In contrast to the temperature, seasonal variations in both salinity (Manning, 1991; Mountain, 2003) and cross-shelf salinity gradient (Shearman and Lentz, 2003) tend to be small, except over the inner shelf (depth $<60 \mathrm{~m})$ where there can be an enhanced crossshelf salinity gradient due to spring runoff (Ullman and Codiga, 2004). The plan view maps (Figure 1-3b) clearly show the proximity of the 34.5 isohaline, which defines the core of the shelfbreak front at mid-depth to the bathymetry offshore of the $100 \mathrm{~m}$ isobath throughout the MAB. There also exists a slight freshening over Georges Bank to New Jersey during the summer season. Mountain (2003) observed that the volume and salinity of MAB shelf water exhibited larger interannual variability than its seasonal cycle, depending on the seasonal input of fresh water advected from the St. Lawrence River. Therefore in the following section salinity will be used to track the interannual variability of the shelf/slope front.

Finally, we examine the model skill in reproducing the interannual variability of the sea surface height by comparing model simulations with satellite altimeter data. We obtained the $1 / 3^{\circ} \times 1 / 3^{\circ}$ along-track sea surface height anomaly (SSHA) from the Archiving, Validation, and Interpretation of Satellite Oceanographic data (AVISO, http://www.aviso.oceanobs.com/) with two descending (i.e. cross-shelf) tracks falling inside the MAB (black dashed lines in Figure 1-2). Because the along-track satellite data are only available every 9.9 days, for direct comparison we sample model-simulated subtidal SSHA at the same time interval when the altimeter observations are available. The Hovmöller diagrams of the satellite-observed and model-simulated SSHA along the two 
selected tracks are shown in Figure 1-4 a, b. Along the two tracks, both AVISO and ROMS indicate that large SSHA variation, with an increasing magnitude of up to $0.5 \mathrm{~m}$, occurs offshore toward deeper waters where energetic meanders and eddies often exert strong spatial-temporal influence on the shelf circulation. Although the model misses some of the fine-scale sea level structures, it captures the seasonal and interannual variability of the sea level reasonably well. Specifically, over the lower continental slope, the sea level variation had a pronounced interannual signal. Han et al. (2002) proposed the interannual sea-level variability is forced by fluctuations of the Gulf Stream position, which seems to be related to the North Atlantic Oscillation (NAO), and the baroclinic Labrador Current transport. This assumption will be examined with our model experiment hierarchy in the following section.

In summary, the abovementioned model-observation comparisons suggest that our model performs reasonably well and is reliable for understanding the mean state, seasonal and interannual variability over the MAB shelf and slope regions.

\subsection{Mean State}

Even though the focus of this study is the interannual variability of the MAB shelf/slope front and jet system, it is still necessary to examine its mean state and climatological seasonal variations to gain an understanding of the fundamental dynamics. In this section we will present an analysis based on the model results from experiment REAL. 


\subsubsection{Annual mean}

The principal circulation features of the modeled mean surface circulation are shown in Figure 1-5. Consistent with the schematic of Figure 1-1 (as drawn from observations), the continental shelf circulation includes an inflow from the Scotia Shelf to Gulf of Maine, a cyclonic circulation in the Gulf of Maine, an anticyclonic circulation on the Georges Bank, and a southwestward along-shelf flow over the MAB. Over the shelfbreak to continental slope (bounded by the isobaths from 100 to $1000 \mathrm{~m}$ ) the shelfedge current carries southwestward outflow along the Scotian Shelf and upper slope, with a small branch entering the Gulf of Maine through the Northeast Channel, and a larger branch directly merging with the anti-cyclonic gyre over the Georges Bank creating a narrow but intensified jet equatorward along the MAB shelfbreak. The shelf waters and shelfbreak jet converge with the northward moving Gulf Stream near Cape Hatteras, then turns northeastward further offshore of Cape Hatteras.

In order to illustrate the mean structure of the along-shelf jet, we construct twodimensional cross-shelf fields of the along-shelf velocity and hydrography (Figure 1-6) by performing along-shelf averaging in the southern New England region (shaded area in Figure 1-5). The mean along-shelf velocities are mostly southwestward and range from zero to about $0.25 \mathrm{~m} \mathrm{~s}^{-1}$ in the center of the shelfbreak jet with a surface intensified velocity structure spanning the 100 to $200 \mathrm{~m}$ isobaths (Figure 1-6a). At the shelfbreak the upward tilted salinity front, centered on the 34.5 isohaline, extends all the way to the surface. Unlike the temperature, which exhibits a strong seasonal thermocline, the shelfbreak salinity front is a persistent feature throughout the year, with a gradient of about 1 PSU over $10-40 \mathrm{~km}$. In previous studies, more often than not, the 34.5 isohaline 
is used as a distinct separation in properties between the shelf and slope water and to indicate the shelfbreak front (Beardsley and Flagg, 1976; Linder and Gawarkiewicz, 1998; Linder et al., 2006; Chen and He, 2010). It is worth-noting that, over the outer shelf and shelfbreak, the contributions of the cross-shelf temperature and salinity gradient to the density gradients cancel each other (Figure 1-6 b, c). It is the salinity front that creates a strong density gradient that is primarily responsible for the strong shelfbreak jet.

The momentum budget analysis provides further insights into the shelf/slope flow. Here we focus on the momentum budget in the cross-shelf direction in order to identify the fundamental dynamical balances dominating the along-shelf jet. Figure 1-7 illustrates the cross-shelf distributions of the Coriolis force, the horizontal pressuregradient force (PGF), the viscosity term (horizontal and vertical diffusion combined), and nonlinear advection term (horizontal and vertical advection combined), and these terms are all along-shelf averaged within the shaded area in Figure 1-5. As expected, the Coriolis force and pressure-gradient force are dominant terms and they nearly balance each other. The viscosity term is relatively strong on the shelf near the bottom boundary, while the nonlinear advection term is relatively strong over the shelfbreak due to the energetic currents. But both viscosity and nonlinear advection terms are one order of magnitude weaker than the leading geostrophic terms. This indicates that the along-shelf jet is in geostrophic balance to leading order, which is consistent with previous observational studies (Shearman and Lentz, 2003).

\subsubsection{Seasonal means}

The seasonal means of the along-shelf velocity are illustrated in Figure 1-8. Henceforth, four typical months (February, May, August and November) are used to 
represent the four seasons. The shelfbreak jet accelerates in the fall and is strongest in winter with a maximum mean speed of over $0.35 \mathrm{~m} \mathrm{~s}^{-1}$ and a width of $30 \mathrm{~km}$. This is also the time when the jet core shifts offshore within a thin surface-trapped layer (shallower than $60 \mathrm{~m}$ ). In May, the jet core starts to move onshore and the poleward current is intensified as a subsurface feature seaward of the shelfbreak. The intensity of the shelfbreak jet is significantly reduced in August with mean speeds less than $0.2 \mathrm{~m} \mathrm{~s}^{-1}$, and the reduced southwestward flow expands to a width of 50 to $60 \mathrm{~km}$, consistent with the observation of Flagg et al. (2006). As discussed earlier, the along-shelf jet is nearly in thermal wind balance. The seasonal variability of the along-shelf jet can largely be attributed to the seasonal changes in the cross-shelf density gradient. Several sources of seasonal variation in the cross-shelf density structure, like the tidal mixing front over Georges Bank (Flagg, 1987), surface heat flux (Shearman and Lentz, 2003), and spring runoff near the MAB coast (e.g., Zhang et al. 2009), could be identified and have been studied in detail within different sub-regions over the MAB. Therefore, in the following, we will primarily focus on the interannual variability of the along-shelf jet.

\subsection{Interannual Variability and Its Origins}

\subsubsection{Along-shelf Transport}

Our 10-year-long numerical simulations provide a unique opportunity to investigate the interannual variability in both circulation and hydrography field. A straightforward way to identify interannual variability is through a time series of alongshelf transport. For this we select a cross-shelf section that represents the upper bound of the northern MAB, marked as $\mathrm{T}_{1}$ in Figure 1-1, between $50 \mathrm{~m}$ to $1000 \mathrm{~m}$ isobaths, i.e. from the outer shelf to the upper slope, and calculate the monthly averaged upper water 
column transports from experiment REAL by integrating the monthly averaged alongshelf velocity from the surface to $300 \mathrm{~m}$. The result is represented as a black line labeled REAL in all of the three panels of Figure 1-9.

The magnitude of the total along-shelf transport variation during the 10-year simulation period is about $4.0 \mathrm{~Sv}$ across $\mathrm{T}_{1}$. Two features are notable: 1) the southwestward along-shelf transport is higher during wintertime both in 2009 and 2010 as compared with other years and, 2) there are three significant reversals of southwestward along-shelf transport that occur in 2004 October, 2005 September and 2007 July.

Two questions naturally arise. 1) What is the origin of this response of the circulation, i.e., is it the direct influence of local surface forcing or of remote forcing? 2) If it is the latter, then how does an upstream influence, where the southwestward Labrador Current from Scotia Shelf flow into the region, compete with any offshore influence, where the subtropical gyre and the Gulf Stream interact in this region? These two questions will be addressed in the following section.

\subsubsection{Origins of Interannual Variability}

We now focus on the comparisons of the along-shelf transport along the $T_{1}$ transect between the REAL experiment and the other five experiments described in Section 2. In Figure 1-9a, there is hardly a discernible difference of along-shelf transport after controlling the surface wind with climatology, and only subtle distinctions after replacing both surface wind and buoyancy forcing with their climatologies. We can therefore confidently conclude that the interannual variability along transect $T_{1}$ does not 
appear to be caused by local atmospheric momentum or buoyancy forcing but rather must be due to processes on a much larger scale.

Focusing now on the impact of remote forcing we compare experiments REAL and OBCs (Figure 1-9b). Unsurprisingly, the interannual variability of the along-shelf transport across $\mathrm{T}_{1}$ (REAL) disappears in OBCs (which only retains the climatological fluxes; see Table 1-2). The seasonal cycle remains in OBCs with a regular range of 0.8 Sv between its winter maximum and summer minimum. This further supports our previous conclusion that it is the variability of the remote forcing that accounts for the interannual variability of the along-shelf front/jet system along this transect.

We next seek to determine whether this signal derives from upstream or offshore influence by comparing the time series of $\mathrm{T}_{1}$ along-shelf transport among experiments REAL, UPSTREAM and OFFSHORE. In Figure 1-9c, the red line represents the results after we control the upstream forcing with its climatology. It shows a high correlation with REAL, especially with respect to the minimum values in 2004, 2005, and 2007. After 2010, the transport of experiment UPSTREAM is generally higher than REAL. We conclude that the upstream influence from the Labrador Current is mainly contributing to the rise of the along-shelf transport.

The magenta line in Figure 1-9c represents the results of experiment OFFSHORE in which we control the offshore forcing with its climatology. The three periods of reversed along-shelf transport before 2009 completely vanish with several of the minimum values (REAL) replaced by maxima and an increasing transport from 2004 to 2008. If we take an average of the along-shelf transport from two five-year periods separately, experiment REAL increases by $1 \mathrm{~Sv}$ (or 83\%) from $1.2 \mathrm{~Sv}$ for 2004-2008 to 
2.2 Sv for 2009-2013. However, in experiment OFFSHORE the mean transport has only a minor change from $2.2 \mathrm{~Sv}$ for 2004-2008 to $2.1 \mathrm{~Sv}$ for 2009-2013. The significantly lower transport for 2004-2008 in REAL is therefore due to an offshore influence, i.e. where Gulf Stream eddies interact closely with the shelfbreak jet during this period. Next, we will try to understand the underlying mechanism and seek a physical explanation using both observations and our model results.

\subsection{Influence of Remote Processes}

In the previous section, based on the numerical experiments, we have made the preliminary conclusion that it's the upstream Labrador Current transport that mainly contributes to the rise of along-shelf transport in the MAB, especially with respect to the high value in 2009/2010 winter as compared with other years. Meanwhile, the drop in transport is due to the offshore influence of the changes in the position of the Gulf Stream. In particular, the averaged along-shelf transport of 2004-2008 is 1 Sv lower than 20092013. In this section, we will better detail the upstream influence from the Labrador Current and the offshore effects from the energetic Gulf Stream.

\subsubsection{The Labrador Current}

In order to isolate the influence from local sources of coastal runoff and precipitation, the 10-year averaged winter temperature and salinity fields are obtained at $50 \mathrm{~m}$ depth from experiment REAL for the entire region (Figure 1-10a and $\mathrm{c}$ ). As mentioned above, the winter is averaged over January, February and March. Figures 1$10 \mathrm{a}$ and 1-10c clearly reveal the cooler and fresher shelf water as compared with the 
oceanic slope water. The shelf/slope front acts as a boundary between these two water masses in the narrow transition region between the 100 and $1000 \mathrm{~m}$ isobaths.

By subtracting the winter climatology, hydrographic temperature and salinity anomalies of each year are obtained, and the 2009 anomalies are presented in Figures 1$10 \mathrm{~b}$ and 1-10d. A low anomaly, both in temperature and salinity, with the largest magnitudes of $-3^{\circ} \mathrm{C}$ and $-1 \mathrm{PSU}$, respectively, dominate the MAB shelf/slope region. Such hydrographic anomalies are spatially coherent throughout the Scotia Shelf to Cape Hatteras and with a temporal extension into the 2010 winter (not shown).

The cold and fresh water in our model domain originates from the north, as far as the Labrador Sea, and is part of a large-scale current system that extends from Labrador to Cape Hatteras. With that we conjecture that there should be a signal of strong southwestward currents, along the northeastern boundary of our model domain. This can be illustrated by comparing the wintertime hydrography and the along-shelf velocity component between climatologies with 2009 values (Figure 1-11). The basic structure of the wintertime hydrography (Figure 1-11 a, c) shows that temperature and salinity values generally increase with depth and distance offshore, with the largest horizontal gradients occurring on the inner shelf and at the shelf edge. This is consistent with the long-term observations of hydrographic properties on the Halifax section by Loder et al. (2003). Over the upper continental slope, a wedge of relatively fresh and cold upper-layer shelf water overlie two types of slope waters, which are identified by Pershing et al. (2001): 1) a layer of Warm Slope Water (temperature of $8-12^{\circ} \mathrm{C}$ and salinity of $34.7-35.5 \mathrm{PSU}$ ) and, 2) Labrador Slope Water $\left(4-8^{\circ} \mathrm{C}, 34.3-35.3\right.$ PSU) at intermediate depth. Below these is the so-called Classical Labrador Sea Water (cLSW) with a characteristic potential 
temperature of $3^{\circ} \mathrm{C}$ and a salinity of 34.88 PSU (Smethie et al., 2000). The dominant features of the velocity fields along the northeast boundary are surface-intensified southwestward flows on both the inner shelf (the Nova Scotia Current described by Drinkwater et al., 1979) and near the shelf edge over the upper slope, which is part of the downstream remnant of the shelf-edge Labrador Current (Loder et al., 1998). The subsurface northeastward flows are identified as the slope current that is strongly influenced by Gulf Stream meanders and anti-cyclonic warm-core rings (Joyce 1991). The most striking feature in the 2009 winter that is different from the climatology is the strong southwestward velocity. Even though this could not be easily identified by the hydrography (especially when it comes to salinity due to its coarse representation in HYCOM) the velocity field (Figure 1-11 e, f) does reveal the spreading of cLSW along the entire slope, replacing the slope current. We will have more to say about this figure in the next section.

\subsubsection{The Gulf Stream}

The close proximity of the Gulf Stream in southern New England results in a large number of meanders and anti-cyclonic warm core rings (WCRs) each year that, from time to time, impinge upon the continental slope in the MAB. These rings could generate significant temporal and spatial variability in the currents, i.e. reversing the flow at the shelfbreak (Beardsley et al., 1985), pulling streamers of shelf water into the interior (Joyce et al., 1991), or stimulating shear instabilities due to the enhanced horizontal velocity gradients of the shelfbreak jet (Ramp et al., 1983).

During our 10-year numerical simulation, there are three significant reversals of southwestward along-shelf transport on the shelf/slope: 2004 October, 2005 September 
and 2007 July. For each reversal, we plot the latitude/longitude structure of the surface speed and velocity in Figure 1-12 a-c. An anti-cyclonic ring circulation occurred during each period between 37.5 and $40.5^{\circ} \mathrm{N}$ in the vicinity of the $1000 \mathrm{~m}$ isobath just south of Georges Bank, which has been well documented as a place with maximum ring activity (Chaudhuri et al., 2009), and impacted the circulation further to the north by interacting with the shelf/slope front. To support this, we also retrieve daily snapshots of satellite altimetry observed sea level anomalies (SLA) as a more reliable proxy for the presence and duration of warm core rings (WCRs). The gridded SLA fields with spatial resolution of $1 / 4^{\circ} \times 1 / 4^{\circ}$ are obtained from AVISO based on the Jason- 1 and Jason-2 missions. In accordance with the numerical simulations, the daily snapshots reveal notable WCRs with a diameter of more than $150 \mathrm{~km}$ in the same location (Figure 1-12, d-f). Actually, the similarity of these three periods is that the WCRs features are present almost without change for longer than 10 days; a time-longitude plot (not shown) indicates their westward propagation speed is very slow at $\sim 3 \mathrm{~km}$ day $^{-1}$.

The along-shelf velocity and isopycnals across the $T_{1}$ transect during the abovementioned three reversal periods are presented in Figure 1-13 a-c. As expected, the southwestward jet is fully replaced by northeastward currents over the entire water column at the shelfbreak. The result is consistent with previous studies, i.e. the currents in the northern MAB appear to strengthen southwestward when the Gulf Stream shifts southward in winter-spring but are weak or even reversed in summer-fall when the Gulf Stream shifts northward (Peña-Molino and Joyce, 2008). The dynamics of how these fluctuations could temporarily break down the jet were the focus of our analysis. We find that, to leading order, the geostrophic and hydrostatic along-shelf flow obeys the thermal- 
wind balance; the frontal density gradient is in balance with the vertical shear of alongshelf velocity. In wintertime the density front is more sloped than it is in summer and fall, when a strong seasonal pycnocline develops isolating much of the front from the surface (Figure 1-13 a-c, black lines). Therefore the model shelfbreak jet is weaker in summer than in winter. The presence of offshore eddies from the shelfbreak to the slope affects the magnitude of the along-shelf velocity by completely eliminating the cross-shelf density gradient so that the spatial structure of the velocity field is primarily set by the slope eddy and not the shelfbreak frontal structure.

Observations suggest that the interaction of Gulf Stream rings with the shelfbreak jet may transport significant volumes of shelf water into the slope region (Joyce et al., 1991). Flagg et al. (2006) found that total along-shelf transport for the shelfbreak and upper slope is just less than $3 \mathrm{~Sv}$, and Chaudhuri et al. (2009) estimated that the annul shelf-wide WCRs could advect $0.75 \mathrm{~Sv}$ of shelf water, accounting for more than $25 \%$ of the total transport in the slope sea region. Moreover, Chaudhuri et al. (2009) also found that the offshore transport of shelf water by WCRs in Georges Bank is approximately $0.23 \mathrm{~Sv}$, with its maximum reaching as high as $1.9 \mathrm{~Sv}$ in certain years co-varying with maximum WCRs occurrence. Therefore, our model results together with the observational evidence suggest that the decrease of the along-shelf transport is due to Gulf Stream WCRs impinging onto the continental slope in the MAB.

\subsection{Decadal Variability}

In this section we focus on the decadal variability of the along-shelf transport in our model simulations. It should be noted that 'decadal variability' here refers to the transition of the averaged state from the first 5-year period to the second 5-year period 
during the entire length of simulation. Besides the $T_{1}$ transect discussed earlier, we select two more cross-shelf sections in the model domain, noted as $T_{2}$ and $T_{3}$, respectively, in Figure 1-1; $\mathrm{T}_{2}$ is located in the southern MAB area, which is characterized as another distinct region along the U.S. east coast continental margin (Linder et al., 2006), and $\mathrm{T}_{3}$ is close to the northern boundary of the regional model domain. Using the same analysis as the $T_{1}$ transect, we calculate the monthly averaged transports cross $T_{2}$ and $T_{3}$ from experiment REAL (black heavy lines in the three panels of Figure 1-14) and OBCs (black dashed lines) in the upper water column. For each transect the time series of the alongshelf transport anomaly is obtained by subtracting the results of the experiment OBCs from that of experiment REAL (black thin lines).

An interesting spatial and temporal coherence of $T_{1}$ and $T_{2}$ is seen as a long-term period of negative anomalies of the along-shelf transport before 2009 which, however, is not the case for the $T_{3}$ transect. For each transect, we also take a five-year average of the along-shelf transport with 2009 as the time division point; these values are indicated by blue horizontal lines during 2004-2008 and red ones during 2009-2013 in Figure 1-14. The five-year averaged values of both $T_{1}$ and $T_{2}$ show a significant increase in 2009 from the first to the second 5-year period, an almost doubling of transport. In contrast, there is hardly any discernible increase for $\mathrm{T}_{3}$ between these two periods. This indicates that there was a decadal transition of the along-shelf transport across $T_{1}$ and $T_{2}$ around the year of 2009.

In our model domain, the variability of the Labrador Current strength upstream, the migration of Gulf Stream's north-south position and the occurrence of the WCRs offshore are all potential contributors to the interannual-to-decadal changes of oceanic 
circulation and hydrographic properties. As a part of a broad transitional area between the subpolar and subtropical gyres, they are all subject to strong influences from the largescale atmospheric circulation in the form of the North Atlantic Oscillation (NAO) on these interannual-to-decadal time scales which is generally represented by the winter NAO index (Hurrell, 1995; Figure 1-15). Previous studies have suggested that the NAO could have a large impact on the circulation patterns and hydrography of the MAB. For example, the position of the Gulf Stream North Wall (GSNW) is observed to move northward (southward) during positive (negative) phases of the NAO with a lag of about 1-2 years (Rossby and Benway, 2000). Chaudhuri et al. (2009) found that the eddy kinetic energy in the Gulf Stream region plays a major role in WCRs occurrences and responds significantly to the NAO with a lag of a year. A more recent numerical study by Luo et al. (2013) has shown that the southwestward jet near the southern New England shelf break is intensified (weakened) during the low (high) phases of the NAO with a lag of about 1 year. However, their correlation between the along-shelf transport and the NAO winter index does not appear to be significant (with a correlation of 0.38 ).

One should exercise caution in any attempt to identify 'normal' or 'standard' NAO patterns of behavior, and the associated ocean response will necessarily be oversimplified and difficult to associate with the NAO (Visbeck et al., 2001), not to mention the wintertime NAO itself also exhibits significant decadal to multi-decadal variability (Hurrell, 1995). Therefore, we put our effort on identifying short-term NAO 'events' that could be related to ocean climate changes. For instance, it has been found that when the winter NAO shifted from persistent and strong positive to strong single-year negative in 1996 (Figure 1-15), the Gulf Stream front retreated southward, which allows the 
penetration of the Labrador Current onto the Scotia Shelf and Slope (Han, 2007). Afterwards, the Labrador Slope Water was observed to steadily advance along the shelfbreak during this transition, penetrating to the southwest as far as the MAB (Drinkwater et al., 1999; Pershing et al., 2001).

Another notable NAO event occurred around the five-year period of 2009-2013 (Figure 1-15). Gawarkiewicz et al. (2013) observed an unusual tilt in the Gulf Stream path in fall/winter of 2011, bringing Gulf Stream water near the MAB shelfbreak. The daily NAO index was negative and large during this time. Indeed, the winter 2009/10 had the most negative NAO index measured during the almost 190-year record (Osborn TJ, 2011; Figure 1-15). This contradicts the notion that a negative NAO should lead a southerly path of Gulf Stream by several months to several years (Taylor, 2011). On the contrary, the 2011 Gulf Stream anomaly occurred before the warm and mild winter of 2012, which featured the most strongly positive NAO since 2000 (Figure 1-15).

The 10-year numerical results enable an exploration of potential decadal variability in other fields besides the along-shelf transport. Here, we look at the sea surface height (SSH) from the experiment REAL. In order to determine the migration of the northern edge of the Gulf Stream, Taylor and Stephens (Taylor, 2011) constructed a measure of the latitude of the current, known as the Gulf Stream north wall (GSNW) index since 1966 (Taylor, 2011). By mapping his climatological path of the GSNW (black dots in Figure 1-16) with our simulated climatological SSH, we find the $35 \mathrm{~cm} \mathrm{SSH}$ contour is most close to the Gulf Stream mean path (white lines in Figure 1-16) and so we choose this SSH contour as a proxy to track the Gulf Stream northern edge migration in each year. 
The path of the Gulf Stream northern edge during 2004-2008 (red contours in Figure 1-16) is north of its mean position and from 2009 to 2013, the Gulf Stream exhibits an imperceptible variance of its mean meridional position. If we attribute the reduced along-shelf transport in the MAB shelf/slope during 2004-2008 to the northern migration of the Gulf Stream, which delivered more energetic rings that entrained shelf water offshore, then the rise of along-shelf transport can be attributed to the Gulf Stream retreat to its climatological position after 2009. Further explanation can be given by looking at the SSH anomaly during 2004-2008 (color in Figure 1-16), which is obtained by subtracting the 10-year averaged SSH field from the average during 2004-2008. In the MAB, the SSH anomaly increases from shelf to slope and thus creates a cross-shelf pressure gradient opposing the along-shelf jet. This leads to the reduction of the alongshelf transport as well as the jet strength during 2004-2008. The dramatic fluctuations of the NAO after this time period has an impact on the activity of the Gulf Stream as well as to the local circulation and hydrography in the MAB, but a longer time series of observations would be required to resolve these interactions.

\subsection{Summary}

This study sets out to better understand the origin of the interannual-to-decadal variability of along-shelf transport and water properties of the MAB. ROMS is employed to simulate the front/jet system along the U.S. Northeast continental shelf/slope region for the decade from January 2004 to December 2013. The model is forced by realistic atmospheric and tidal forcing, and its open boundary conditions are derived from a global eddy-resolving numerical simulation provided by HYCOM/NCODA. Model solutions

are first compared with observation and then a detailed investigation of the mean state 
and seasonal variability of MAB shelf/slope circulation and hydrography is presented. Term-by-term analyses of momentum equation confirm that the shelfbreak jet is essentially in thermal wind balance.

Special attention has been given to explore the origins of interannual variability of the circulation, especially the along-shelf transport in the northern MAB. Results from a series of process-oriented experiments indicate that remote forcing from the open boundary plays a more important role than local atmospheric forcing. More specifically, the upstream influence of the Labrador Current is the major source leading to an increase of along-shelf transport in the MAB. By contrast, the influence from the Gulf Stream and its associated anticyclonic warm core rings is the key factor in reducing the along-shelf transport as well as impacting its interannual variability.

A spatial and temporal analysis of the anomalous along-shelf transport in the MAB before 2009, along with a comparison of the five-year averaged along-shelf transport between 2004-2008 and 2009-2013, reveals that its decadal variability is mainly due to the behavior of the Gulf Stream. The underlying mechanism is that the Gulf Stream was able to maintain an anomalous northerly path during the high-NAO phases before 2009 . However, the Gulf Stream returns to its climatological position after the 2009/2010 winter, which also featured the largest negative NAO index in the 190-year record. Such a return to climatology persisted for several years, which could lead to a change of coastal water environment, especially with respect to the significant regional responses of marine ecosystems, e.g. primary productivity and the biological export of carbon (Drinkwater et al., 2003). An extensive observational/modeling effort will be required for 
further understanding the long-term variability of the front/jet system in the MAB shelf/slope and its impacts on the coastal environment.

\section{References}

Beardsley, R. C., Flagg, C. N., 1976. The water structure, mean currents, and shelf water/slope water front on the New England Continental shelf, Memoires Societé Royale des Sciences de Liége, ${ }^{\mathrm{e}}$ serie, tome $\mathbf{X}, 209-255$.

Beardsley, R. C., Boicourt, W. C., 1981. On estuarine and continental shelf circulation in the Middle Atlantic Bight, in Evolution in Physical Oceanography, edited by B. A. Warren and C. Wunsch, pp. 198-233, MIT Press, Cambridge, Mass.

Beardsley, R. C., Chapman, D. C., Brink, K. H., Ramp, S. R., Schlitz, R., 1985. The Nantucket Shoals Flux Experiment (NSFE79), Part 1: A basic description of the current and temperature variability, J. Phys. Oceanogr., 15, 713-748.

Biscaye, P. E., Flagg, C. N., Falkowski, P. G., 1994. The shelf edge exchange processes experiment, SEEP-II: an introduction to hypotheses, results and conclusions, DeepSea Res. II, 41, 231-252, doi:10.1016/0967-0645(94)90022-1.

Taylor, A.H., 2011. The Dance of Air and Sea: How Oceans, Weather and Life Link Together. Oxford Univ. Press.

Chaudhuri, A.H., Gangopadhyay, A., Bisagni, J.J., 2009. Inter-annual variability of Gulf Stream warm-core rings in response to the North Atlantic Oscillation, Cont. Shelf Res., 29, 856-869. 
Chaudhuri, A. H., Bisagni, J. J., Gangopadhyay, A., 2009. Shelf water entrainment by Gulf Stream warm-core rings between $75^{\circ} \mathrm{W}$ and $50^{\circ} \mathrm{W}$ during $1978-1999$, Cont. Shelf Res., 29, 393-405.

Chen, C., Beardsley, R. C., Franks, P. J. S., 2001. A 3-D prognostic model study of the ecosystem over Georges Bank and adjacent coastal regions. Part I: Physical model, Deep Sea Res., 48, 419-456, doi:10.1016/S0967-0645(00)00124-7.

Chen, K., He, R., 2010. Numerical investigation of the Middle Atlantic Bight shelfbreak frontal circulation using a high-resolution ocean hindcast model, J. Phys. Oceanogr., 40, 949-964.

Dickey, T., Williams III, A. J., 2001. Interdisciplinary ocean process studies on the New England shelf, J. Geophys. Res., 106, 9427-9434, doi: 10.1029/2000JC900155.

Drinkwater, K. F., Petrie, B., Smith, P.C., 2002. Hydrographic variability on the Scotian Shelf during the 1990s, NAFO SCR Doc. 02/42:16pp.

Flagg, C. N., 1987. Hydrographic structure and variability, in Georges Bank, edited by R. H. Backus and D. W. Bourne, pp. 108-124, MIT Press, Cambridge, Mass..

Flagg, C. N., Dunn, M., Wang, D.-P., Rossby, H. T., Benway, R. L., 2006. A study of the currents of the outer shelf and upper slope from a decade of shipboard ADCP observations in the Middle Atlantic Bight, J. Geophys. Res., 111, C06003, doi:10.1029/2005JC003116.

Flather, R.A., 1976. A tidal model of the northwest European continental shelf. Mem. Soc. R. Sci. Liege, Vol. 10, No. 6., pp. 141-164. 
Fratantoni, P. S., Pickart, R. S., 2003. Variability of the shelf break jet in the Middle Atlantic Bight: Internally or externally forced?, J. Geophys. Res.,108(C5), 3166, doi: 10.1029/2002JC001326.

Gawarkiewicz, G.G., Todd, R.E., Plueddemann, A.J., Andres, M., Manning, J.P., 2012. Direct interaction between the Gulf Stream and the shelfbreak south of New England, Sci. Rep. 2, 553; DOI:10.1038/srep00553.

Greene, C.H. Pershing, A.J., 2003. The flip-side of the North Atlantic Oscillation and modal shifts in slope-water circulation patterns, Limnol. Oceanogr., 48, 319- 322.

Han, G., Tang, C. L., 2001. Interannual variations of volume transport in the western Labrador Sea based on TOPEX/Poseidon and WOCE data, J. Phys. Oceanogr., 31, $199-211$.

Han, G., 2002. Interannual sea level variations in the Scotia-Maine region in the 1990s. Can. J. Remote Sens., 28, 581-587.

Han, G., 2007. Satellite Observations of Seasonal and Interannual Changes of Sea Level and Currents over the Scotian Slope., J. Phys. Oceanogr., 37, 1051-1065. doi: http://dx.doi.org/10.1175/JPO3036.1

He, R., Weisberg, R. H., 2002. West Florida shelf circulation and temperature budget for the 1999 spring transition, Cont. Shelf Res., 22, 719-748.

Houghton, R. W., R. Schlitz, R. C. Beardsley, B. Butman, and J. L. Chamberlin (1982), The Middle Atlantic Bight cold pool: Evolution of the temperature structure in summer 1979, J. Phys. Oceanogr., 12, 1019-1029.

Hurrell, J.W., 1995. Decadal trends in the North Atlantic Oscillation: regional temperatures and precipitation. Science 269, 676-679. 
Joyce, Terrence M., 1991. Review of U.S. contributions to warm-core rings, Reviews of Geophysics, Supplement (U.S. National Report to International Union of Geodesy and Geophysics 1987-1990), 610-616.

Lentz, S. J., 2008a. Observation and a model of the mean circulation over the Middle Atlantic Bight Continental Shelf, J. Phys. Oceanogr., 38, 1203-1221.

Lentz, S. J., 2008b. Seasonal variability in the circulation over the Middle Atlantic Bight Continental Shelf, J. Phys. Oceanogr., 38, 1486-1500.

Linder, C. A., Gawarkiewicz, G.G., 1998. A climatology of the shelfbreak front in the Middle Atlantic Bight, J. Geophys. Res., 103, 18,405-18,423.

Linder, C. A., Gawarkiewicz, G. G., Taylor, M, 2006. Climatological Estimation of Environmental Uncertainty Over the Middle Atlantic Bight Shelf and Slope, IEEE J. Oceanic Eng., 31, 308-324.

Loder, J. W., Petrie, B., Gawarkiewicz, G.G., 1998. The coastal ocean off northeastern North America: A large-scale view, in The Sea, Vol. 11, The Global Coastal Ocean, Regional Studies and Syntheses, edited by A. R. Robinson and K. H. Brink, pp. 105133, John Wiley, New York.

Loder, J. W., Hannah, C. G., Petrie, B. D., Gonzalez, E. A., 2003. Hydrographic and transport variability on the Halifax section, J. Geophys. Res. Oceans, 108(C11), 8003, doi:10.1029/2001JC001267.

Lozier, M. S., Gawarkiewicz, G.G., 2001. Cross-frontal exchange in the Middle Atlantic Bight as evidenced by surface drifters, J. Phys. Oceanogr.,31, 2498-2510. 
Luo, Y., Rothstein, L., Liu, Q., Zhang, S., 2013. Climatic variability of the circulation in the Rhode Island Sound: A modeling study, J. Geophys. Res. Oceans, 118, doi: $10.1002 /$ jgrc. 20285 .

Manning, J., 1991. Middle Atlantic Bight salinity: Interannual variability, Cont. Shelf Res., 11, 123-137.

Mellor, G. L., Yamada, T., 1982. Development of a turbulence closure model for geophysical fluid problems, Rev. Geophys., 20, 851-875.

Mountain, D. G., 2003. Variability in the properties of shelf water in the Middle Atlantic Bight, 1977-1999, J. Geophys. Res., 108(C1), 3014, doi: 10.1029/2001JC 001044.

Peña-Molino, B., Joyce, T. M., 2008. Variability in the Slope Water and its relation to the Gulf Stream path, Geophys. Res. Let.,35,LO3606, doi: 10.1029/2007GL032183.

Pershing, A.J., Greene, C.H., Hannah, C., Sameoto, D., Head, E., Mountain, D.G., Jossie, J.W., Benfield, M.C., Reid, P.C., Durban, T.G., 2001. Oceanographic responses to climate in the Northwest Atlantic, Oceanography, 14, 76-82.

Ramp, S. R., Beardsley, R. C., Legeckis, R., 1983. An observation of frontal wave development on a shelf-slope/warm core ring front near the shelfbreak south of New England, J. Phys. Oceanogr., 13, 907-912..

Rossby, T., Benway, R. L., 2000. Slow variations in mean path of the Gulf Stream east of Cape Hatteras, Geophys. Res. Lett., 27, 117-120.

Rossby, T., Flagg, C., Donohue, K., 2005. Interannual variations in upper ocean transport by the Gulf Stream and adjacent waters between New Jersey and Bermuda, J. Mar. Res., 63, 203-226. 
Rossby, T., Flagg, C., Donohue, K., 2010. On the variability of Gulf Stream transport from seasonal to decadal timescales, J. Mar. Res., 68, 503-522.

Shchepetkin, A. F., McWilliams, J. C., 2005. The Regional Oceanic Modeling System (ROMS): A split-explicit, free surface, topography-following-coordinate oceanic model, Ocean Modell., 9, 347-404.

Shearman, R. K., Lentz, S. J., 2003. Dynamics of mean and subtidal flow on the New England shelf, J. Geophys. Res.,108(C8), 3281, doi:10.1029/2002JC001417.

Smethie, W. M., Schlosser, Jr., P., Bönisch, G., Hopkins, T. S., 2000. Renewal and circulation of intermediate waters in the Canadian Basin observed on the SCICEX 96 cruise, J. Geophys. Res., 105, 1105-1121, doi:10.1029/1999JC900233.

Ullman, D. S., Codiga, D. L., 2004. Seasonal variation of a coastal jet in the Long Island Sound outflow region based on HF radar and Doppler current observations, $J$. Geophys. Res., 109, C07S06, doi: 10.1029/2002JC001660.

Visbeck, M. H., Hurrell, J. W., Polvani, L. \& Cullen, H. M., 2001. The North Atlantic Oscillation: past, present, and future. Proc. Natl Acad. Sci., USA 98, 12 876-12 877.

Walsh, J.J., Biscaye, P.E., Csanady, G.T., 1988. The 1983-84 shelf edge exchange processes (SEEP)-I experiment: hypotheses and highlights, Cont. Shelf Res., 8, 435456.

Zhang, W. G., Wilkin, J. L., Chant, R.J., 2009. Modeling the pathways and mean dynamics of river plume dispersal in the New York Bight, J. Phys. Oceanogr., 39, $1167-1183$. 
Table 1-1 Hierarchy of experiments conducted in this study.

\begin{tabular}{c|c|c|c}
\hline \hline \multirow{2}{*}{$\begin{array}{c}\text { Experiment } \\
\text { Name }\end{array}$} & \multicolumn{2}{|c|}{ Surface Forcing } & \multicolumn{2}{|c}{ Remote Forcing } \\
Rind & Buoyancy & Upstream & Offshore \\
WIND & Climatology & Daily 10Yr & \multicolumn{2}{|c}{ Monthly 10Yr } \\
SURF & Climatology & \multicolumn{2}{|c}{ Monthly 10Yr } \\
OBCs & Daily 10Yr & \multicolumn{2}{|c|}{ Climatology $10 \mathrm{Yr}$} \\
UPSTREAM & Daily 10Yr & Climatology & Monthly 10Yr \\
OFFSHORE & Daily 10Yr & Monthly 10Yr & Climatology \\
\hline
\end{tabular}


Table 1-2 Comparison between modeled and observed (Lentz, 2008a) along-shelf volume transport at six cross-shelf transects within the MAB. The standard deviations are listed in parenthesis. The coastal endpoints of each transect and the water depths at the shelfbreak are also listed.

\begin{tabular}{rcccc|c}
\hline \hline Transect & Lat $\left({ }^{\circ} \mathrm{N}\right)$ & Lon $\left({ }^{\circ} \mathrm{W}\right)$ & Shelfbreak & \multicolumn{2}{c}{ Transport (Sv) } \\
\cline { 5 - 6 } & & & depth $(\mathrm{m})$ & Observation & Model \\
\hline Georges Bank & $41.28^{\circ}$ & $67.72^{\circ}$ & 95 & 0.44 & $0.43( \pm 0.10)$ \\
Cape Cod & $41.33^{\circ}$ & $70.56^{\circ}$ & 125 & 0.64 & $0.66( \pm 0.13)$ \\
Long Island & $40.75^{\circ}$ & $72.82^{\circ}$ & 90 & 0.41 & $0.44( \pm 0.10)$ \\
New Jersey & $39.46^{\circ}$ & $74.26^{\circ}$ & 85 & 0.27 & $0.23( \pm 0.06)$ \\
Maryland & $38.03^{\circ}$ & $75.22^{\circ}$ & 75 & 0.16 & $0.18( \pm 0.05)$ \\
North Carolina & $36.25^{\circ}$ & $75.71^{\circ}$ & 45 & 0.09 & $0.09( \pm 0.02)$ \\
\hline
\end{tabular}




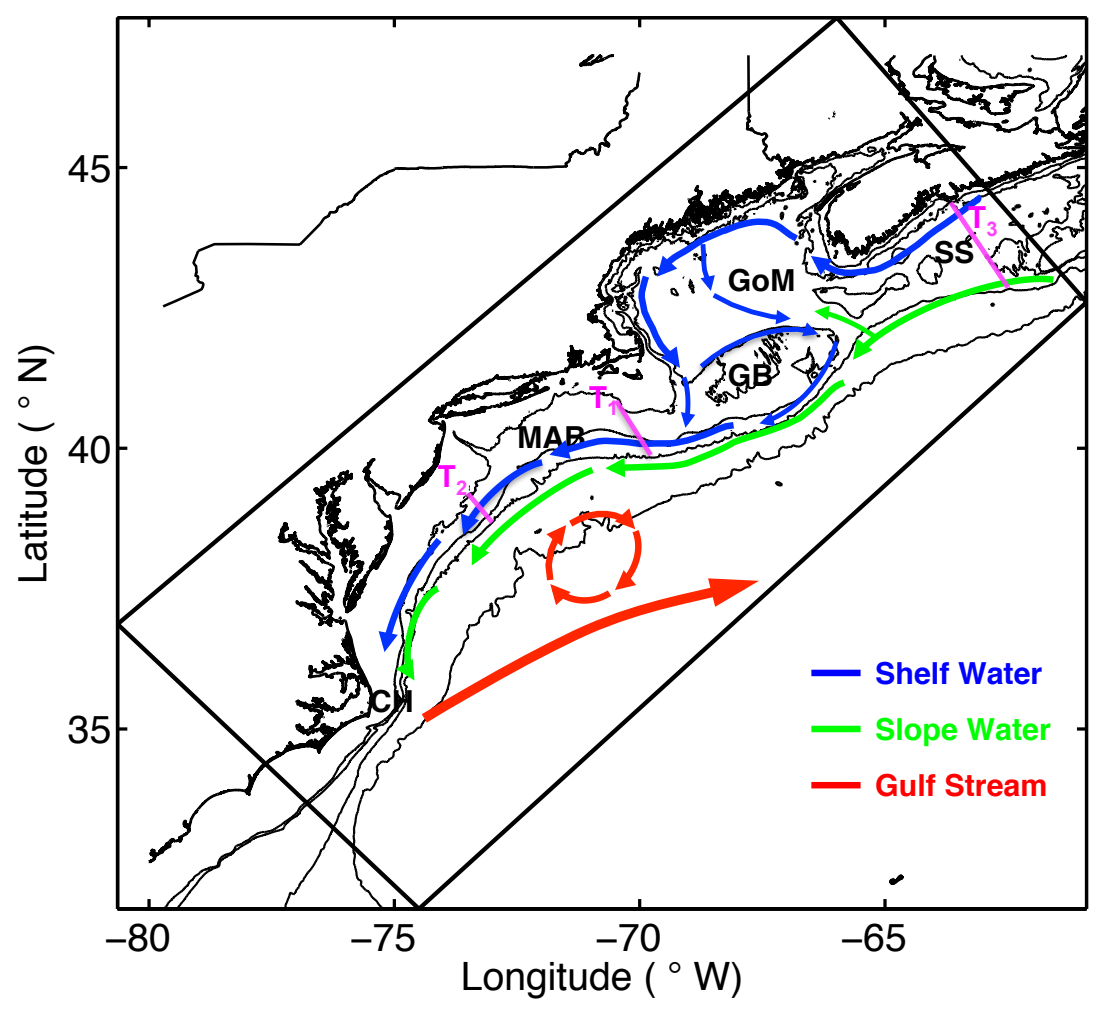

Figure 1-1 Map of the Northeast U.S. continental shelf/slope region and the regionalscale ROMS model domain (black box). The primary geographical features are the Scotia Shelf (SS), the Gulf of Maine (GoM), Georges Bank (GB), the Middle Atlantic Bight (MAB) and Cape Hatteras (CH). The 50, 100, 1000 and $3000 \mathrm{~m}$ isobaths are represented by black contours. Principal circulation features are equatorward flow of shelf and slope waters and poleward flow of the Gulf Stream; a warm core ring is also depicted (Based on http://www.nefsc.noaa.gov/ecosys/ecology/Oceanography/). The three selected crossshelf sections discussed in the text are marked as $T_{1}, T_{2}$ and $T_{3}$. 


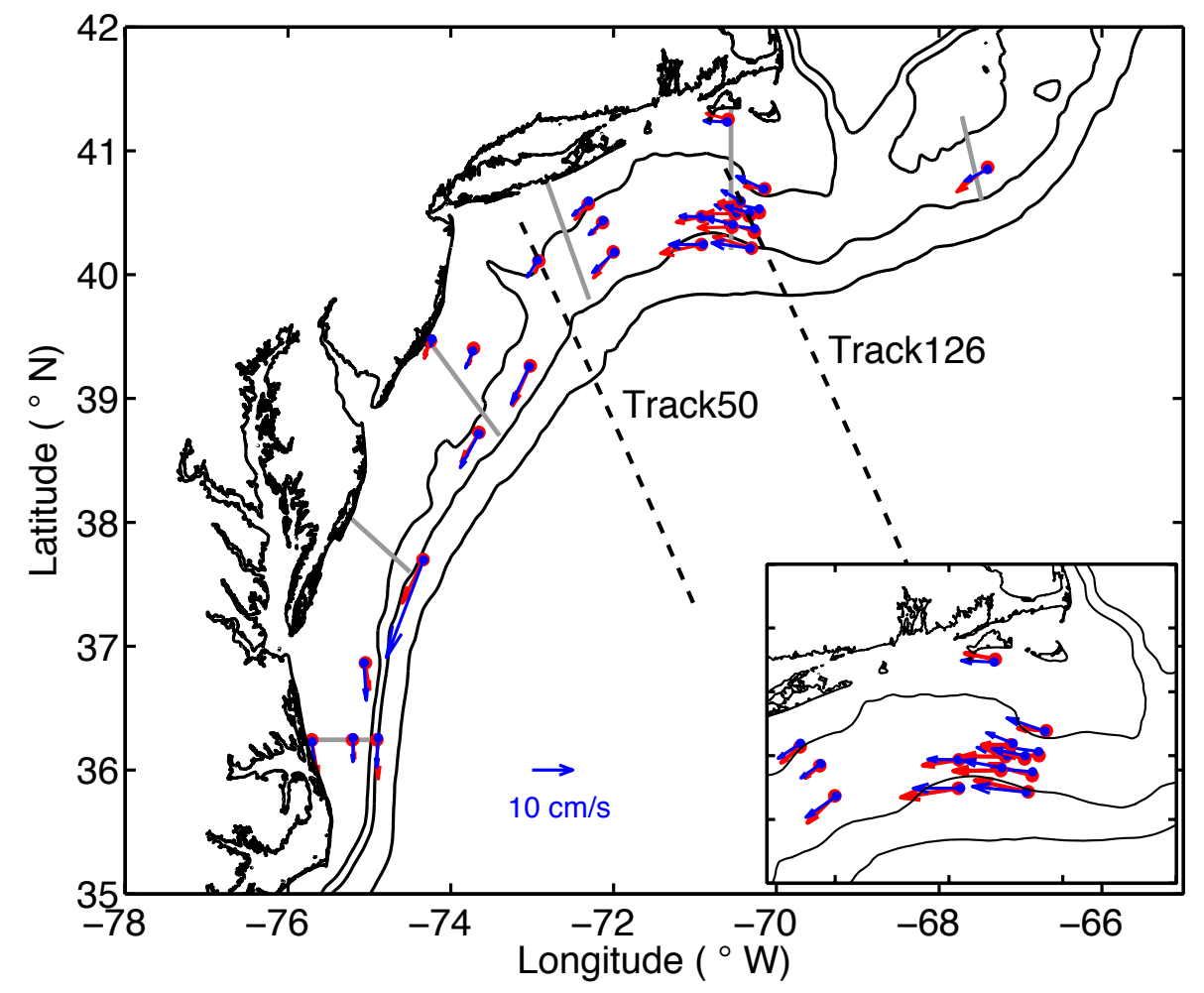

Figure 1-2 Comparison of depth-averaged currents between the model (blue arrows) and observations (red arrows); the southern New England shelf area is highlighted and inserted in the lower right corner. Thick, light-grey lines indicate six cross-shelf transects from the coast to the shelfbreak; their corresponding locations are listed in Table 1-2.

Black dashed lines are the two satellite tracks, along which the SSHA data are sampled. The 50, 100, and $1000 \mathrm{~m}$ isobaths are also shown. 

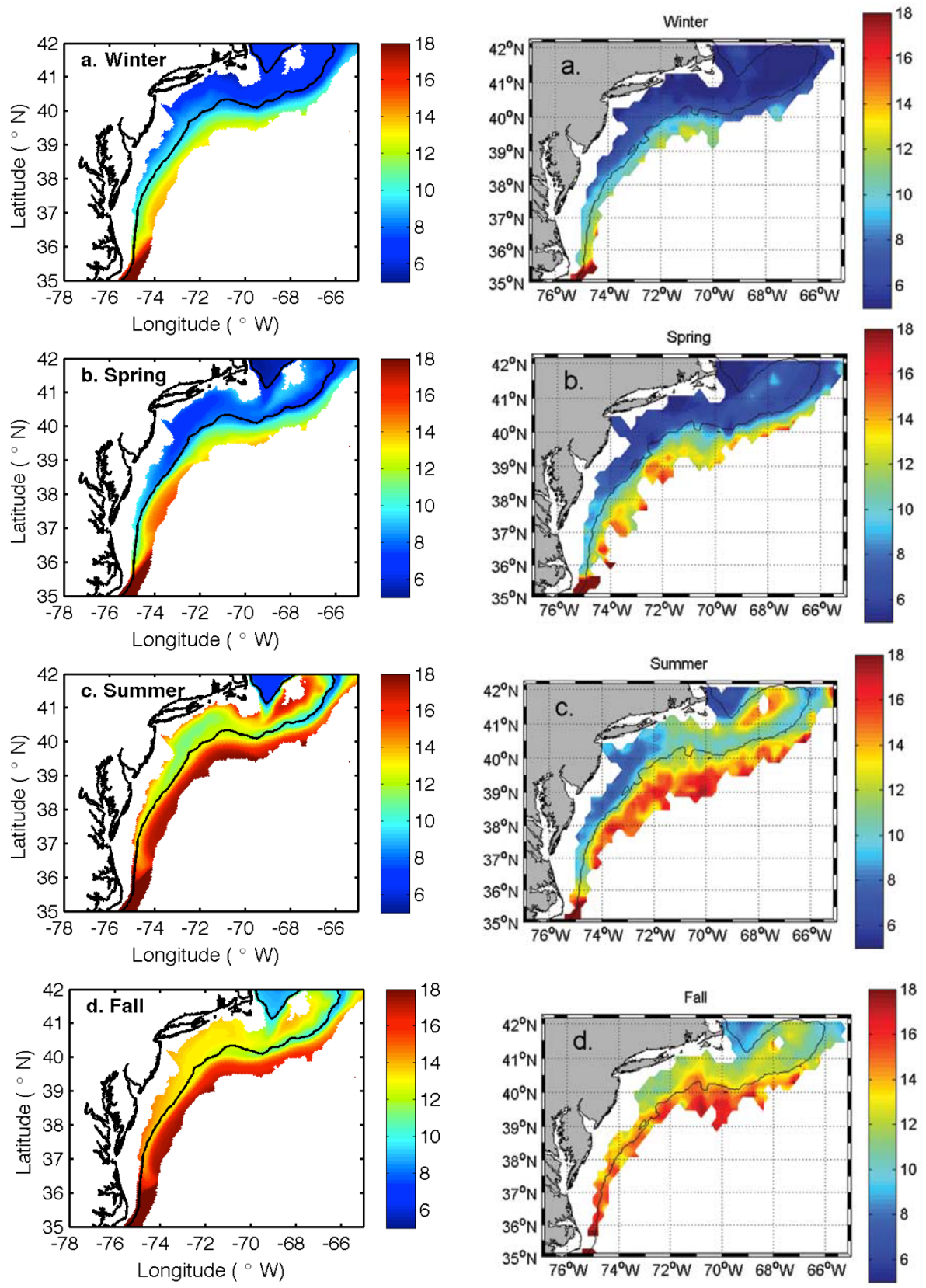

Figure 1-3a The comparison between the model solutions for seasonal mean temperatures (left column) and the climatology produced by Linder et al. (2006) (right column) at middepth (40-55 m) in (a) winter, (b) spring, (c) summer, and (d) fall. Black line indicates $100 \mathrm{~m}$ isobath. 

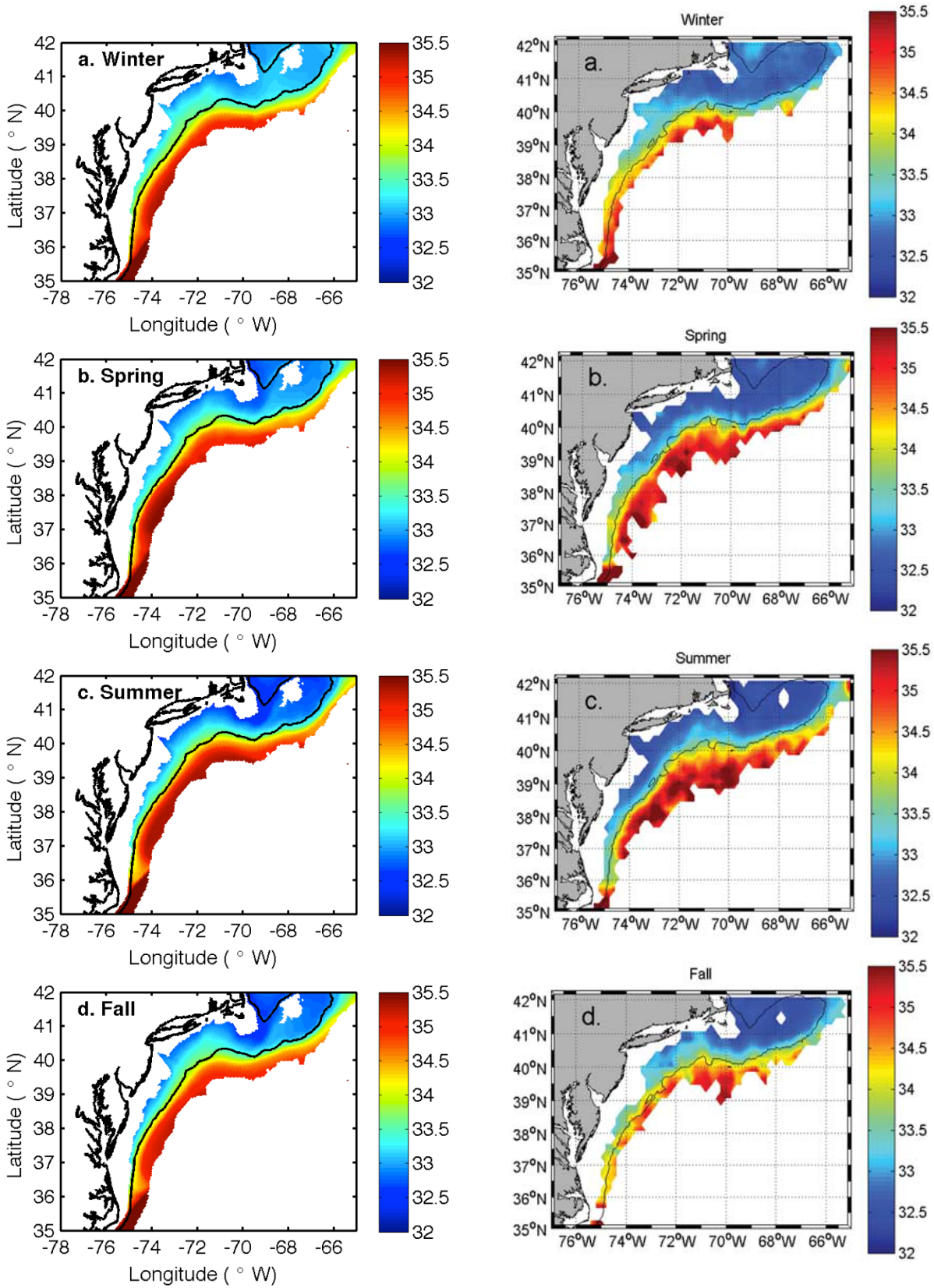

Figure 1-3b As in Figure 1-3a, but for salinity. 

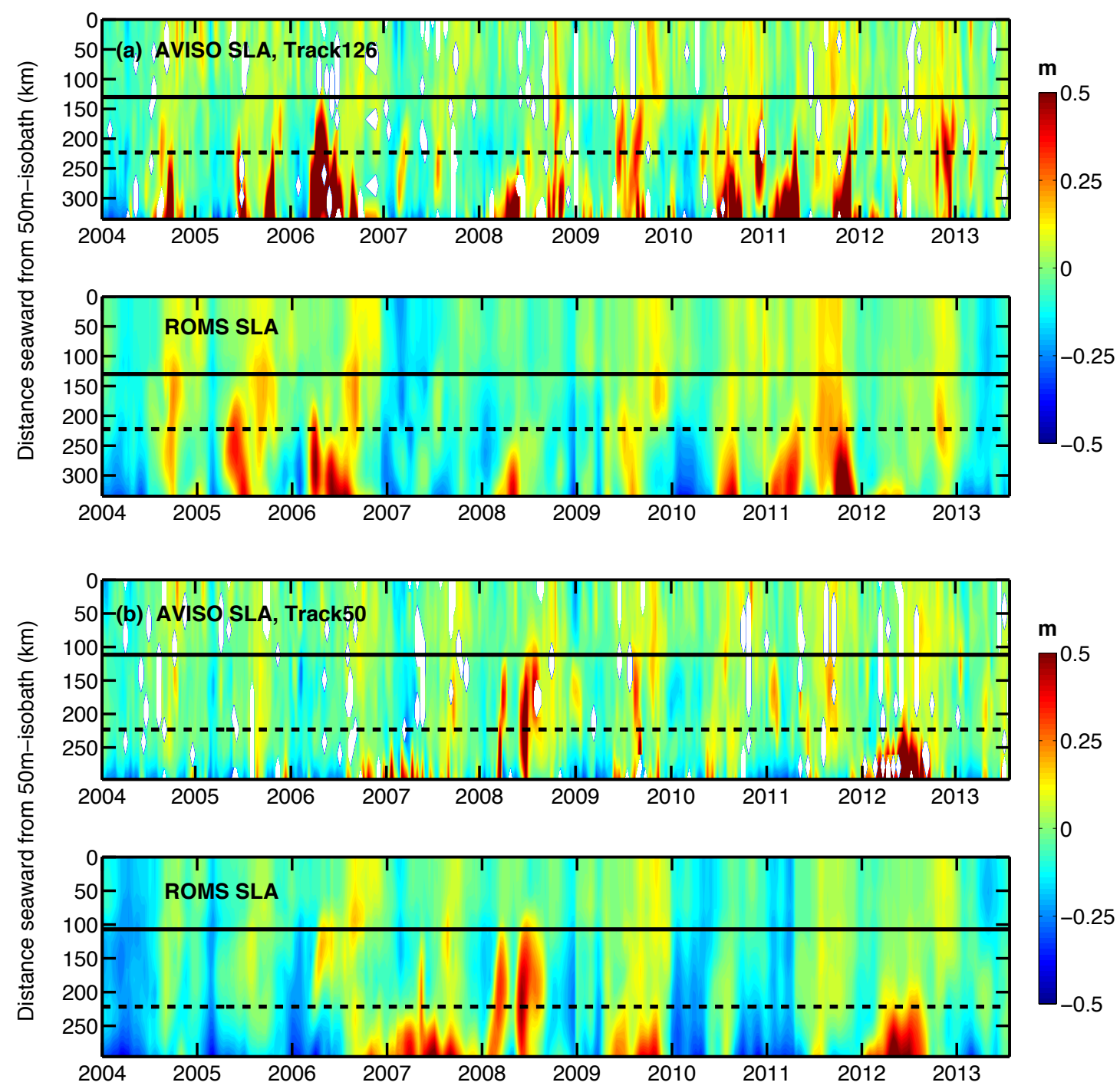

Figure 1-4 Hovmöller diagrams of satellite-observed (upper panel) and model-simulated (lower panel) cross-shelf transect of SSHA along (a) Track-126; (b) Track-50 from Jan 2004 to Dec 2013. The black solid line and the dash line indicate the 1000 and $3000 \mathrm{~m}$ isobaths, respectively. 


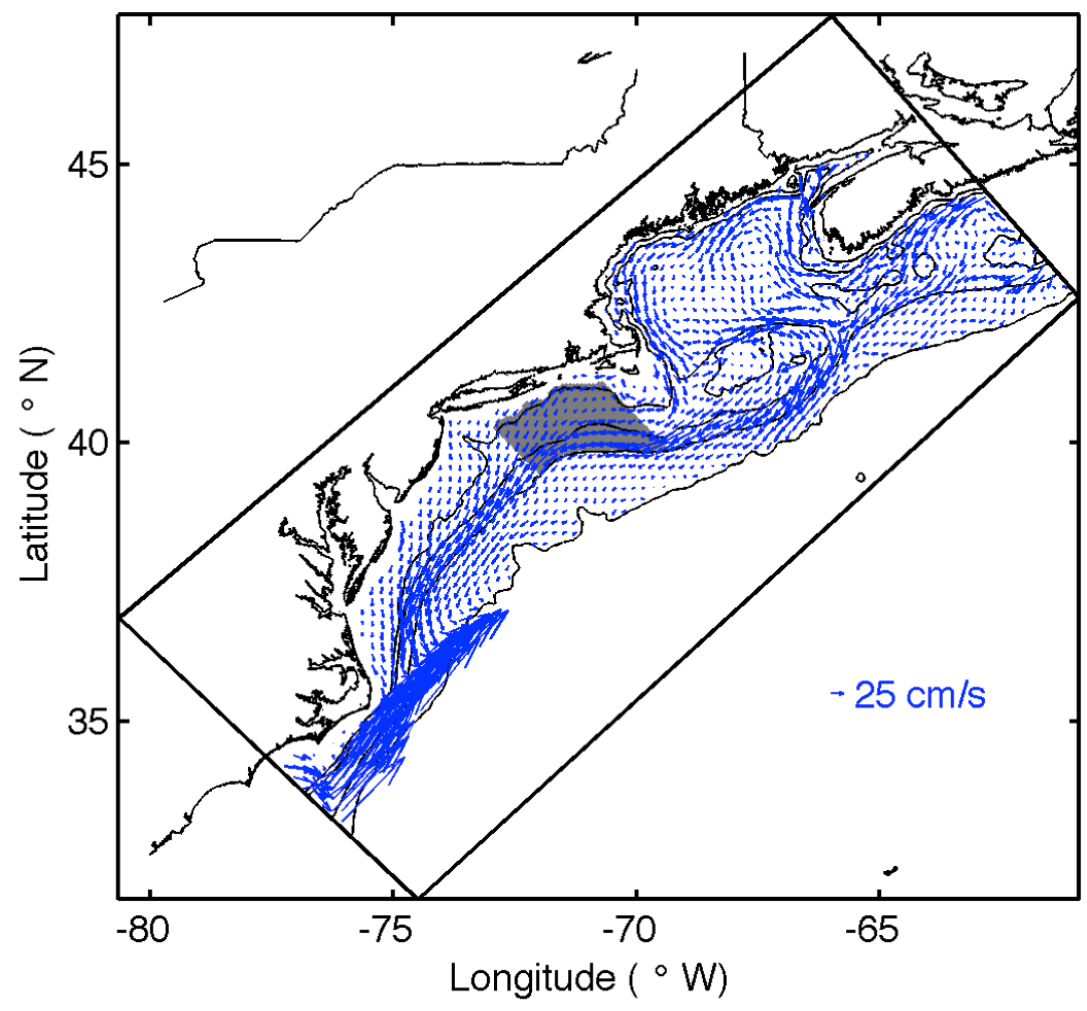

Figure 1-5 Mean-state surface velocity from experiment REAL. The shaded area denotes the region where the along-shelf average is obtained. The 50,100,1000, and $3000 \mathrm{~m}$ isobaths are also shown. 

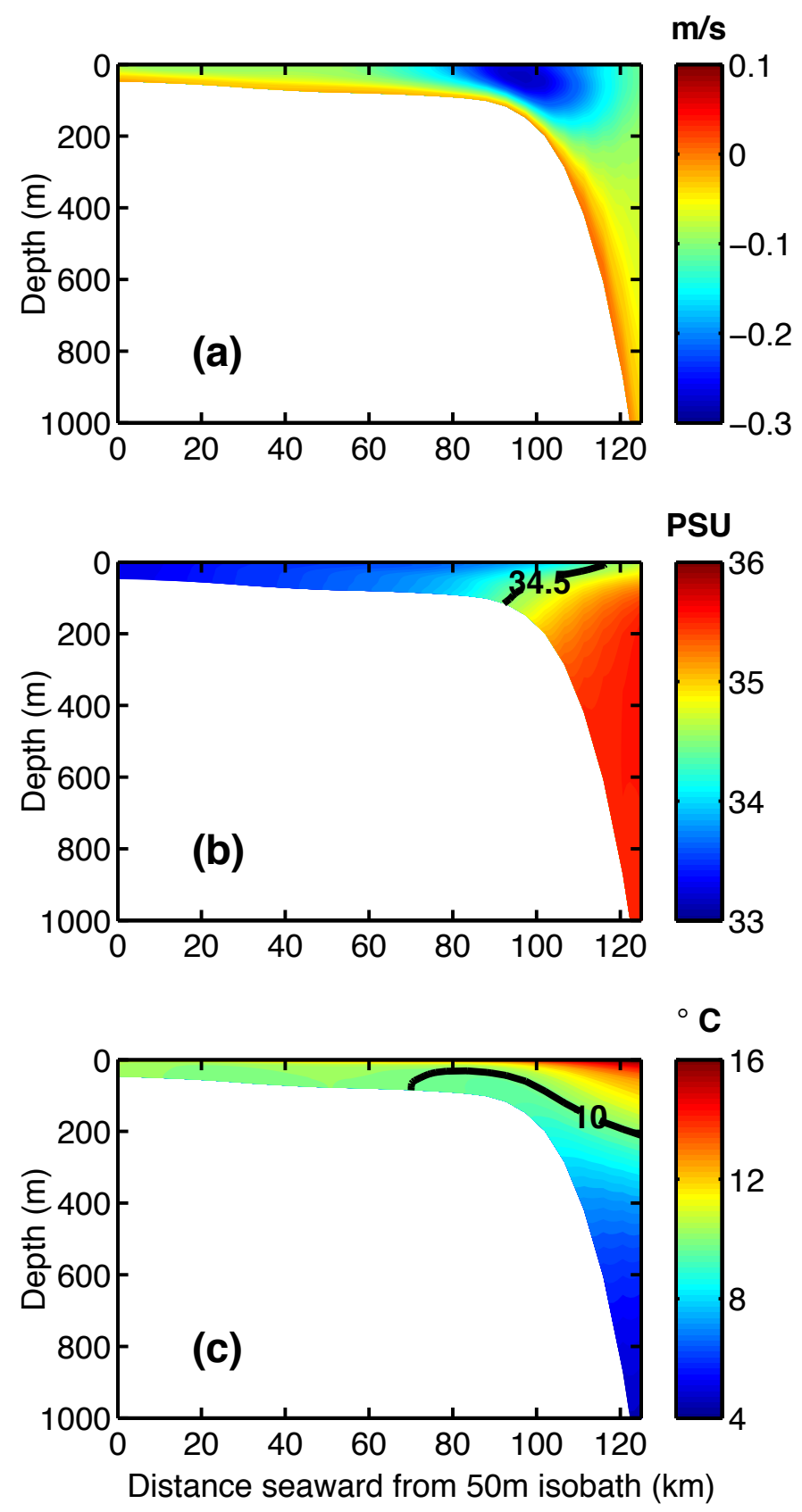

Figure 1-6 Mean-state along-shelf (a) velocity (represented by the colors; negative values indicate southwestward direction); (b) salinity (34.5 PSU isohaline is highlighted by black contour); (c) temperature $\left(10^{\circ} \mathrm{C}\right.$ isothermal is highlighted by black contour) in the southern New England shelf/slope area (shaded area in Figure 1-5). 

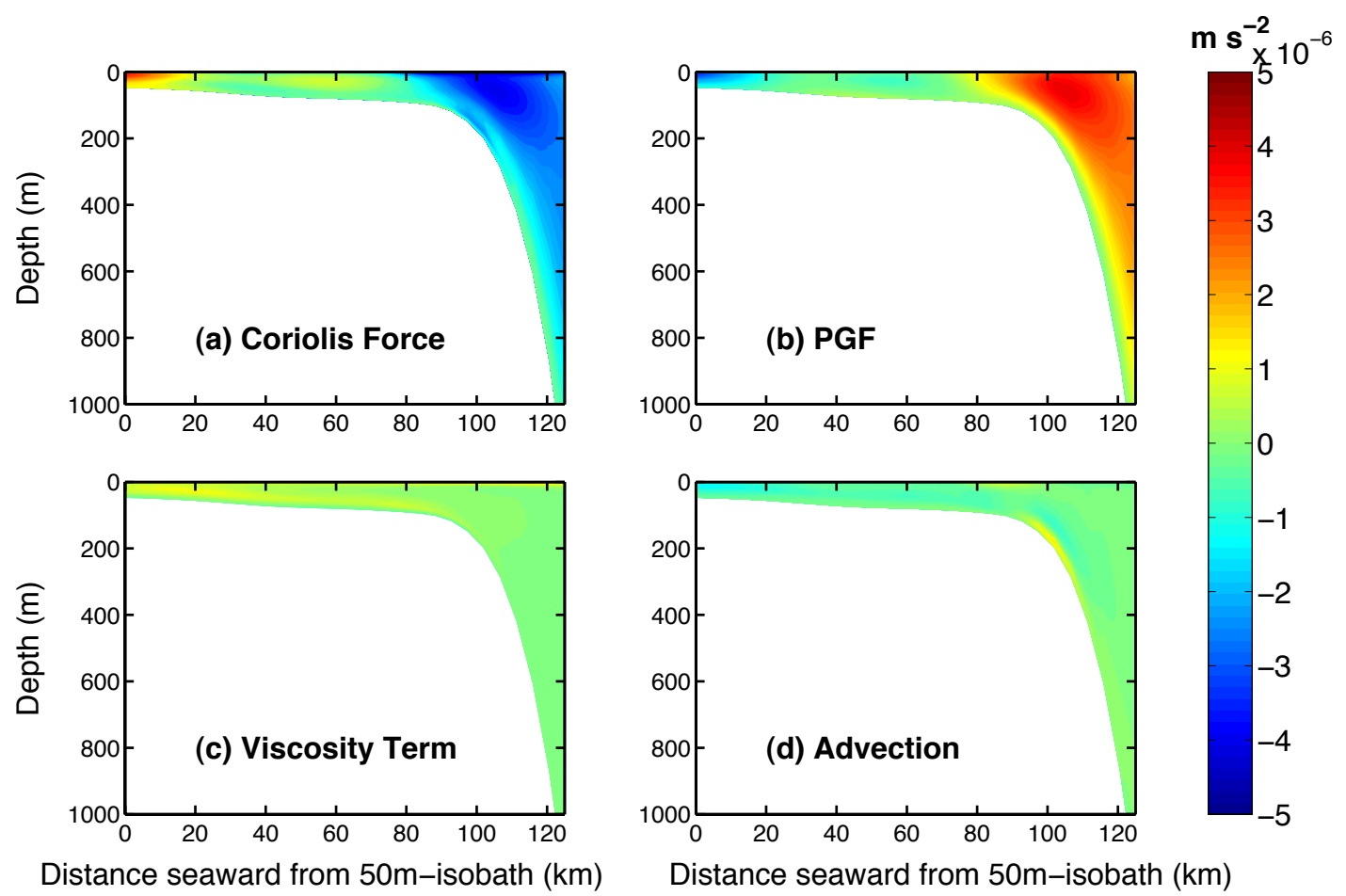

Figure 1-7 Cross-shelf distribution of the along-shelf momentum budget terms: (a) the Coriolis force, (b) the PGF, (c) the viscosity and (d) the nonlinear advection terms. 

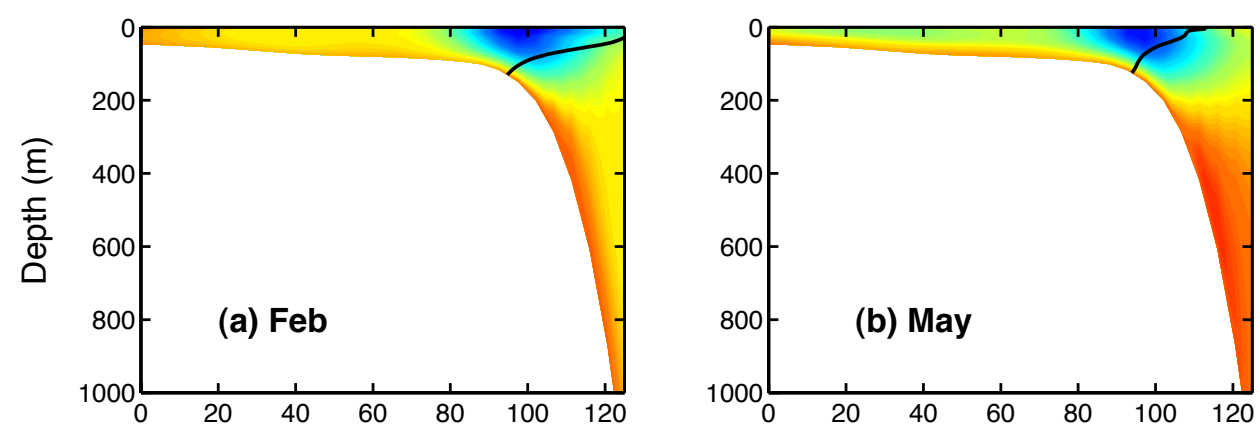

$\mathrm{m} \mathrm{s}^{-1}$
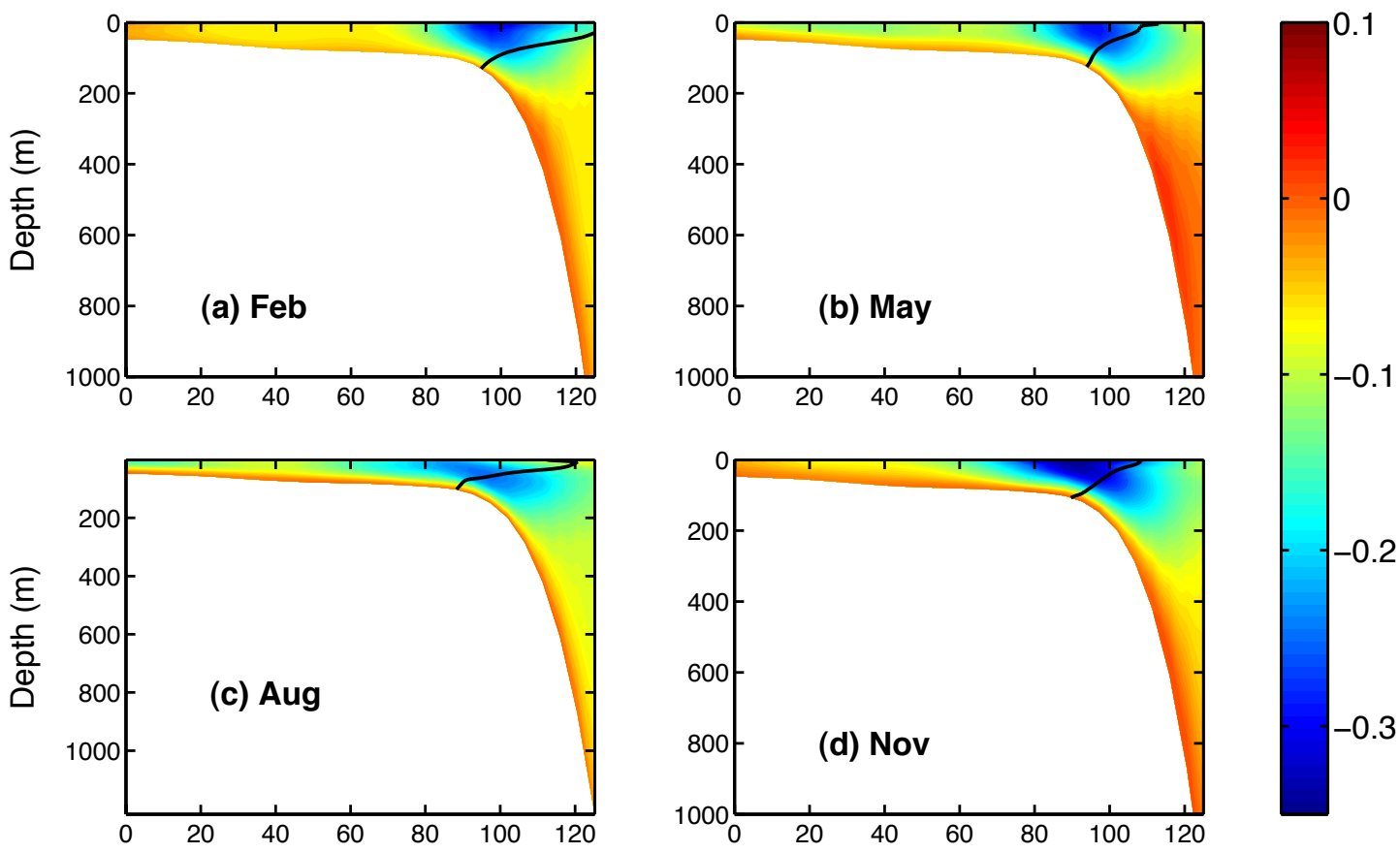

Distance seaward from $50 \mathrm{~m}$-isobath $(\mathrm{km})$

Figure 1-8 Cross-shelf distributions of the along-shelf velocity (represented by the colors; negative values indicate southwestward direction) and 34.5 PSU isohaline (black contour, indicating the shelfbreak front) averaged in the southern New England shelf/slope area in (a) February, (b) May, (c) August, and (d) November. 

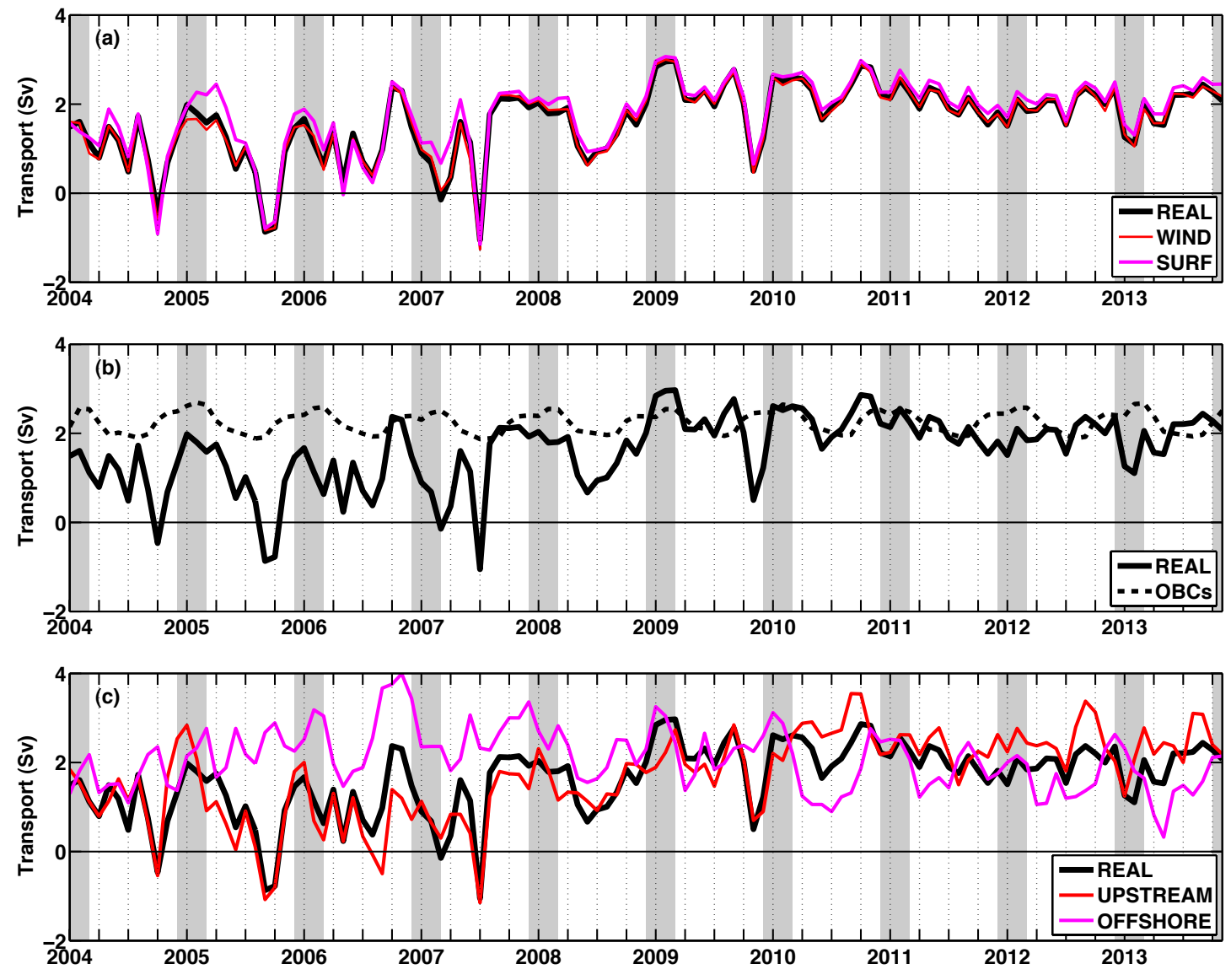

Figure 1-9 Time series of the along-shelf transport cross $T_{1}$ transect in different experiments: (a) REAL, WIND and SURF; (b) REAL and OBCs; (c) REAL, UPSTREAM and OFFSHORE. 

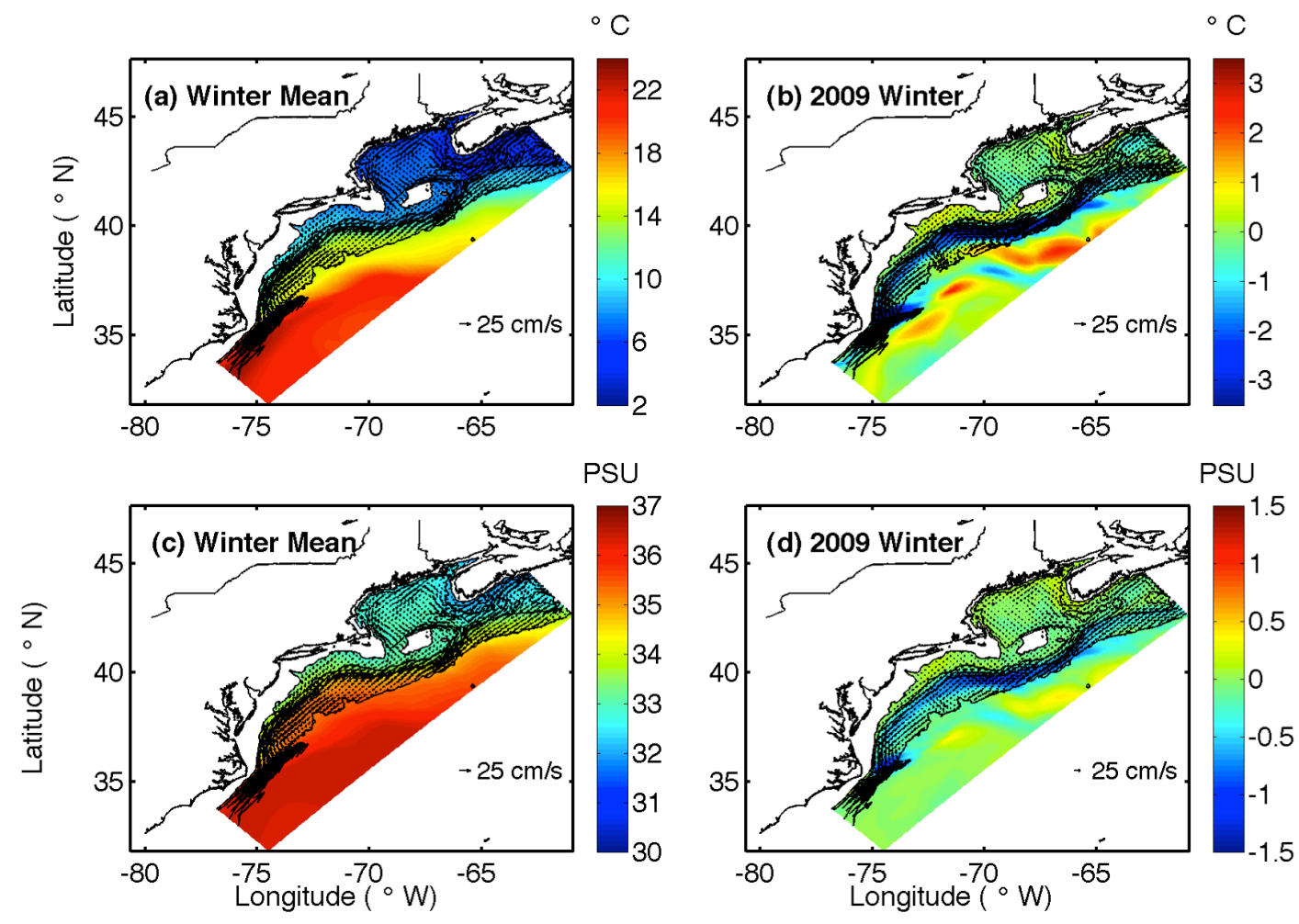

Figure 1-10 Mid-depth (50m) distribution of (a) 10-year averaged winter temperature (color) and surface velocity (vectors) and (b) temperature anomaly for the 2009 winter (color) and surface velocity (vectors) from experiment REAL. (c) and (d) are for salinity. The 50,100,1000, and $3000 \mathrm{~m}$ isobaths are also shown. 

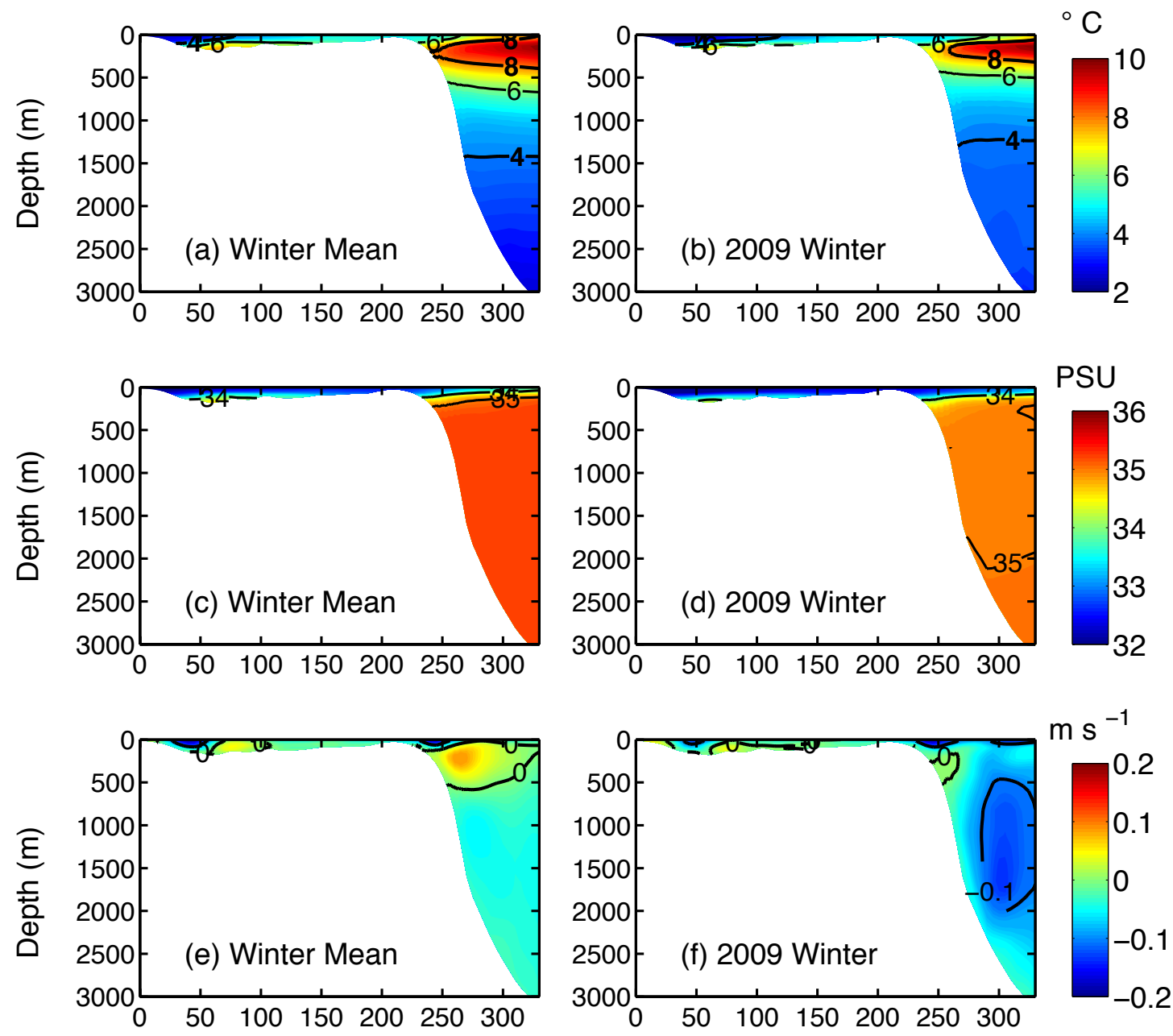

Distance seaward from coast $(\mathrm{km})$

Distance seaward from coast $(\mathrm{km})$

Figure 1-11 Comparison between the winter-averaged physical fields in the climatological state (left) and in 2009 (right) along the northeastern boundary of the model domain. (a)-(b): temperature, with $4{ }^{\circ} \mathrm{C}$ and $8^{\circ} \mathrm{C}$ isothermals highlighted; (c)-(d) salinity, with 34 and 35 PSU isohalines highlighted; (e)-(f) along-shelf velocity, with the negative values indicating a southwestward current. 

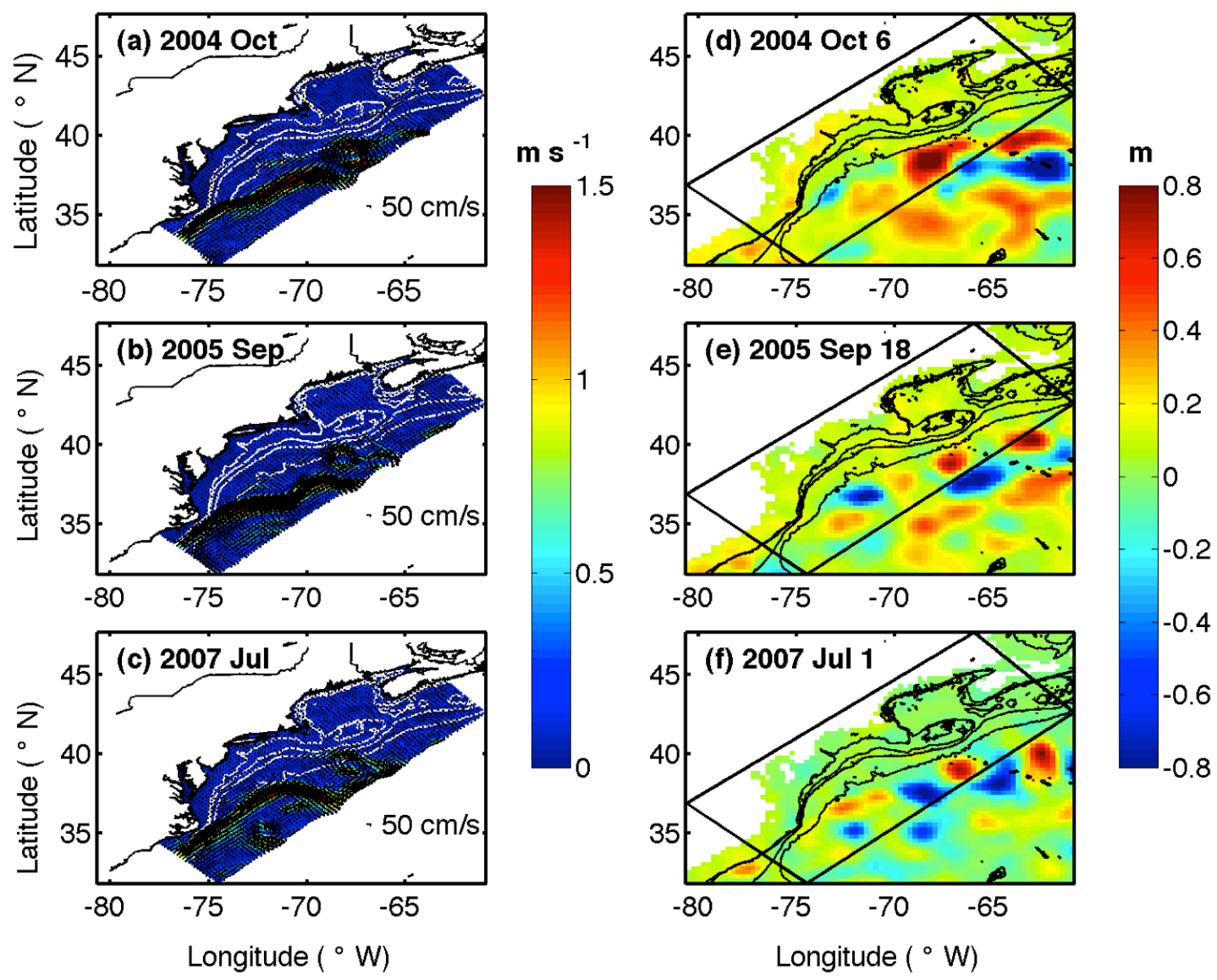

Figure 1-12 (Left Column) Monthly mean surface velocity (vectors) and current speed (color) for (a) 2004 October, (b) 2005 September and (c) 2007 July. (Right Column)

Daily snapshots of gridded AVISO SLA on (d) Oct 6, 2004, (e) Sep 18, 2005 and (f) Jul 1, 2007. The 50, 100, 1000, and $3000 \mathrm{~m}$ isobaths are shown. 

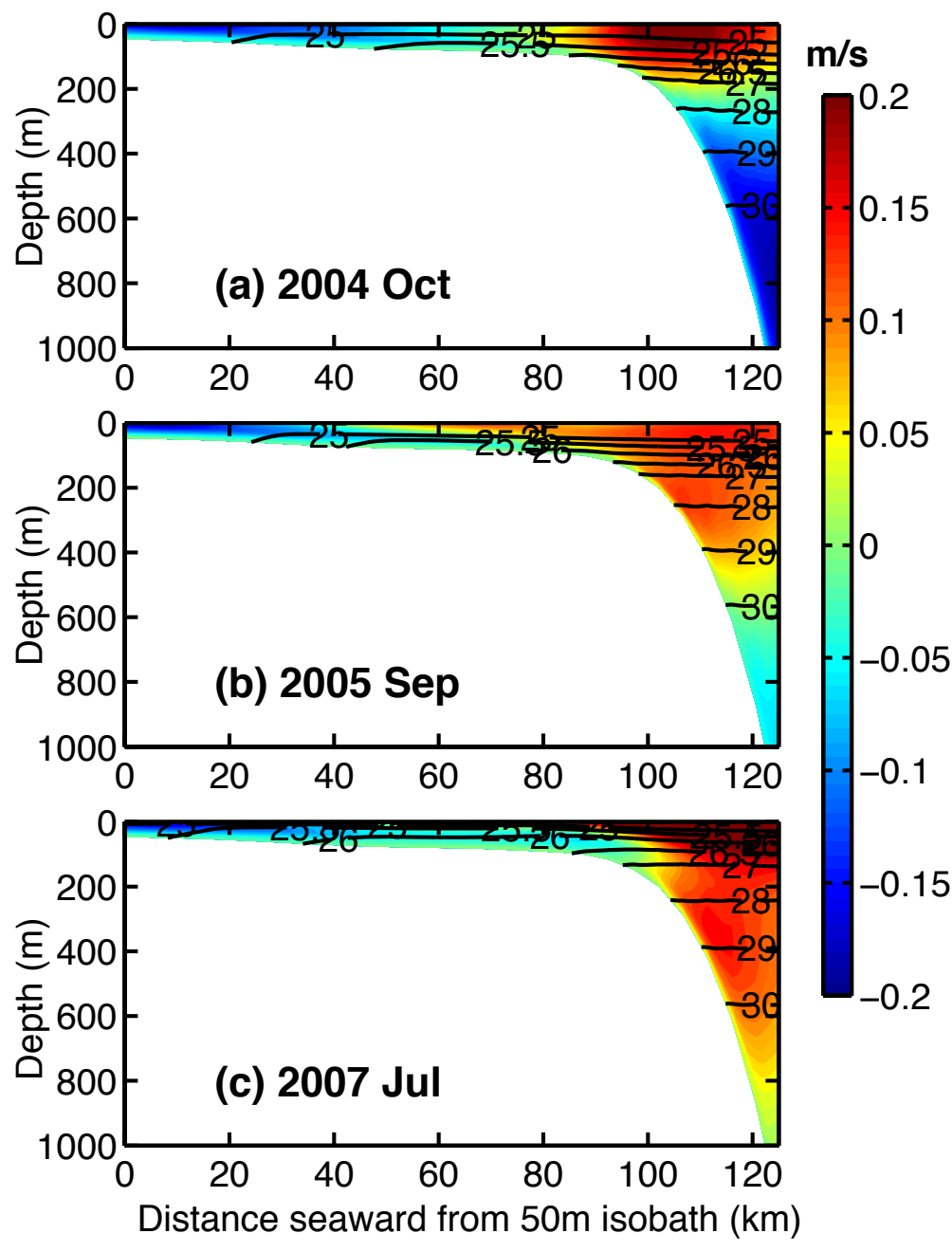

Figure 1-13 Cross-shelf distributions of the along-shelf velocity (represented by the colors; negative values indicate southwestward) and the potential density (represented by the black contours) along $\mathrm{T}_{1}$ section in (a) October 2004, (b) September 2005 and (c) July 2007. 

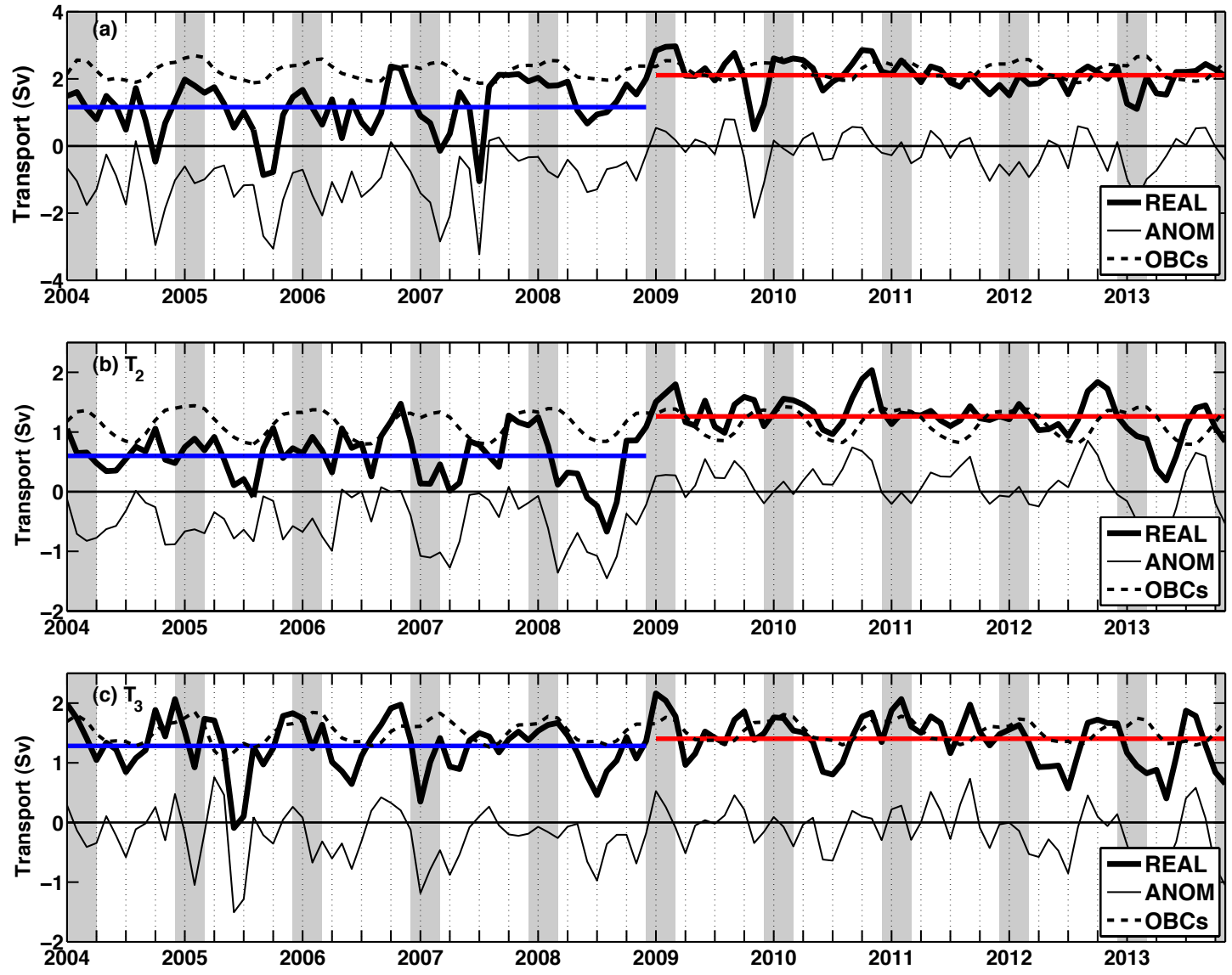

Figure 1-14 Time series of the along-shelf transport integrated between 50 and $300 \mathrm{~m}$ from experiment REAL (black heavy lines) and experiment OBCs (black dashed lines) along (a) $T_{1}$, (b) $T_{2}$ and (c) $T_{3}$. The transport anomalies (black thin lines) are calculated by subtracting OBCs from REAL. The five-year averaged along-shelf transports during 2004-2008 (2009-2013) are represented by the blue (red) lines in (a)-(c). Positive values indicate southwestward flow. The shaded areas denote winter months, which are December, January, February and March. 


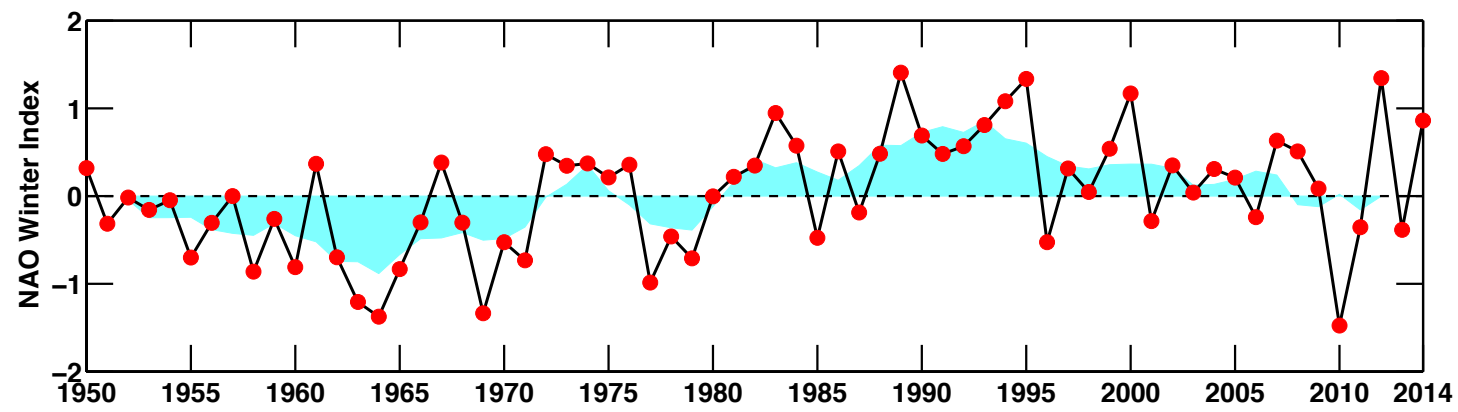

Figure 1-15 The winter (Dec-Mar) NAO index defined by Hurrell (1995), obtained from the NOAA National Weather Service Climate Prediction Center (http://www.cpc.ncep.noaa.gov/products/precip/CWlink/pna/nao.shtml). The blue area denotes smoothed values from a 5-year moving average (the mean of the five years preceding and including the data point). The moving average is often applied to remove the large year-to-year variability and to emphasize the longer term and more slowly varying changes of climate. Though a moving average can be of any length less than the length of the entire record, five years is commonly chosen because it emphasizes the decadal variability associated with changes in the regional and global atmospheric and oceanic circulations but maintains details of the timing and amplitude of decadal changes. 


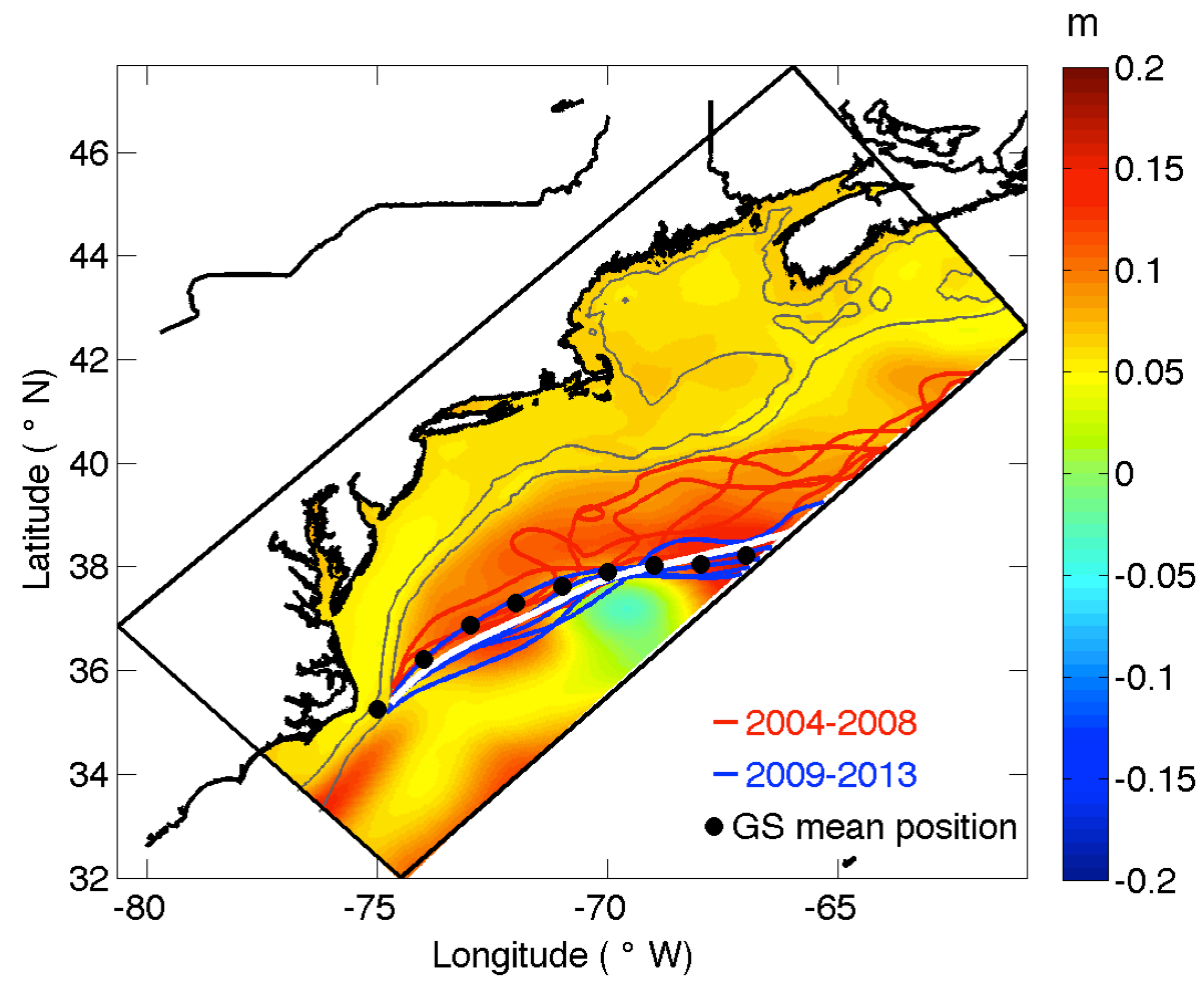

Figure 1-16 The spatial distribution of the SSH anomaly during 2004-2008, which is obtained by subtracting the 10-year averaged SSH from its average of 2004-2008, is represented by the colors. The climatological mean locations of the Gulf Stream North Wall from Taylor (2011) are denoted by the black dots. The 10-year averaged $35 \mathrm{~cm} \mathrm{SSH}$ from experiment REAL is highlighted by the white contour, and the annual averaged 35 cm SSH during 2004-2008 (2009-2013) are represented by the red (blue) contours. The $100 \mathrm{~m}$ and $1000 \mathrm{~m}$ isobaths are shown by thin black lines. 


\section{CHAPTER 2}

Physical Controls on Phytoplankton Blooms in Rhode Island Coastal Waters

by

Shuwen Zhang $^{1}$, Lewis M. Rothstein ${ }^{1}$

to be submitted to Estuarine, Coastal and Shelf Science

${ }^{1}$ Graduate School of Oceanography, University of Rhode Island, Narragansett, RI 02882. 


\section{Abstract}

The objective of this study is to obtain a fundamental understanding of the mechanisms controlling the seasonal variation and spatial distribution of phytoplankton biomass in Rhode Island (RI) coastal waters based on satellite observations and numerical model simulations. First, we apply an Empirical Orthogonal Function (EOF) analysis to a nine-year monthly chlorophyll-a dataset obtained by the Moderate Resolution Imaging Spectroradiometer (MODIS) in order to determine the spatial/temporal structure of the signal. The first EOF mode, which accounts for $44.1 \%$ of the total variability, shows that the spatial variations of chlorophyll-a are in phase from the RI coast to the outer shelf, with that mode's temporal variations dominated by a strong seasonal cycle characterized by a broad peak during the fall-winter months (October to March). The spatial distribution of chlorophyll-a indicates that the phytoplankton biomass decreases with distance offshore as the water depth increases. To understand the mechanisms controlling the abovementioned features, we first set idealized one-dimensional (1-D) numerical experiments, using a well-known physicalbiological model (ROMS-NPZD), to isolate advective processes. Results show that the fall-winter bloom is initiated by enhanced vertical turbulent mixing, which brings nutrients up into the euphotic zone. The enhanced vertical turbulent mixing results from the combined effects of the increased surface momentum forcing and surface cooling. At the same time the extensive mixing also has a detrimental effect on the fall-winter bloom as phytoplankton are carried below the euphotic layer by the mixing. In deeper waters, turbulent eddies are less affected by the presence of the ocean bottom and thus lead to stronger mixing; the stronger turbulent transport of phytoplankton to greater water depths 
causes a reduction of the surface phytoplankton biomass. A three-dimensional (3-D) experiment is then conducted to validate the key conclusions drawn from the 1-D simulations. Results from the 3-D experiment are qualitatively in agreement with those from the 1-D experiments. 


\subsection{Introduction}

With its direct connection to the Southern New England continental shelf, the Rhode Island (RI) coastal area is referred to as a 'mixing-basin' (Beardsley et al., 1985) because of the diversity of water types and ecological species that were observed during the past several decades. The ecosystem is nourished by high concentrations of phytoplankton and has been identified as providing significant economic value through commercial fishing (Sherman et al., 1996a).

Analyses of historical in situ and satellite observations in this region, though more often focusing on the entire Middle Atlantic Bight (MAB), have portrayed a general pattern of chlorophyll distributions; the seasonal cycle is similar to Longhurst's Model 3 (Yoder et al., 2001) 'Winter-Spring Production with Nutrient Limitation' and high chlorophyll concentrations occur in near-shore regions and decrease with a log-normal distribution in the offshore direction to the shelfbreak (O'Reilly and Zetlin, 1998; Yoder et al., 2002). With the exception of a few areas influenced by large river discharge, the significant seasonality and spatial distribution of phytoplankton biomass are maintained by nutrients supplied from the deep water determined by vertical mixing (Nixon et al., 1983), which itself is associated with the stratification and de-stratification of the water column.

There have been several studies of this physical mechanism regulating the biological processes. For example, Chen et al. (1988) formulated a two-mixed-layer model in Long Island Sound including the effects of wind forcing, surface cooling in the upper layer and the spring tide in the lower layer to show that the combination of these physical mechanisms supported an upward nutrient transport that led to the 
phytoplankton bloom that is typically observed in early fall. Xu et al. (2013) found that the upper mixed layer over the entire MAB shelf is dynamically dominated by wind and surface buoyant plumes, and they influence mixing which have both positive and negative impacts on the evolution of a phytoplankton bloom, i.e. an increase of mixing will increase nutrients availability but decrease light availability. Fields et al. (2015) measured surface chlorophyll-a in Rhode Island Sound and Block Island Sound and, when accounting for hydrographic observations, found that the significant regional heterogeneity in both the timing and magnitude of the seasonal bloom was due to strong tidal mixing variability.

However, several issues remain from these previous studies. For example, the spatially scattered and short-term in-situ observations might be insufficient for drawing any further, detailed conclusions. In addition, ocean color satellite remote sensing does provide both spatial and temporal continuity, but it has limitations in coastal waters due to extensive cloud cover especially during winter, and the presence of sediment and colored dissolved organic matter (CDOM) (Harding et al., 2004). Also, those numerical simulations that so far have been applied to these issues, while facilitating the study of temporal and spatial variability, treat the entire shelf as if it were a dynamically homogenous region, neglecting the fact that shelf processes are inherently nonlinear and exhibit variations over a broad range of spatial and temporal scales. Most importantly, analyses of previous model results of this region are usually statistical, with a lack of fundamental dynamical explanation. With all of this, the physical controls of much of the ecosystem dynamics in RI coastal waters are still not understood. 
This study aims to understand the dominant features, and the underlying physical mechanisms, that help to shape both the temporal and spatial variation of phytoplankton in RI coastal waters. The rest of this paper is organized as follows. Section 2 presents the analyses of satellite observations. Section 3 describes the physical-biological model used in this study and the experiment design. Section 4 discusses the model results and Section 5 presents a summary of the key findings of this study.

\subsection{MODIS observations}

The seasonal and spatial variations of sea surface chlorophyll-a in RI costal waters are analyzed based on a nine-year dataset obtained by the Moderate Resolution Imaging Spectroradiometer (MODIS) sensor aboard National Aeronautics and Space Administration (NASA)'s Aqua satellite. The merged Level-3 products with 3-day temporal resolution and 4-km spatial resolution were acquired from NASA Goddard Space Flight Center, Ocean Ecology Laboratory, Ocean Biology Processing Group. Here we calculate monthly surface chlorophyll-a concentrations from January 2004 to December 2012 by taking the geometric mean of all non-missing and non-masked values at each pixel. Considering the bio-optical complexity and the high heterogeneity in the near shore waters, we exclude waters shallower than $10 \mathrm{~m}$. We also exclude data for water deeper than $1000 \mathrm{~m}$, as our focus is on the continental shelf.

The distribution of surface chlorophyll-a concentrations throughout the study area during the nine-year average is presented in Figure 2-1, which shows a general pattern of onshore-offshore decrease from the coast to the shelf edge. Regional differences are evident, particularly on Nantucket Shoals, inside of the Long Island Sound and in the immediate near-shore of the New Jersey shelf, which are all featured by high 
concentrations. However, the limitations of ocean color algorithms in coastal waters, due to the extensive presence of suspended sediment and colored dissolved organic matter (CDOM), can influence the accuracy of observed chlorophyll-a with errors as large as $100 \%$ (Harding et al., 2004). Therefore, in the following we will focus on the area indicated by the black frame in Figure 2-1, mainly covering the entire RI coastal waters and southern New England shelf.

An Empirical Orthogonal Function (EOF) approach is used to identify the dominant temporal signal in the nine-year chlorophyll-a dataset. This method of data reduction is well suited for analyzing ocean color images, which possess long time series and significant spatial variability (e.g. Yoder et al., 2001; Yoder et al., 2002; Xu et al., 2011). While the statistical EOF modes do not necessarily correspond to direct physical forcing mechanisms, partitioning the spatial and temporal variance of a dataset into modes are beneficial to reveal spatial functions having time-varying amplitudes that can be interpreted in relation to physical processes.

Here we apply the computationally efficient, singular value decomposition (SVD) method to calculate eigenvectors, eigenvalues and time-varying amplitudes. Considering $\mathrm{N}$ monthly composites, the spatial and temporal variance of a dataset, $x_{m}(t)$, can be partitioned into modes, $i$, that result in spatial functions, $\phi_{i}(m)$, having time-varying amplitudes, $a_{i}(t)$ (also known as principal components) such that

$$
x_{m}(t)=\sum_{i=1}^{N}\left[a_{i}(t) \phi_{i}(m)\right]
$$

This means that the time variation of chlorophyll-a for each pixel is the summation of the spatial functions, $\phi_{i}$, whose amplitudes, $a_{i}(t)$, indicate how the spatial modes vary with 
time. Prior to performing an EOF analysis, we fill any gaps in the data by running a three-by-three pixel median filter to replace missing values over small gaps. Moreover, the temporal mean, i.e. the black frame in Figure 2-1, is subtracted from each pixel so as to emphasize the anomalies from the general mean pattern.

The first mode explains $44.1 \%$ of the anomalous variability of the chlorophyll-a datasets (Figure 2-2). The spatial function shows consistently positive values over the study area. This reveals, on the one hand, that the spatial variations are in phase and, on the other hand, when multiplied in conjunction with positive values of time-varying amplitude coefficients, the entire field of chlorophyll-a increases with respect to the climatological average. The temporal signal is dominated by a strong seasonal cycle characterized by a broad peak during fall-winter (October to March) with minimum values in summer. This is consistent with previous studies and is believed to be a result of strong impacts of processes that govern the availability of nutrients (O'Reilly and Zetlin, 1998; Yoder et al., 2001) with specific, triggering physical factors varying by region (e.g. $\mathrm{Xu}$ et al., 2011; Siedlecki et al., 2011). In our focused region, vertical mixing plays the dominant role in bringing the nutrient-rich bottom water to the surface to support phytoplankton growth (Fields et al., 2015), whereas the specific mixing mechanism remains under debate. This will be detailed later.

Concurrent with the time series of surface chlorophyll-a we present, for the same region, a nine-year monthly-averaged wind speed record at 10-m height as derived from the National Oceanic and Atmospheric Administration (NOAA) National Centers for Environmental Prediction North America Regional Reanalysis (NCEP/ NARR) in Figure 2-3. It is easy to see that high chlorophyll-a concentrations occur simultaneously with 
strong winds during the fall-winter months. The correlation coefficient for the two time series, with the annual cycle removed, is $\sim 0.43$.

Another dominant feature from the spatial distribution of MODIS derived surface chlorophyll-a is the decreasing concentrations seaward with an increase in water depth. This can also be seen when examining a time series taken from two selected locations of the MODIS dataset, indicated as the black dots along a cross-shelf section in Figure 2-1, that are representative of the inner (40 $\mathrm{m}$ depth) and outer $(80 \mathrm{~m} \mathrm{depth})$ shelf, respectively. There is a notable difference between these two locations (Figure 2-4), with consistently higher mean chlorophyll-a levels and variances throughout the fall-winter months in the inner shelf.

Based on the abovementioned analyses, we raise two questions:

i) Does the seasonal variation of vertical mixing associated with surface forcing control the fall-winter bloom in RI costal waters?

ii) Can the decrease of chlorophyll-a with distance offshore be explained by the change in the physical environment that is affected by the depth of the water column?

To answer these two questions, we use a hierarchal numerical modeling approach with both one-dimensional and three-dimensional configurations.

\subsection{Numerical approach}

\subsubsection{Model description}

The numerical model used in this study is the Regional Ocean Modeling System (ROMS) version 3.7. ROMS is a split-explicit and free-surface model that assumes a Boussinesq and hydrostatic fluid when solving the primitive equations (Shchepetkin and 
McWilliams, 2005). (A more detailed description of this model can be found in Chapter 1 of this thesis). There are also several ecological models included in ROMS for biogeochemical and bio-optical applications.

We choose a relatively simple, four-compartment nutrient-phytoplanktonzooplankton-detritus (hereafter referred to as NPZD) model to represent lower trophic level dynamics. The primary reason for choosing this model type is that it captures the biological food web at its most fundamental level and is relatively straightforward for analyzing physical vs. non-physical processes as these affect the temporal and spatial evolution of the ecology. Despite its relative simplicity, the NPZD model that is embedded in the ROMS circulation model can offer important insights on the issues we aim to address in this study. The governing equations for the four state variables are as follows (the state variables are all in the nitrogen-based unit of $\mathrm{mmol} \mathrm{N} \mathrm{m}$ and the governing equations mostly follow Powell et al., 2006):

$$
\begin{aligned}
& \frac{D N}{D t}=\delta D+(1-\gamma) G Z-U P+h \frac{N_{o}-N}{\tau}+\frac{\partial}{\partial z}\left(k_{v} \frac{\partial N}{\partial z}\right) \\
& \underbrace{\frac{D P}{D t}}_{D P T}=\underbrace{U P-G Z-\sigma_{d} P}_{B I O}+\underbrace{\frac{\partial}{\partial z}\left(k_{v} \frac{\partial P}{\partial z}\right)}_{D I F} \\
& \frac{D Z}{D t}=\gamma G Z-\zeta_{d} Z^{2}+\frac{\partial}{\partial z}\left(k_{v} \frac{\partial Z}{\partial z}\right) \\
& \frac{D D}{D t}=\sigma_{d} P+\zeta_{d} Z^{2}-\delta D+w_{d} \frac{\partial D}{\partial z}+\frac{\partial}{\partial z}\left(k_{v} \frac{\partial D}{\partial z}\right)
\end{aligned}
$$

(Please refer to Table 2-1 for definitions of all of the free parameters in these and the following equations). The left-hand side of each equation is the material derivative of the biological variable. The last term in each equation on the right-hand side represents vertical diffusion, and the remaining terms depict various biological processes. In particular, a restoration term $h \frac{N_{o}-N}{\tau}$ is added in equation (1), which restores the near- 
bottom nutrient fields towards the observed value $\left(\mathrm{N}_{\mathrm{o}}\right)$ on a time scale $(\tau)$. This term is added for better representing sediment re-suspension processes, which are not well represented in this particular NPZD model. In practice, this term is only considered in the deep layers $z>D$, where $D$ is a threshold depth that requires specification. In our study, $D$ is set to $25 \mathrm{~m}$ and the time scale $\tau$ is set to 1 day.

The photosynthetic growth and uptake of nitrogen by phytoplankton (U), grazing on phytoplankton by zooplankton (G), and irradiance (I) are formulated as follows:

$$
\begin{aligned}
& U=\frac{V_{m} N}{k_{f(N)}+N} \underbrace{\frac{\alpha I}{\sqrt{V_{m}^{2}+\alpha^{2} I^{2}}}}_{f(I)} e_{f(T)}^{C_{p}\left(T-T_{0}\right)} \\
& G=R_{m}\left(1-e^{-\Lambda P}\right) e^{C_{Z}\left(T-T_{0}\right)} \\
& I(z)=\beta I_{0} \exp \left(k_{z}+k_{p} \int_{0}^{Z} P\left(z^{\prime}\right) d z^{\prime}\right)
\end{aligned}
$$

Here $T$ is temperature and $I_{0}$ is surface irradiance. According to equation (5), the phytoplankton growth rate $\mathrm{U}$ depends on nutrient concentrations, the photosynthetically active radiation $I$ and temperature, and is calculated as a multiplication of three functions: $\mathrm{f}(\mathrm{N})$ adopts the Michaelis-Menten curve to describe the change in uptake rate as a function of nutrient; $\mathrm{f}(\mathrm{I})$ represents the photosynthesis-irradiance (P-I) relationship; and $f(T)$ reflects the impacts of temperature on the growth rate (Eppley, 1972).

The modifications of equations (1)-(7) from the original NPZD model of Powell et al. (2006) that we adopt (because they are better suited for the continental shelf to shelfbreak region) have been described by Zhang et al. (2013). In brief, there are three important modifications. First, phytoplankton growth and zooplankton grazing rates are assumed to be temperature dependent (through the $\mathrm{Q}_{10}$ terms; Eppley, 1972). Since the annual temperature in coastal water varies within a range of $20^{\circ} \mathrm{C}$, this dependency is 
necessary to account for seasonal variations in maximal growth rates. Second, the linear zooplankton mortality is replaced with a quadratic functional dependence, which is a more effective way of parameterizing the predation of zooplankton by higher trophic levels (Steele and Henderson, 1981; Fasham, 1995). And third, the nudging term $h \frac{N_{O}-N}{\tau}$ is used to restore the near-bottom nutrient fields towards the observed climatology. In our study we further adjust this near-bottom nutrient restoration value and initial slope of the P-I curve due to local water type in order to better represent the sediment re-suspension processes in RI coastal waters.

The turbulence closure scheme adopted in this study is the Mellor-Yamada Level 2.5 scheme (Mellor and Yamada, 1982). This scheme is widely used in coastal ocean modeling and has reasonable skill in depicting coastal mixing processes, with the advantage of explicitly solving the bulk characteristics of the turbulent motions (Allen et al. 1995). The turbulent diffusivity $k_{v}$ is written as

$$
k_{v}=l q S+k_{\text {back }}
$$

in which $l$ is the turbulent length scale that physically reflects the size of turbulent eddies, $q$ is the turbulent velocity scale, $\frac{1}{2} q^{2}$ is the turbulent kinetic energy, $S$ is a nondimensional stability coefficient, and $k_{\text {back }}$ is the background turbulent diffusivity that is set to a constant value $1 \times 10^{-4} \mathrm{~m}^{2} \mathrm{~s}^{-1}$. The turbulent kinetic energy (TKE) and $l$ can be obtained by solving two prognostics equations (see Allen et al. (1995) for the detailed formulations). 


\subsubsection{Experiment design}

a) One-dimensional experiments

In our primary set of experiments, we focus on the impacts of the local physical environment on the biological environment. Thus we configure one-dimensional (1-D) simulations, in which only the vertical variations are considered; we initially neglect horizontal advective processes, the main simplification in these experiments. Five experiments are conducted representing water depths $(\mathrm{H})$ that vary from $40 \mathrm{~m}$ to $80 \mathrm{~m}$ in $10 \mathrm{~m}$ increments. The five experiments will be referred to as $\mathrm{H} 40-\mathrm{H} 80$, respectively. The vertical levels in these experiments are evenly distributed with uniform $1 \mathrm{~m}$ spacing. The model is forced with climatological surface forcing including winds, temperature, and short wave and long wave radiations at daily frequencies. The surface forcing is derived from the NOAA National Centers for Environmental Prediction North America Regional Reanalysis (NCEP/NARR) dataset and all variables are obtained by both spatial averaging within the southern New England shelf and temporal 30-day smoothing to damp out any higher-frequency variability. The initial conditions for $\mathrm{N}, \mathrm{P}, \mathrm{Z}$, and $\mathrm{D}$ in the five 1-D experiments are vertically uniform. The initial value for $\mathrm{N}$, i.e. $\mathrm{N}_{0}$, is set equal to the average value of nitrate $\left(3.15 \mathrm{mmol} \mathrm{N} \mathrm{m}^{-3}\right)$ derived from the report of the Ocean Special Area Management Plan (OSAMP). P, Z and D are set to a small value of 0.1 mmol $\mathrm{N} \mathrm{m}^{-3}$. All biological parameters in equations (1)-(7) are listed in Table 2-1.

All the experiments are integrated for two climatological years and the transient non-equilibrium behavior only occurs in the first three months. Therefore, in the following sections all the analyses are based on the period from July 1st of the first year until June 30th of the second year so as to form an entire annual climatology. 
b) Three-dimensional experiment

We additionally conduct a three-dimensional (3-D) experiment to validate the results from the 1-D experiments. The physical circulation model used in the 3-D experiment was originally developed and described by Luo et al. (2013). Briefly, it is a coastal ocean model nested within a larger-scale regional ocean model. The coastal model domain includes the Rhode Island Sound and the adjacent inner shelf area (Figure 2-5). The coastal ocean model uses a high horizontal resolution with grid intervals varying from $600 \mathrm{~m}$ over the shelf to $1 \mathrm{~km}$ along the boundaries, and 30 terrain-following vertical layers. In addition to the climatological daily surface forcing described in the above section a) above, the model is also forced by five tidal harmonics and climatological monthly river discharge (please see Luo et al. 2013 for those locations). The configurations of the NPZD model in the 3-D experiment are set similarly to the 1-D experiments; the same biological parameters (Table 2-1) and near-bottom nutrient restoration values are used. If the local water depth is larger than $25 \mathrm{~m}$, the threshold depth $D$ is set to $25 \mathrm{~m}$; if not, $D$ is set to the depth of the lowest model level. The riverine inputs of dissolved and particulate biological constituents are derived from the total nitrogen in the nitrate pool based on Howarth et al., (1996), multiplied by the freshwater transport to give discharge rates. The 3-D ROMS-NPZD model is also run for two years to achieve a quasi-periodic state. 


\subsection{Model results and analyses}

\subsubsection{Biological seasonal variability}

a) Surface chlorophyll

The seasonal variations of surface chlorophyll from the 1-D experiments are presented here in order to show that the 1-D model is capable of reproducing the key features of the satellite observations as identified in Section 2. We assume the chlorophyll content per phytoplankton cell is constant $\left(\mathrm{C}: \mathrm{Chl}=60 \mathrm{mgC}(\mathrm{mg} \mathrm{Chl})^{-1}\right)$ by multiplying by the carbon to nitrogen ratio $(\mathrm{C}: \mathrm{N}=6.6)$. This assumption is commonly used in ecosystem models to reduce the number of unconstrained parameters. We do not account for the fact that the relationship between chlorophyll and phytoplankton biomass is nonlinear due to the photosynthetic apparatus of the cell as it acclimates to changes in light and nutrient conditions (Falkowski, 1980). We therefore rate this assumption as common and necessary.

Time series of the surface chlorophyll concentration in the five experiments are shown in Figure 2-6. In all five experiments, the phytoplankton bloom begins in midOctober and then continues into the winter months, which is consistent with the MODIS observations. The moderate broad peak in Nov-Dec attenuates slightly during Dec-Feb owing to solar radiation being lowest during this time of year. This is followed by a more discernable increase in late-March when both sufficient light and nutrients are present. After that peak the high chlorophyll concentrations decrease rapidly; minimum surface chlorophyll concentrations occur during the summer months. Moreover, Figure 2-6 suggests that the surface chlorophyll concentrations decrease as the water depth increases, which is also in agreement with the satellite observations. These experiments 
give us confidence in using the numerical simulations to understand in more detail the processes responsible for this seasonal signal in the water column. We next focus on the depth dependence evident in Figure 2-6 by focusing on the two extreme cases, experiments $\mathrm{H} 40$ and $\mathrm{H} 80$.

\section{b) Vertical distribution of biological variables}

The advantage of these relatively simplified 1-D numerical simulations is that they allow us to efficiently analyze the processes responsible for the seasonal variability of the vertical distributions of the phytoplankton. The results from experiments $\mathrm{H} 40$ and H80 are presented in Figures 2-7 and 2-8, respectively. To enhance legibility and enable comparisons between the two experiments, the color scales are the same with blanks indicating zero values for each variable.

The simulated nitrate $(\mathrm{N})$ concentration below $30 \mathrm{~m}$ does not deviate far from its initial condition throughout the year in the lower water column in both experiments. During the spring-summer months, the nitrate is depleted in the upper $20 \mathrm{~m}$, with a persistent subsurface nitracline (i.e. the depth where nitrate concentration begins to increase from zero) forming. After that the nitrate vertically homogenizes in the fallwinter months.

There are large seasonal variations in phytoplankton biomass $(\mathrm{P})$ in the water column. In experiment H40, the annual cycle of phytoplankton is divided into three phases: i) from November to February, the phytoplankton is nearly vertically homogenous; ii) during late February to March, a vertical gradient appears with highest values in the upper $20 \mathrm{~m}$ and; iii) from April to September, phytoplankton concentrations are relatively low near the surface and a subsurface maximum exists in the vicinity of the 
pycnocline $(20-35 \mathrm{~m})$, which is ubiquitous in stratified coastal waters during summer (O'Reilly and Zetlin, 1998). In experiment H80, the three phases of phytoplankton show similar patterns to $\mathrm{H} 40$, only with smaller concentrations.

Simulated zooplankton $(Z)$ concentrations also show strong seasonal variability, featuring two periods of high concentrations: one at subsurface in late summer and the other is vertically uniform in the mixed layer during the fall-winter. Given that our lower trophic level model represents all zooplankton losses mathematically, rather than biologically, by justified closure functions (Steele and Henderson, 1992), it is beyond the scope of this study to investigate the detailed biological dynamics regulating zooplankton seasonality. We do, however, present a detailed parameter sensitivity study (Appendix A) to address some of these issues. Instead, we evaluate the importance of zooplankton grazing on phytoplankton.

As expected, the seasonal variations of detritus (D) concentrations are similar to that of phytoplankton; higher in fall-winter and again in March, while lower in summer. The simulated detritus concentrations increase with depth during all seasons, with peak values $\left(0.8-1.1 \mathrm{mmol} \mathrm{N} \mathrm{m}^{-3}\right)$ occurring near the bottom in the $40 \mathrm{~m}$ depth experiment and at the base of the mixed layer in the $80 \mathrm{~m}$ depth experiment. We set a sinking rate of detritus at $8 \mathrm{~m} \mathrm{day}^{-1}$ in all experiments and, with a constant remineralization rate of 0.1 day $^{-1}$, we obtain a remineralization vertical length scale of $80 \mathrm{~m}$ for suspended particles and dissolved organic nitrogen (DON) that is not explicitly included in the model (Spitz et al, 2003). The importance of detritus remineralization will also be estimated in our sensitivity study (Appendix A). 
In summary, the 1-D simulations reproduced two of the key features identified in the MODIS observations: i) the annual cycle of phytoplankton in all experiments is characterized by a distinct fall-winter bloom and, ii) the water column depth is a key parameter in affecting the magnitude of the phytoplankton biomass. In the following, we will further analyze the model results to answer the two questions raised in Section 2.2.

\subsubsection{Mechanisms responsible for the fall-winter phytoplankton bloom}

Since the seasonal variations of the phytoplankton in all 1-D experiments (H40H80) are qualitatively similar, we only show the analyses of the results from experiment H40 as an example.

We start by analyzing the processes contributing to the growth of phytoplankton. As identified in equation (2), the time change of phytoplankton biomass (DPT) depends on the total effect of biological processes (BIO) and the physics of vertical diffusion (DIF). Figure 2-9 illustrates a climatological seasonal cycle of the budget terms in equation (2) for experiment H40. The DPT term has a relatively large value starting from mid-October, followed by an undetectable negative growth rate during December and then another moderate positive period through January and February. In March, there is a transient rise in the upper $20 \mathrm{~m}$ and in succeeding months is dominated by an abrupt decrease. During the other periods of the year, DPT has relatively small values. During fall-winter months, the BIO term exhibits a two-layer structure, with positive values in the upper $10 \mathrm{~m}$ and negative values below (Figure 2-9(b)). This means that the growth of phytoplankton exceed its loss terms due to either mortality or zooplankton grazing, and vice versa. The DIF term demonstrates an opposite distribution to the BIO term, which 
suggests that the physics of turbulent diffusion acts to reduce the gradient of concentrations in the water column (Figure2-9(c)).

Next we examine the seasonal variations of phytoplankton growth rate, $U$, and the important components affecting $\mathrm{U}$, as shown in equation (5). The time-depth variations of $\mathrm{U}, \mathrm{f}(\mathrm{N})$ and $\mathrm{f}(\mathrm{I})$ are all presented in Figure 2-10. Small values of $\mathrm{f}(\mathrm{N})$ or $\mathrm{f}(\mathrm{I})$ indicate nutrient- or light-limitation, respectively, while values near 1 correspond to no limitation. A dominant signal in the temporal evolution of $U$ is that it rapidly rises to its annual maximum of 0.5 day $^{-1}$ in late October and early November, and maintains relative high values until March in the upper $10 \mathrm{~m}$ (Figure 2-10(a)). Correspondingly, nutrientlimitation, shown in Figure 2-10(b), is strongest during the summer months in the upper water column associated with a nutricline at $20 \mathrm{~m}$. At the time of destratification of the nutricline in late October, there is essentially no nutrient-limitation in the water column, which stimulates the rapid increase of phytoplankton growth rate, i.e., a vertical flux of nutrients sufficiently supplies phytoplankton growth. Beginning in March, nutrientlimitation re-develops from the surface, slowly extending to $20-\mathrm{m}$ depth. The patterns of light-limitation are a mirror opposite to the nutrient-limitation in many respects (Figure 210(c)). As expected, there is always a pronounced vertical gradient in the spring and summer months when the light intensity is strongest, while in late fall and winter light is limited throughout the water column. The phytoplankton growth rate is determined by the product of $f(N)$ and $f(I)$, which largely compensate each other across the vertical gradient, and is merely modulated by the temperature-dependent value of the maximum growth rate, which contributes to the distinct seasonal cycle in phytoplankton growth rate. The onset of pronounced phytoplankton growth in late fall is thus directly dominated by the 
availability of nutrients in the upper water column, and the duration of such a strong growth rate is regulated by the light intensity. To this extent, physical mixing processes have a central role in influencing both light and nutrient budgets, and thus regulating phytoplankton bloom.

With the above results our focus now turns to the seasonal variation of the physical environment. The time series of surface wind speed and direction, as well as the net surface heat flux are shown in Figure 2-11. All of these time series have been filtered with a 30-point moving average and subsampled at daily intervals in order to eliminate the high-frequency variability induced by strong storms. The local winds are predominantly northwesterly in the winter months, shifting to southwesterly during summer. Starting from October, the wind speed gradually increases, reaching its annual maximum in January, then weakening in late February that features a more rapid rate of decrease than increase. The net surface heat flux exhibits a large seasonal variation, with positive (into the ocean) values in spring and summer, reaching a maximum of $200 \mathrm{Wm}^{-2}$ in July. In fall, as solar radiation decreases and cooling due to latent and sensible heat loss increases, the ocean turns from gaining heat to losing heat; the surface net heat flux decreases to its annual minimum of $-200 \mathrm{Wm}^{-2}$ in January. The large heat losses in winter are typically associated with southeastward winds that bring cold, dry air from the continent to the shelf.

Figure 2-12 shows the seasonal variations of the ocean current, temperature and turbulent diffusivity within the water column. The surface forcing is clearly responsible for driving the seasonal variations of currents and thermal stratification in the water column. The current is projected onto both along-wind and cross-wind directions, 
denoted as $\mathrm{U}$ and $\mathrm{V}$, respectively. The vertical distribution of $\mathrm{U}$ and $\mathrm{V}$ demonstrate the classic Ekman current structure throughout the entire year: $U$ (the along-wind component) is positive near the surface and negative at depth while $\mathrm{V}$ (the cross-wind component) is generally negative. The intensity and the vertical extent of the current are both enhanced when the winds increase in strength. As for the evolution of thermal stratification and destratification, in Figure 2-12(c), during the summer and following the isothermal $18{ }^{\circ} \mathrm{C}$, a strong thermocline forms near surface then gradually deepens, corresponding to the period when the wind is weakest and the surface heat flux is strongest. The thermal stratification starts to weaken from October and the water column essentially becomes unstratified in early November, lasting until March. Lentz et al. (2003) argued that the breakdown of the seasonal thermocline in fall was primarily due to wind forcing under specific conditions, not surface cooling, according to their 1-year moored array observations on the New England shelf. By contrast, the gradual redevelopment of the thermocline, beginning in April, was primarily a one-dimensional response to increasing surface heat flux.

The bottom panel in Figure 2-12 presents the seasonal cycle of turbulent diffusivity $\left(k_{v}\right)$, a pure physical process. Turbulent mixing starts to develop in late September from the surface as a response to intensified surface winds, and continues to extend downwards over time, creating a maximum in the interior of the water column in mid-December. Upon cessation of the wind stress and surface heating, turbulent mixing rapidly decreases beginning in March.

The mechanism for the fall-winter phytoplankton bloom in the RI coastal waters can thus be summarized as follows. Starting from late September, the surface wind turns 
from a weaker southwestward wind to a stronger northwestward wind and, concurrently, the ocean turns from gaining heat to losing heat. These combine to intensify the turbulent mixing in the water column, which breaks down the stratification and brings nutrients from the bottom up into the euphotic zone. As a result, a phytoplankton bloom is initiated under this favorable environment.

\subsubsection{Impacts of water depth}

This section aims to investigate the second question, i.e., whether the decrease of chlorophyll offshore is due to the change of water depth. Results from experiments $\mathrm{H} 40$ and $\mathrm{H} 80$ are presented, which represent shallow and deep water conditions, respectively. According to the discussion in the previous section, both turbulent mixing and phytoplankton biomass are enhanced during fall-winter months. With that, the results shown here will be all time-averaged during fall-winter months (November to March). We start with analyzing the impacts of the water depth on the physical environment, particularly the turbulent mixing process. Figure 2-13 (a) shows the time-averaged vertical profiles of turbulent diffusivity in experiments $\mathrm{H} 40$ and $\mathrm{H} 80$. The patterns of the vertical distribution of $k_{v}$ are similar in the two experiments, with a maximum at depth and minima both at the surface and the bottom due to the presence of Ekman boundary layers. The differences are noticeable: while the vertical extent of $k_{v}$ reaches proportionally similar depths in both experiments, the maximum value of $k_{v}$ is almost double in the $\mathrm{H} 80$ experiment (up to $0.04 \mathrm{~m} \mathrm{~s}^{-2}$ ) than the $\mathrm{H} 40$ (about $0.02 \mathrm{~m} \mathrm{~s}^{-2}$ ) experiment. To further examine the key factors affecting the magnitude of the $k_{v}$ distribution in different water depths, we also show the vertical profiles of turbulent kinetic energy (TKE) and turbulent length scale ( $l$ ) in Figure 2-13(b) and (c), 
respectively. In the two experiments, the magnitudes of TKE decrease with depth in a similar way, while the variations of $l$ are similar to $k_{v}$ in the interior water column, indicating that the spatial scale of turbulent eddies is the main physical factor causing the variation of $k_{v}$ with water depth. In the shallow water environment as described in our study (water depth is generally less than $100 \mathrm{~m}$ ), the spatial scale of the turbulence is strongly affected by the presence of the ocean bottom. If the water depth is larger, the turbulence can achieve a greater magnitude. This is essentially the reason that the turbulent length scale $l$, which physically represents the vertical extent of the turbulent eddies, increases with water depth. The main source of this TKE in the fall-winter months, when the stratification is nearly neutral, is the vertical current shear. As shown in Figure 2-14, the differences between the currents and the shear in H40 and those in H80 are small, which explains the small difference of TKE between the two cases.

With the above diagnoses of the physical environment we are now in position to discuss the impact of water depth on phytoplankton biomass. Figure 2-15 shows the timeaveraged budget terms for the phytoplankton biomass in experiments $\mathrm{H} 40$ and H80. The vertical diffusion of phytoplankton in both $\mathrm{H} 40$ and $\mathrm{H} 80$ is negative in the upper water column and positive in the lower water column. This means that turbulent mixing tends to erode the phytoplankton gradients by sweeping down phytoplankton cells from the surface to the bottom. Such an effect inhibits the accumulation of phytoplankton in the euphotic layer and thus has a negative impact on phytoplankton biomass. Clearly, in the deeper water case (H80), the DIF term has a larger vertical extent because of the greater depth. Therefore, the decrease of the phytoplankton biomass with water depth can be explained as follows. In deeper waters, the turbulent eddies are less affected by the 
presence of the ocean bottom and thus cause stronger mixing; the stronger turbulent transport of phytoplankton to greater water depths causes a reduction of the surface phytoplankton biomass.

\subsubsection{Results from the three-dimensional experiment}

Our focus here is to test that the mechanisms controlling the seasonal and spatial variations of the phytoplankton bloom based on the 1-D experiments are robust and also exist in a more realistic 3-D simulation of RI coastal waters.

We first compare the model simulated surface chlorophyll fields with the MODIS monthly climatology to validate the 3-D simulation (Figure 2-16). The 4-km resolution MODIS dataset is mapped onto the northern Middle Atlantic Bight. Four typical months (February, May, August and November) are selected to represent winter, spring, summer and fall, respectively. Before we go any further, one thing needs to be clarified: the atmospheric correction technique for the MODIS data used in this study potentially produces considerable errors in estuaries and some optically complex coastal environments (Werdell et. al., 2007). For the U.S northeast coast this is a common issue for Chesapeake Bay, Gulf of Maine, New York-New Jersey Bight and Long Island Sound (NOAA Coast Watch East Coast Node), where the latter two areas are included in our model domain. Therefore, even though all of the available MODIS chlorophyll-a concentrations are presented, these two areas as well as those with water depth shallower than $10 \mathrm{~m}$ should not be considered in this inter-comparison.

Figure 2-16 shows that the 3-D model captures the main features in the observations reasonably well. In winter, the simulated phytoplankton bloom gradually spreads over the entire coastal region, with a surface chlorophyll concentration of $\sim 3 \mathrm{mg}$ 
$\mathrm{m}^{-3}$, slightly decreasing in the offshore direction. This is consistent with previous studies (e.g., Ryan et al., 1999a; Yoder et al., 2001) showing the occurrence of a shelf-wide chlorophyll enhancement during the fall-winter season. As time progresses, the seasonal stratification starts to develop in spring, leading to a depletion of nutrients so that the surface biomass consequently diminishes in the upper water column. There is a biological front encompassing the Block Island Sound in the model results that is less obvious in the relatively coarse resolution $(4 \mathrm{~km})$ satellite images. This feature has been recognized by Stegmann and Ullman (2004) as a result of strong spring run-off supplying nutrients to phytoplankton but constrained by tidal mixing fronts. In summer, the surface chlorophyll disappears over the entire study domain except for the Block Island Sound and Nantucket Shoals regions, which both feature strong tidal currents. Actually, the higher chlorophyll concentrations are found on Nantucket Shoals in all seasons due to nutrient supply induced by strong tidal mixing (He and Wilkin, 2006). The breakdown of stratification in the fall allows deep-ocean nutrients to reappear in the upper water column, initiating a fall bloom that varies from the coast to outer shelf. In summary, the above comparisons of seasonal maps show that the model is generally able to reproduce the seasonal evolution and major spatial characteristics of the surface chlorophyll fields in RI coastal region.

The monthly mean surface chlorophyll derived from the 3-D experiment is further spatially averaged in RI coastal waters (black rectangle in Figure 2-5). The time series thus obtained, with its standard deviation, are shown in Figure 2-17(a). The temporal evolution shows a relatively pronounced peak in March and a smaller peak in November. The timing of the phytoplankton bloom in the 3-D simulation agrees well with that of the 
1-D simulations (Figure 2-6), indicating that the dominant mechanisms responsible for this distribution does not change. Admittedly, the surface chlorophyll concentration in the 3-D experiment is higher than that in the 1-D experiments from April to July. This discrepancy is likely due to the contribution of horizontal advection in the 3-D experiment. According to Luo et al. (2013), there is a branch of flows that occur around the periphery of Rhode Island Sound owing to tidal mixing and local stratification during spring to summer, which inevitably carries phytoplankton from the higher chlorophyll concentrations of Nantucket Shoals.

Figure 2-17(b) shows a time series of the turbulent diffusivity at $15 \mathrm{~m}$ depth, which is also spatially averaged in RI coastal waters. The seasonal variations of vertical mixing in the 3-D experiment is very similar to those in the 1-D experiments (Figure 212(d)); the turbulent mixing is significantly enhanced from October and strong mixing lasts until March of the next year. The fall-winter phytoplankton bloom in the 3-D experiment is in phase with the enhanced turbulent mixing. This confirms the first conclusion reached previously from the 1-D experiments, i.e. the combined effects of surface cooling and intensified winds enhances the turbulent mixing, which brings nutrients into the euphotic zone and initiates the fall-winter bloom in the RI coastal waters.

The cross-shelf distribution of the model simulated turbulent diffusivity and phytoplankton concentrations in the four typical months (November, February, May and August) are illustrated in Figure 2-18. The phytoplankton biomass generally shows a decrease offshore as the water depth increases. Such a pattern is again in agreement with the MODIS observations and the 1-D experiments. In May and August, vertical mixing is 
weak so that the maximum phytoplankton concentrations occur subsurface. In November and February, phytoplankton are nearly vertically uniform due to strong vertical mixing. Meanwhile, the magnitude of the turbulent diffusivity increases with water depth, which is consistent with the 1-D experiments. The offshore decrease of phytoplankton in November and February is in good agreement with the offshore increase of the turbulent diffusivity. Thus the 3-D experiment results are in accord with the second conclusion we reached from the 1-D experiments, i.e. the offshore decrease of phytoplankton is essentially caused by the increase of vertical turbulent mixing with water depth.

\subsection{Summary}

To obtain a fundamental understanding of the mechanisms controlling the seasonal variation and spatial distributions of the phytoplankton biomass in Rhode Island (RI) coastal waters, we analyzed satellite chlorophyll-a observations and also performed one- and three-dimensional numerical simulations. We first applied an EOF analysis to a nine-year monthly chlorophyll-a dataset from MODIS. The first EOF mode, which accounts for $44.1 \%$ of the total variability, shows that the spatial variation of chlorophylla is in phase from the RI coast to the outer shelf, with the temporal variability dominated by the strong seasonal cycle as characterized by a broad peak during the fall-winter

months. The spatial distribution of chlorophyll-a indicates that the phytoplankton biomass decreases with distance offshore as the water depth increases.

A set of idealized, 1-D numerical experiments were conducted using a physicalbiological model (ROMS-NPZD) that was designed to understand the mechanisms controlling the key features of the temporal and spatial variations of phytoplankton biomass. The key findings are as follows. 1) Enhanced vertical turbulent mixing initiates 
the fall-winter bloom by bringing nutrients from depth into the euphotic zone. The enhanced vertical turbulent mixing is due to the combined effects of increased surface momentum (wind) forcing and surface cooling. 2) The extensive mixing also has a counteractive effect on phytoplankton biomass in the fall-winter months as phytoplankton are carried below the euphotic layer. In deeper waters, turbulent eddies are less affected by the presence of the ocean bottom and thus cause stronger mixing; the stronger turbulent transport of phytoplankton to greater water depths causes a reduction of the surface phytoplankton biomass. We also performed a 3-D NPZD-ROMS simulation to validate the key conclusions drawn from 1-D simulation. It was found that results from the 3-D experiment were qualitatively in agreement with those from the 1-D experiments.

This study indicates that vertical mixing plays a central role in affecting the dominant features of the temporal variations and spatial distributions of the phytoplankton in RI coastal water. However, it is necessary to point out that other physical and biological processes may also be important in affecting the variability of the phytoplankton due to the complexity of the coastal environment. Such processes include spatially-variant, benthic-pelagic coupling processes, the potential impacts from neighboring water bodies (e.g. Long Island Sound and Narragansett Bay), and the potentially considerable influence of a changing and varying climate. Future studies using more sophisticated physical-biological models are recommended to understand the effects of these complex factors. 


\section{References}

Allen, J. S., Newberger, P. A., and Federiuk, J.: Upwelling circulation on the Oregon continental shelf. Part I: Response to Idealized Forcing, J. Phys. Oceanogr., 25, 1843$1866,1995$.

Beardsley, R. C. and Flagg, C. N.: The water structure, mean currents, and shelf/slope water front on the New England continental shelf, Mem. Soc. R. Sci. Liege Collect., 6, 209-225, 1976.

Eppley, R. W.: Temperature and phytoplankton growth in the sea, Fish. Bull., 70, 10631085, 1972.

Chen, D., Horrigan, S.A., and Wang, D.-P.: Vertical nutrient mixing in late summer in Long Island Sound. J. Mar. Res., 46, 753-770, 1988.

Fennel, K., Wilkin, J., Levin, J., Moisan, J., O’Reilly, J., and Haidvogel, D.: Nitrogen cycling in the Middle Atlantic Bight: Results from a three-dimensional model and implications for the North Atlantic nitrogen budget, J. Geophys. Res., 111 (C06003), doi:10.1029/2005JC003116, 2006.

Fields, L., Mercer, J., Hyde, K.J.W., Brush M., Nixon, S.W., Oviatt, C.A., Schwartz, M.L., Ullman, D., Codiga, D.: Comparison of surface chlorophyll, primary production, and satellite imagery in hydrographically different sounds off southern New England. Mar. Ecol. Prog. Ser., 535: 29, 2015.

Harding, Jr., L.W., Magnuson, A., Mallonee, M. E.: SeaWiFS retrieval of chlorophyll in Chesapeake Bay and the mid-Atlantic bight. Estuar. Coastal Shelf Sci., 62, 75-94, 2005. 
He, R. and Wilkin, J. L.: Barotropic tides on the southeast New England shelf: A view from a hybrid data assimilative modeling approach, J. Geophys. Res., 111(C08002), doi:10.1029/2005JC003254, 2006.

Howarth RW, Billen G, Swaney D, Townsend A, Jaworski N, Lajtha K, Downing JA, Elmgren R, Caraco N, Jordan T, Berendse F, Freney J, Kuderyarov V, Murdoch P, Zhu ZL: Regional nitrogen budgets and riverine $\mathrm{N}$ and $\mathrm{P}$ fluxes for the drainages to the North Atlantic Ocean: natural and human influences, Biogeochemistry, 35, 75$139,1996$.

Luo, Y., Rothstein, L., Liu, Q. and Zhang, S.: Climatic variability of the circulation in the Rhode Island Sound: A modeling study, J. Geophys. Res., 118, doi: 10.1002/ jgrc.20285, 2013.

Mellor, G. L., and Yamada,T.: Development of a turbulence closure model for geophysical fluid problems. Rev. Geophys., 20, 851-875, 1982.

Nixon, S. W., and Pilson, M. E. Q.: Nitrogen in estuarine and coastal marine ecosystems, in Nitrogen in the Marine Environment, edited by E. J. Carpenter and D. G. Capone, pp. 565-648, Elsevier, New York, 1983.

O'Reilly, J. E. and Zetlin, C.: Seasonal, horizontal, and vertical distribution of phytoplankton chlorophyll a in the northeast US continental shelf ecosystem, NOAA Technical Report NMFS, 139 pp., US Department of Commerce, 1998.

Ocean SAMP Draft Document Archive, Chapter 2, Ecology of the Ocean SAMP Region http://www.crmc.ri.gov/samp_ocean_archive.html, 2010.

Powell, T. M., Lewis, C. V. W., Curchitser, E. N., Haidvogel, D. B., Hermann, A. J., and Dobbins, E. L.: Results from a three-dimensional, nested biological-physical model of 
the California Current System and comparisons with statistics from satellite imagery, J. Geophys. Res., 111(C07018),doi:10.1029/2004JC002506, 2006.

Ryan, J. P., Yorder, J. A., Barth, J. A., and Cornillon, P. C.: Chlorophyll enhancement and mixing associated with meanders of the shelf break front in the Mid-Atlantic Bight, J. Geophys. Res., 104(C10), 23479-23493, 1999a.

Ryan, J. P., Yorder, J. A., and Townsend, D. W.: Influence of a Gulf Stream warm-core ring on water mass and chlorophyll distributions along the southern flank of Georges Bank, Deep-Sea Res. Pt. 2, 48, 159-178, 2001.

Shchepetkin, A. F. and McWilliams, J. C.: The regional oceanic modeling system (ROMS): a split-explicit, free surface, topography-following-coordinate oceanic model, Ocean Model., 9, 347-404, 2005.

Sherman, K., Jaworski, N. A., and Smayda, T. J.: The Northeast Shelf Ecosystem: Assessment, Sustainability and Management, Blackwell Science, Cambridge, Massachusetts, USA, 1996a.

Siedlecki, S. A., Archer, D. E., and Mahadevan, A.: Modeling mechanisms for nutrient supply and ventilation of benthic gases at the continental shelf break, J. Geophys. Res., 116, C06023, 2011.

Spitz, Y. H., Newberger, P. A., and Allen, J. S.: Ecosystem response to upwelling off the Oregon Coast: Behavior of three nitrogen-based models, J. Geophys. Res., 108(C3), 3062, doi:10.1029/2001JC001181, 2003.

Steele, J.H., and Henderson, E.W.: A simple model for plankton patchiness. Plankton Res., 14, 1397-1403, 1992. 
Stegmann, P. M., and Ullman, D. S.: Variability in chlorophyll and sea surface temperature fronts in the Long Island Sound outflow region from satellite observations, J. Geophys. Res., 109, C07S03, doi:10.1029/2003JC001984, 2004.

Werdell, P. J., Franz, B. A., Bailey, S. W., Harding, L. W., Jr., \& Feldman, G. C.: Approach for the long-term spatial and temporal evaluation of ocean color satellite data products in a coastal environment. Proceedings SPIE 6680, doi:10.1117/12.732489, 2007.

Xu, Y., Chant, R. J., Gong, D., Castelao, R., Glenn, S. M., and Schofield, O.: Seasonal variability of chlorophyll a in the Mid-Atlantic Bight, Cont. Shelf Res., 31, 16401650,2011

Xu, Y., Cahill, B., Wilkin, J., and Schofield, O.: Role of wind in regulating phytoplankton blooms on the Mid-Atlantic Bight, Cont. Shelf Res., 6, S26-S35, 2013.

Yoder, J. A., O’Reilly, J. E., Barnard, A. H., Moore, T. S., and Ruhsam, C. M.: Variability in coastal zone color scanner (CZCS) chlorophyll imagery of ocean margin waters off the US East Coast, Cont. Shelf Res., 21, 1191-1218, 2001.

Yorder, J. A., Schollaert, S. E., and O’Reilly, J. E.: Climatological phytoplankton chlorophyll and sea surface temperature patterns in continental shelf and slope waters off the northeast U.S. coast, Limnol. Oceanogr., 47, 672-682, 2002.

Zhang, W. G., McGillicuddy Jr., D. J., and Gawarkiewicz, G. G.: Is biological productivity enhanced at the New England shelfbreak front?, J. Geophys. Res. Oceans, 118, 517-535, doi:10.1002/jgrc.20068, 2013. 
Table 2-1 Biological parameters used in this study and the ranges in previous studies.

\begin{tabular}{|c|c|c|c|c|}
\hline Parameter Name & Symbol & Units & Value & Range \\
\hline $\begin{array}{l}\text { Fraction of active shortwave } \\
\text { radiation }\end{array}$ & $\beta$ & non-dimensional & 0.43 & $0.43-0.5$ \\
\hline $\begin{array}{l}\text { Seawater light attenuation } \\
\text { coefficient }\end{array}$ & $\mathrm{k}_{\mathrm{z}}$ & $\mathrm{m}^{-1}$ & 0.04 & \\
\hline $\begin{array}{l}\text { Light attenuation by } \\
\text { phytoplankton }\end{array}$ & $\mathrm{k}_{\mathrm{p}}$ & $\mathrm{m}^{2} \mathrm{mmol} \mathrm{N}^{-1}$ & 0.05 & $0.0095-0.076$ \\
\hline Initial slope of P-I curve & $\alpha$ & $\mathrm{m}^{2} \mathrm{~W}^{-1}$ & 0.021 & $0.0016-0.031$ \\
\hline Reference temperature & $\mathrm{T}_{0}$ & ${ }^{\circ} \mathrm{C}$ & 10 & $0-15$ \\
\hline $\begin{array}{l}\text { Temperature coefficient of } \\
\text { phytoplankton growth }\end{array}$ & $\mathrm{C}_{\mathrm{p}}$ & ${ }^{\circ} \mathrm{C}^{-1}$ & 0.06 & $0.059-0.137$ \\
\hline $\begin{array}{l}\text { Temperature coefficient of } \\
\text { zooplankton growth }\end{array}$ & $\mathrm{C}_{\mathrm{z}}$ & ${ }^{\circ} \mathrm{C}^{-1}$ & 0.12 & $0.059-0.137$ \\
\hline Nitrate uptake rate & $\mathrm{V}_{\mathrm{m}}$ & day $^{-1}$ & 1.5 & $0.62-3.0$ \\
\hline $\begin{array}{l}\text { Half-saturation concentration } \\
\text { for uptake of nitrate }\end{array}$ & $\mathrm{k}_{\mathrm{N}}$ & $\left.(\mathrm{mmolN} \mathrm{m})^{-3}\right)^{-1}$ & 0.2 & $0.007-1.5$ \\
\hline $\begin{array}{l}\text { Phytoplankton mortality rate } \\
\text { to detritus }\end{array}$ & $\sigma_{\mathrm{d}}$ & day $^{-1}$ & 0.06 & $0.05-0.2$ \\
\hline $\begin{array}{l}\text { Zooplankton maximum } \\
\text { growth rate }\end{array}$ & $\mathrm{R}_{\mathrm{m}}$ & day $^{-1}$ & 0.33 & $0.01-1.0$ \\
\hline $\begin{array}{l}\text { Ivlev constant for zooplankton } \\
\text { grazing parameterization }\end{array}$ & $\Lambda$ & non-dimensional & 1.5 & $0.065-1.4$ \\
\hline $\begin{array}{l}\text { Zooplankton assimilation } \\
\text { efficiency }\end{array}$ & $\gamma$ & non-dimensional & 0.8 & $0.25-0.8$ \\
\hline $\begin{array}{l}\text { Quadratic Zooplankton } \\
\text { mortality rate to detritus }\end{array}$ & $\zeta_{\mathrm{d}}$ & day $^{-1}$ & 3.0 & $0.05-5.0$ \\
\hline Detritus remineralization rate & $\delta$ & day $^{-1}$ & 0.1 & $0.01-0.25$ \\
\hline Detrital sinking rate & $\mathrm{w}_{\mathrm{d}}$ & $\mathrm{m} \mathrm{day}^{-1}$ & 8 & $0.009-25$ \\
\hline
\end{tabular}




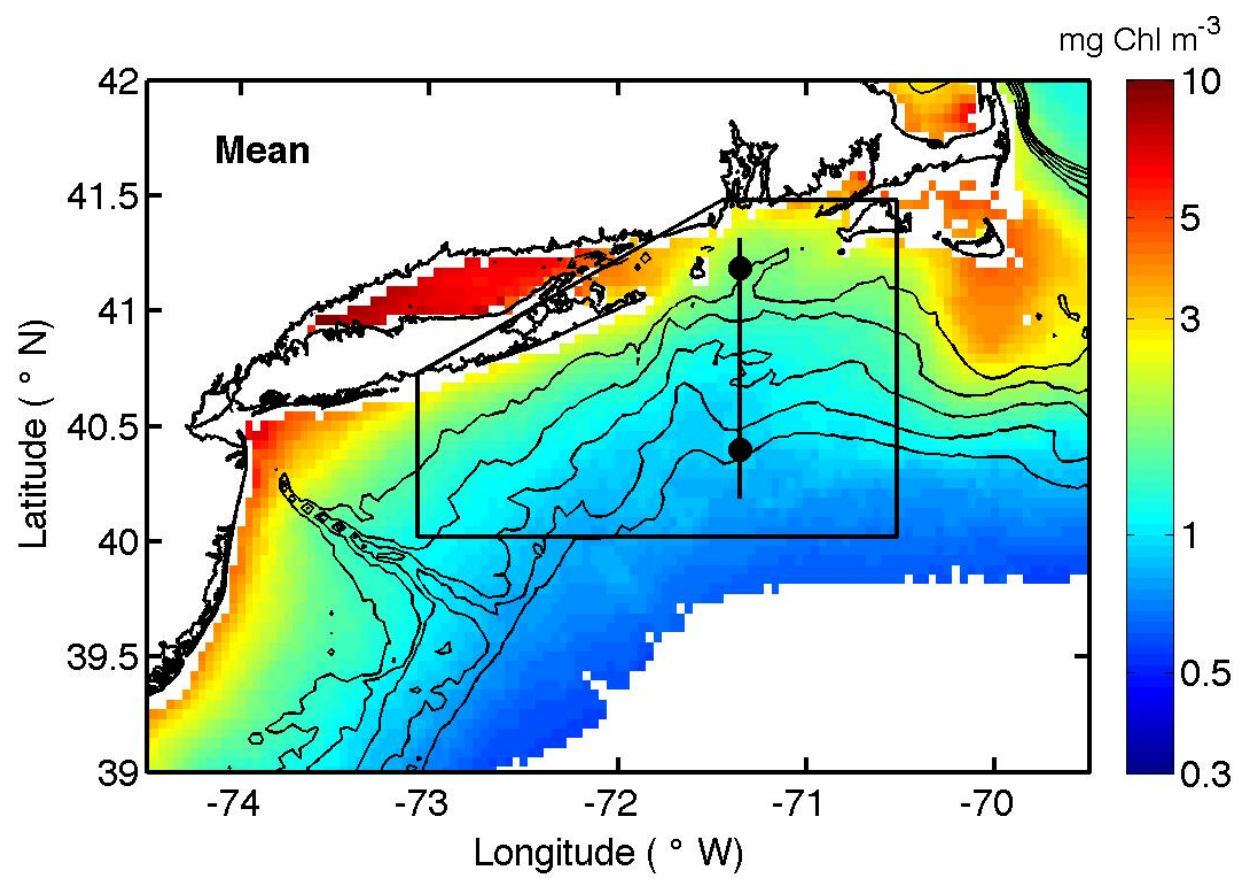

Figure 2-1 Surface chlorophyll-a concentrations averaged from the nine-year (20042012) MODIS dataset. Black contours are isobaths from $40 \mathrm{~m}$ to $80 \mathrm{~m}$ in $10 \mathrm{~m}$ interval. The black frame indicates the study area for the EOF analysis. The two black dots indicate two locations that are representative of the inner $(40 \mathrm{~m})$ and outer $(80 \mathrm{~m})$ shelf, respectively. 

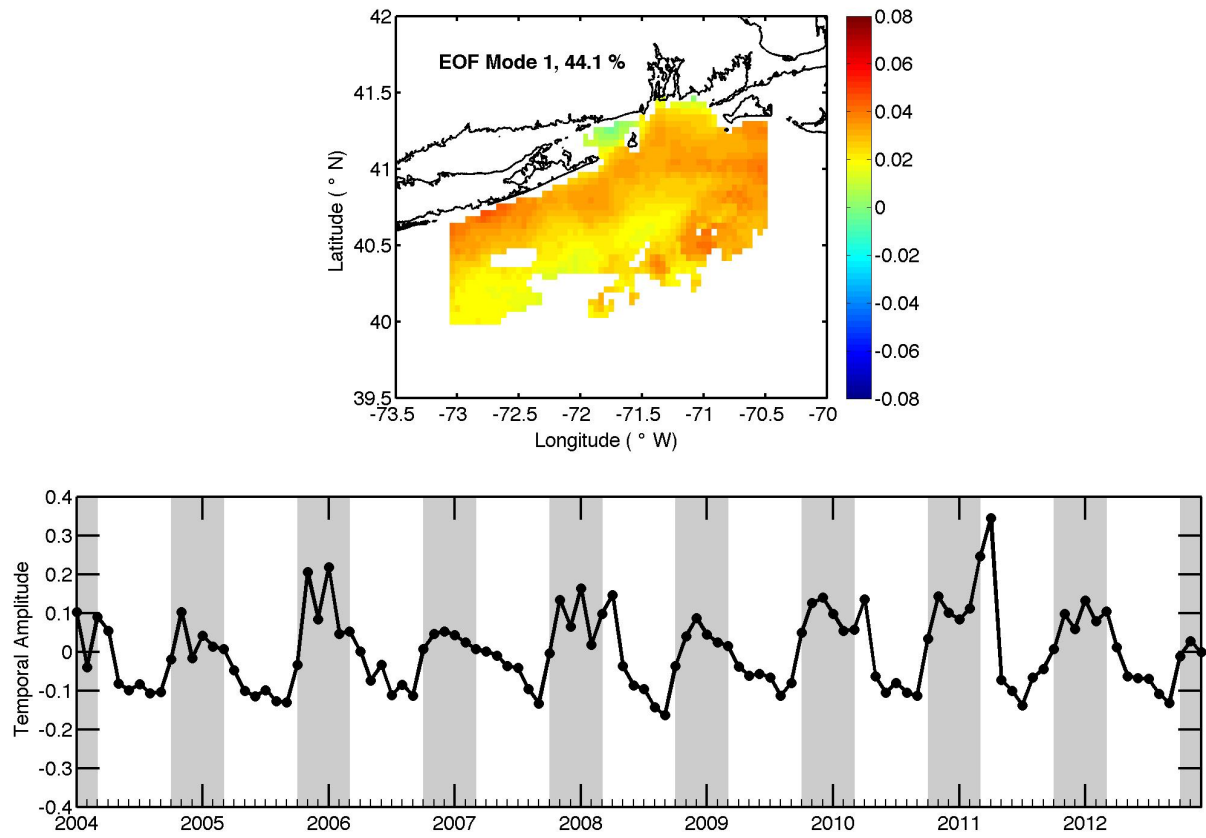

Figure 2-2 Anomalous spatial eigenfunctions (upper panel) and time-varying amplitudes (upper) for Mode 1 from the EOF analysis of the 9-year MODIS observations. The gray transparent areas indicate the fall-winter months (October to March). 

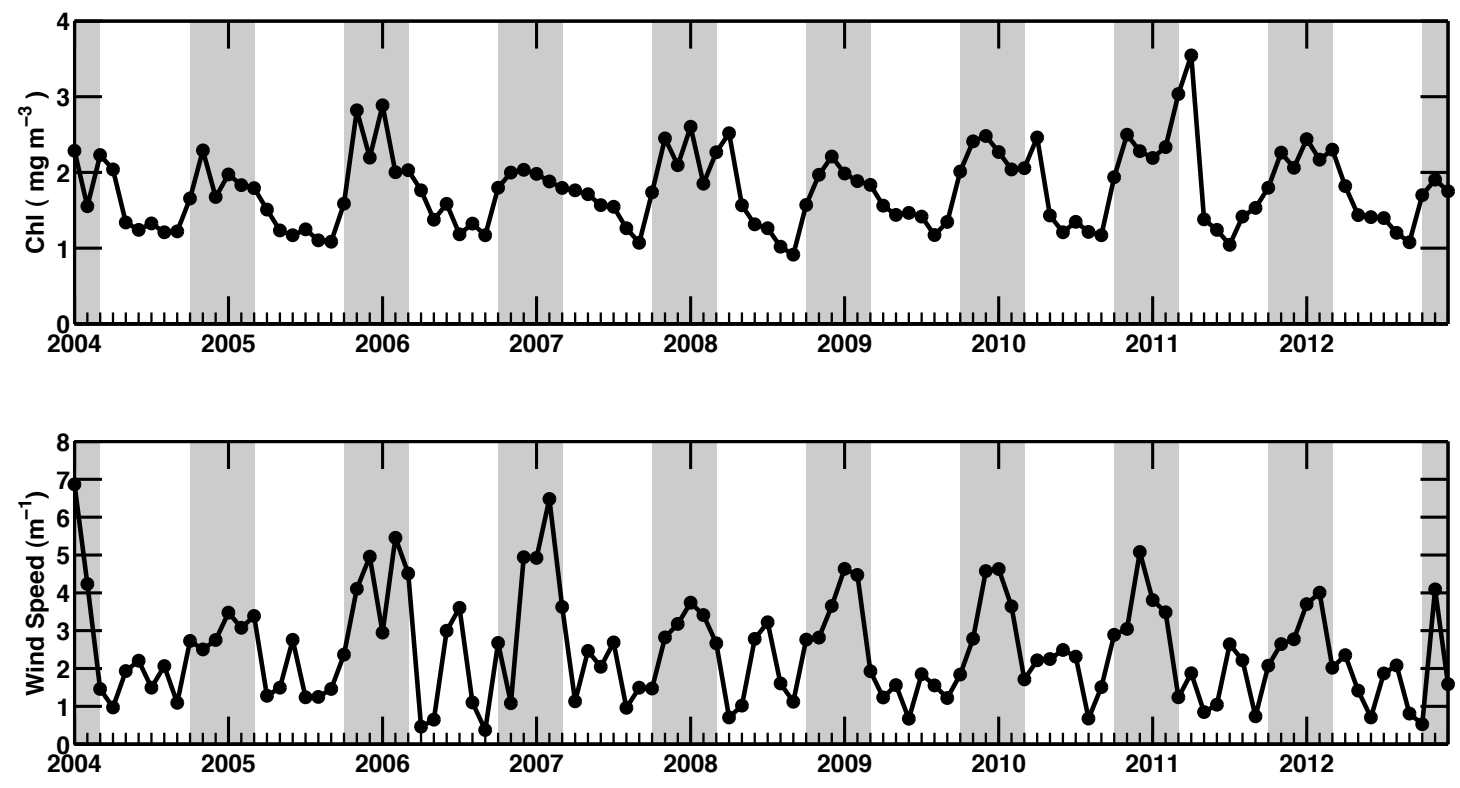

Figure 2-3 EOF mode1 monthly- and spatially- averaged chlorophyll-a concentration in the study area (upper) and surface wind speed (lower) during January 2004-December 2012. The gray transparent areas indicate the fall-winter months (October to March). 


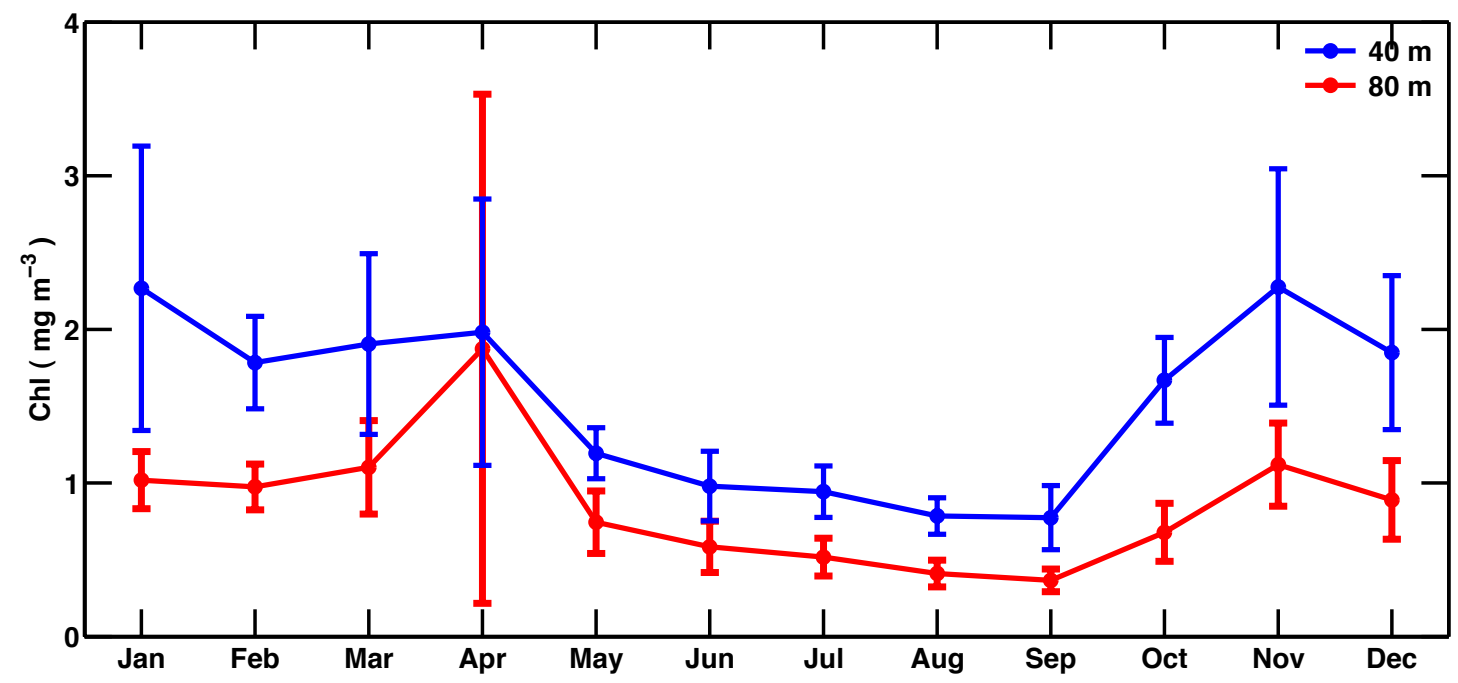

Figure 2-4 Climatological monthly chlorophyll-a concentrations at two locations (indicated in Figure 2-1) at depths of $40 \mathrm{~m}$ and $80 \mathrm{~m}$, respectively. The error bars are the standard deviation of the mean in each month. 


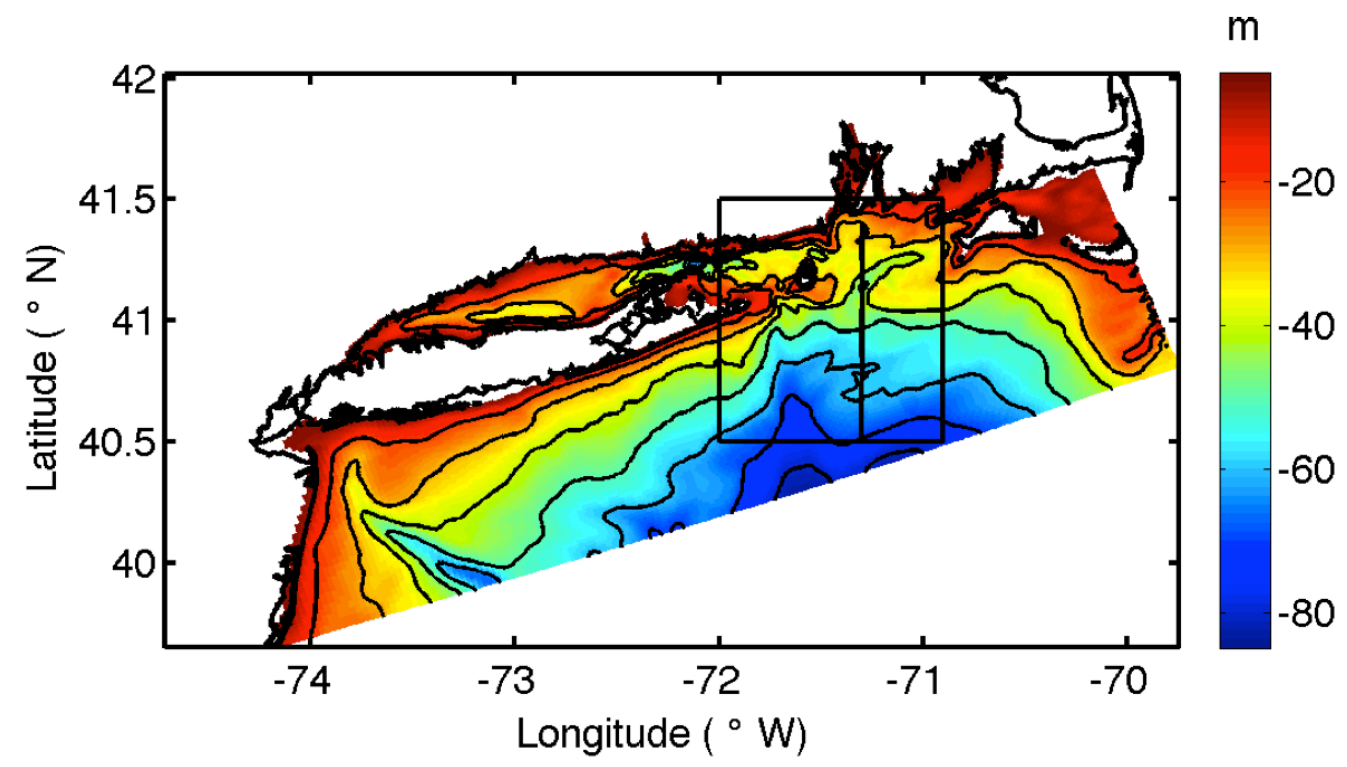

Figure 2-5 Bathymetry of the three-dimensional model domain. Black contours are isobaths from $40 \mathrm{~m}$ to $80 \mathrm{~m}$ in $10 \mathrm{~m}$ intervals. The black rectangle denotes the Rhode Island coastal region, which is the average area for the model-simulated chlorophyll and turbulent diffusivity. The black line indicates the cross-shelf transect that is discussed in the text. 


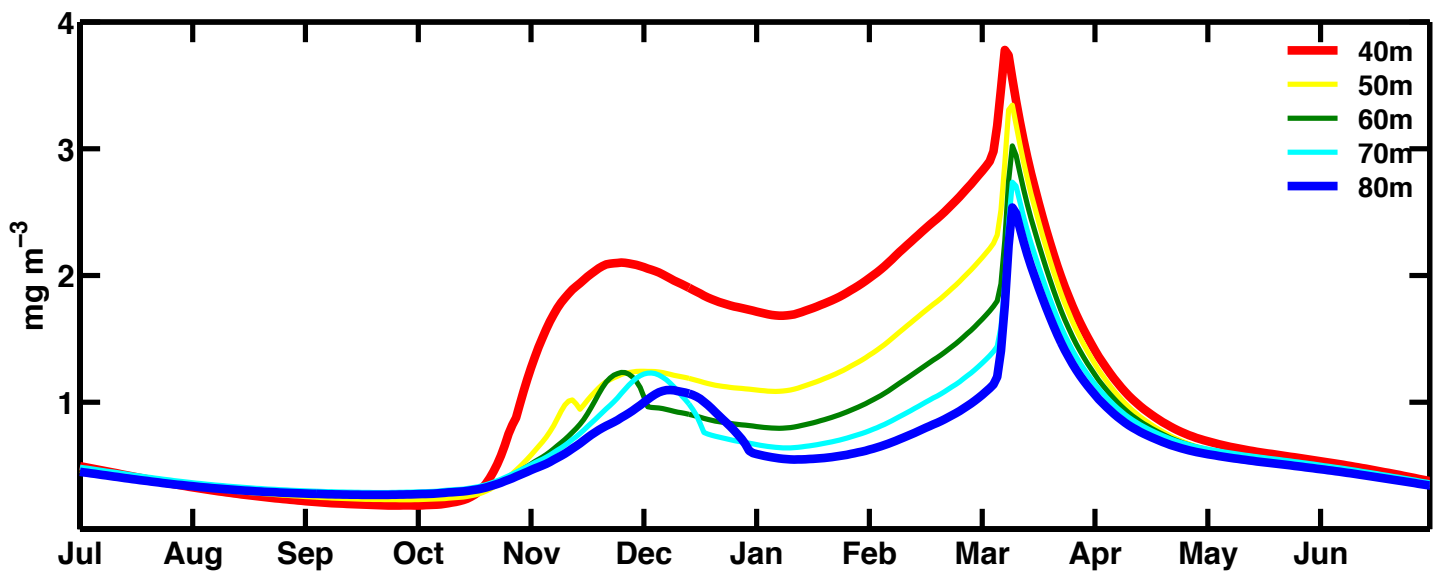

Figure 2-6 Annual cycle of surface chlorophyll concentrations in the five 1-D experiments $\mathrm{H} 40-\mathrm{H} 80$. The water depths used in these experiments are indicated in the figure. Note the $\mathrm{x}$-axis indicates one year from July 1st through June 30th. 

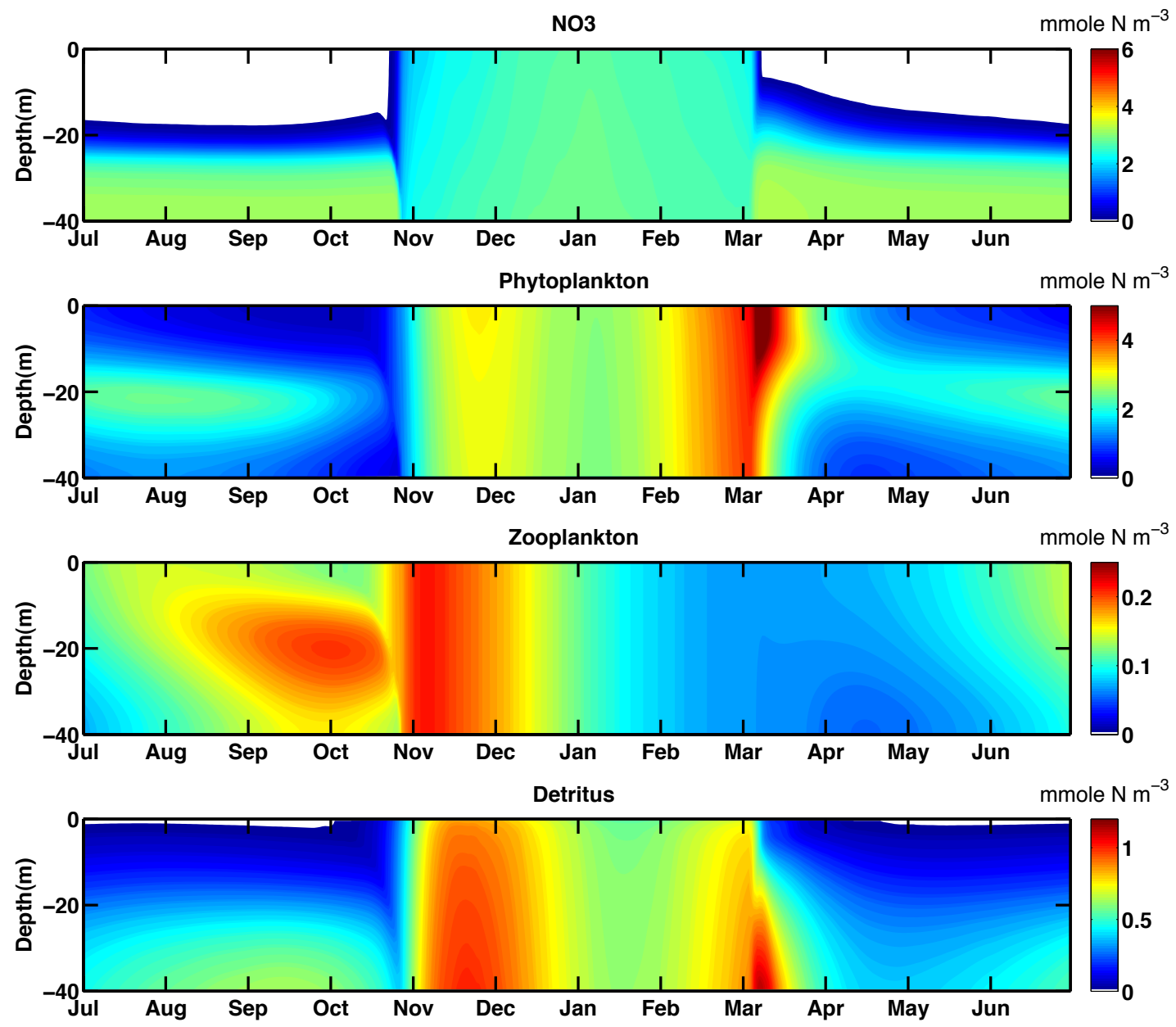

Figure 2-7 Time-depth distributions of N, P, Z and D during one year for experiment H40 (water depth is $40 \mathrm{~m}$ ). 

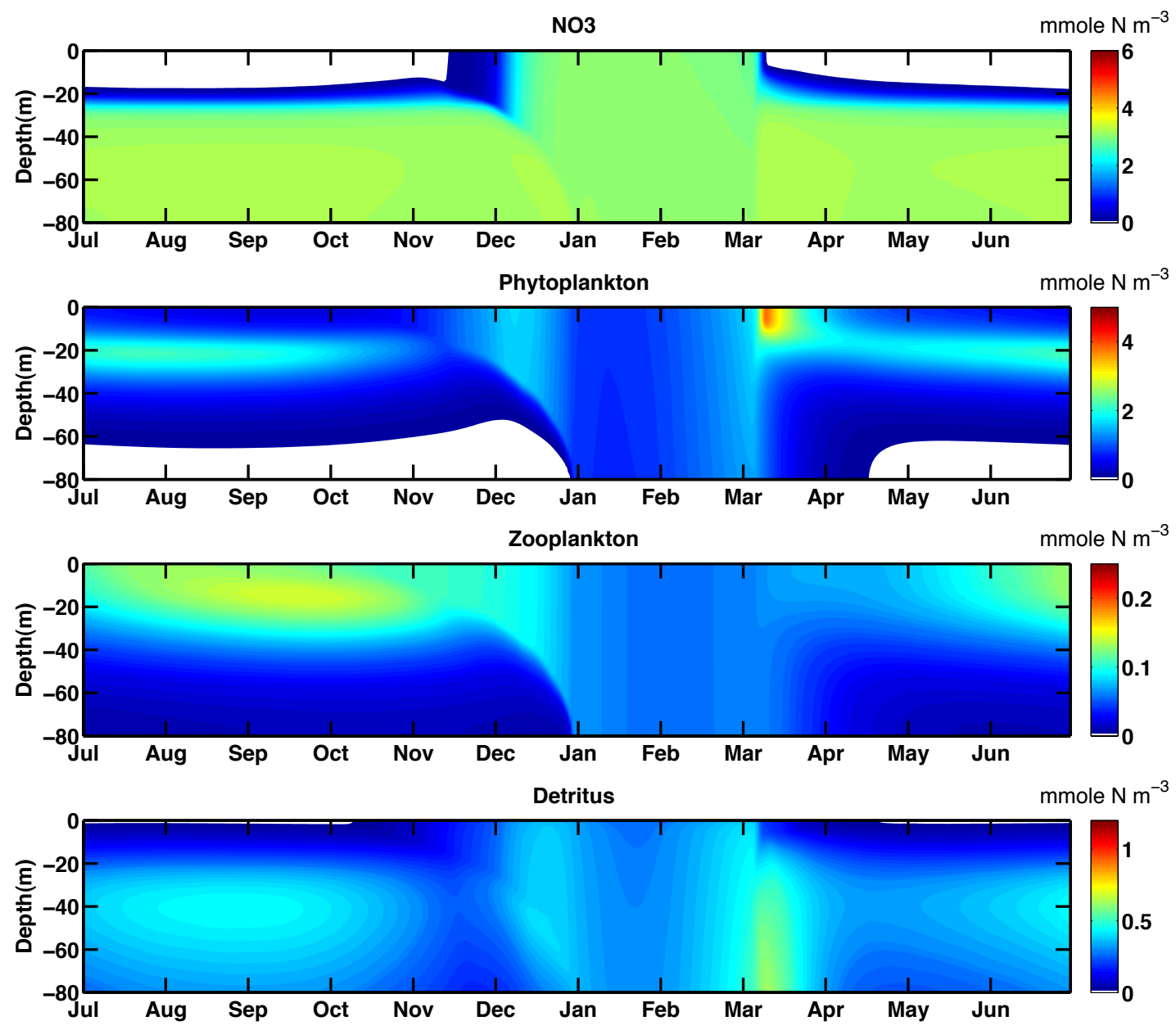

Figure 2-8 Same as Figure 2-7, but for experiment H80 (water depth is $80 \mathrm{~m}$ ). 

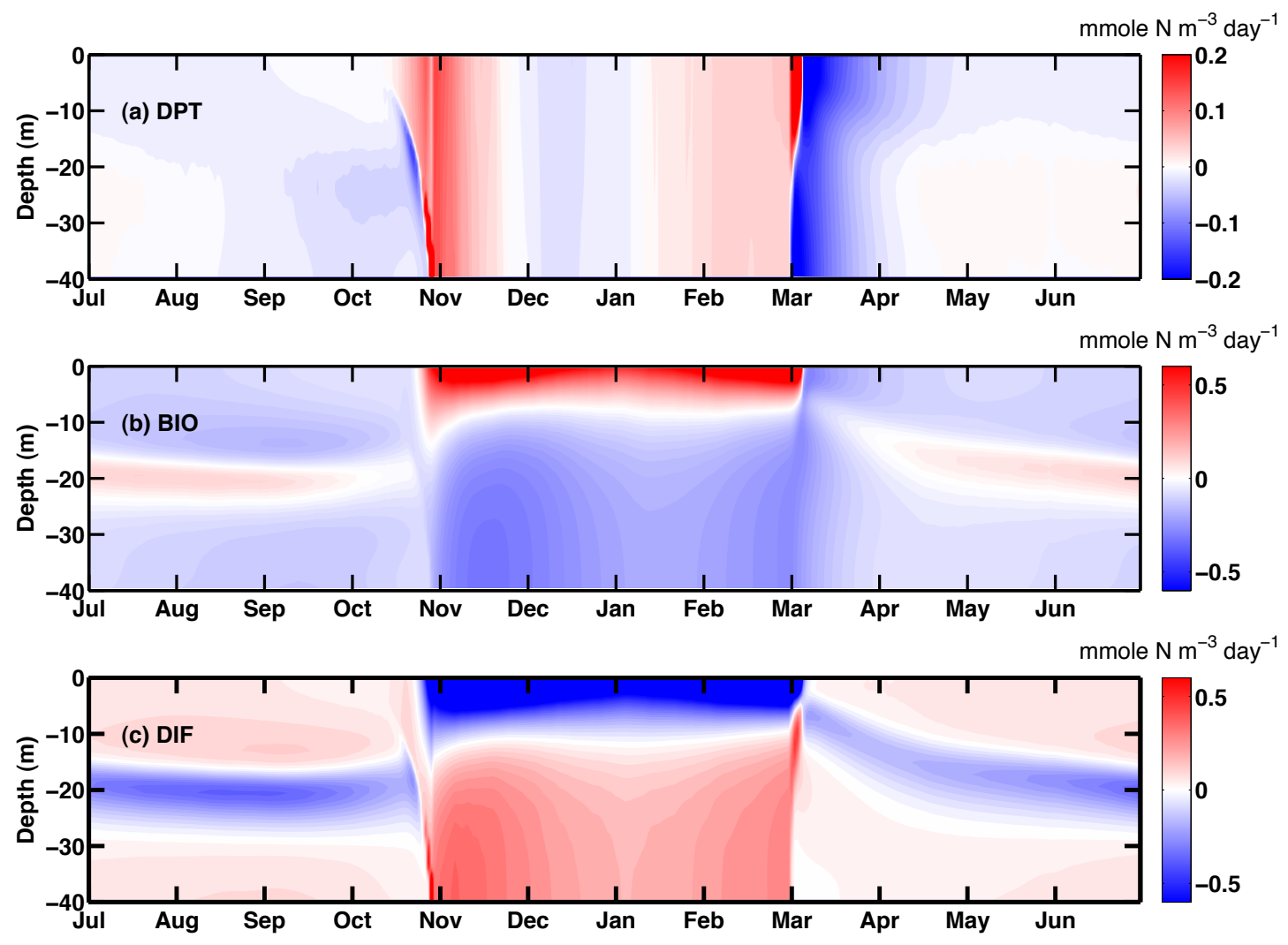

Figure 2-9 Time-depth distributions of the phytoplankton budget terms over the course of a climatological year. (a) DPT: the local changes of the phytoplankton with time; (b) BIO: the sum of phytoplankton growth, zooplankton excretion/egestion and phytoplankton mortality; (c) DIF: the physical effects of vertical diffusion on phytoplankton. See equation (2) in the text. 

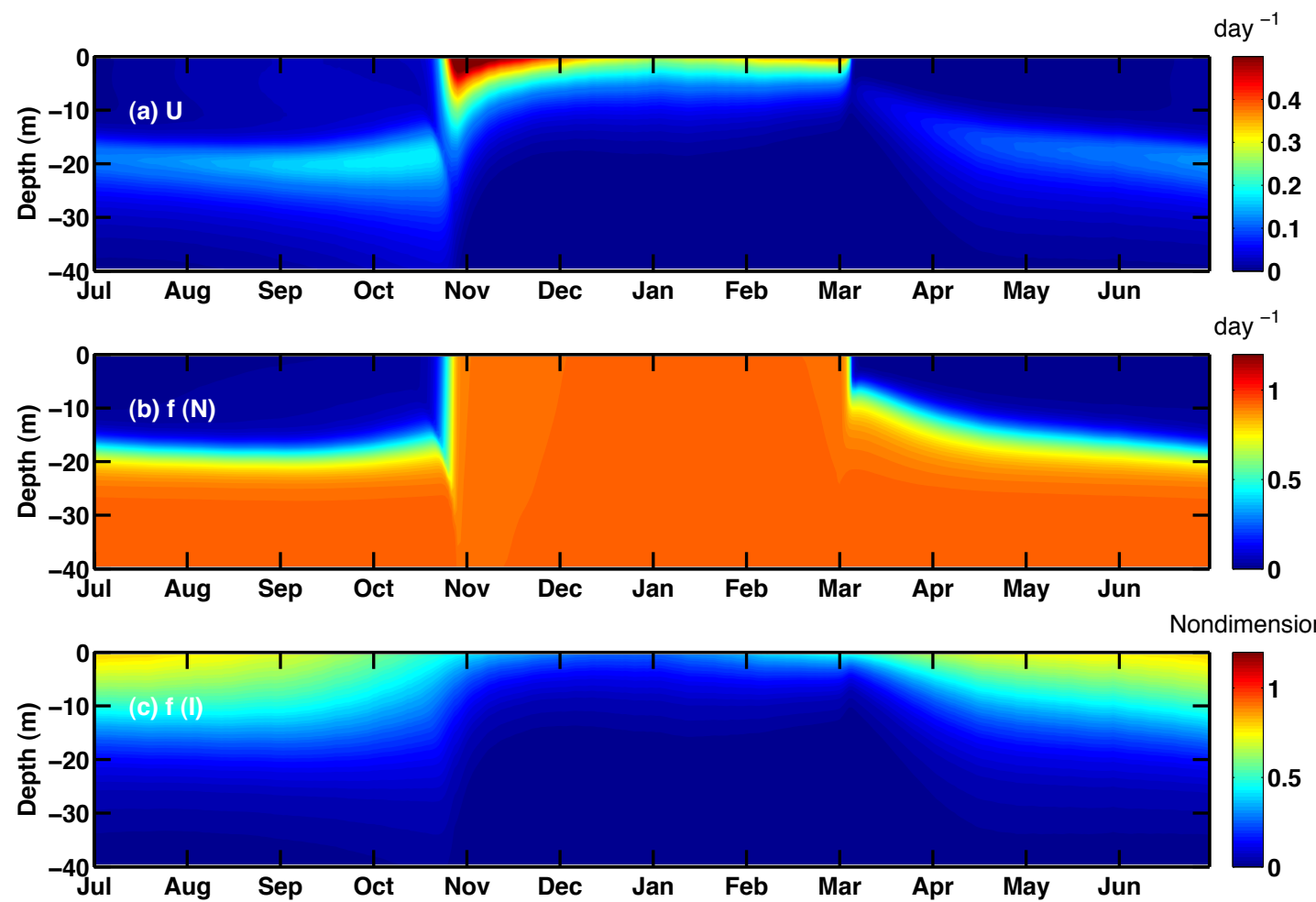

Figure 2-10 Time-depth distributions of: (a) phytoplankton growth rate (U); (b) the Michaelis-Menten curve as a function of nitrate concentration $\mathrm{f}(\mathrm{N})$ and; (c) the photosynthesis-light (P-I) relationship $\mathrm{f}(\mathrm{I})$ during a climatological year. 

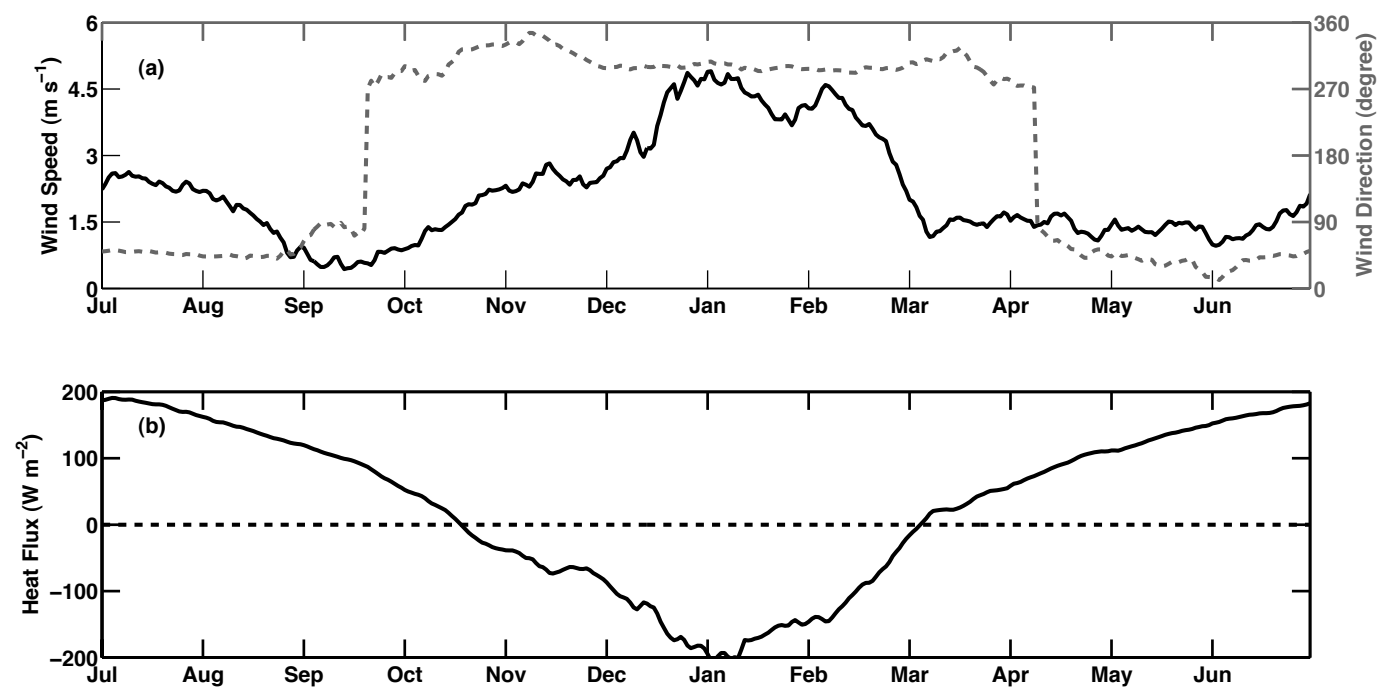

Figure 2-11 Climatological surface (a) momentum forcing (solid - wind speed; dashed wind direction, zero degree is eastward) and (b) net heat flux $\left(\mathrm{W} \mathrm{m}^{-2}\right)$. 

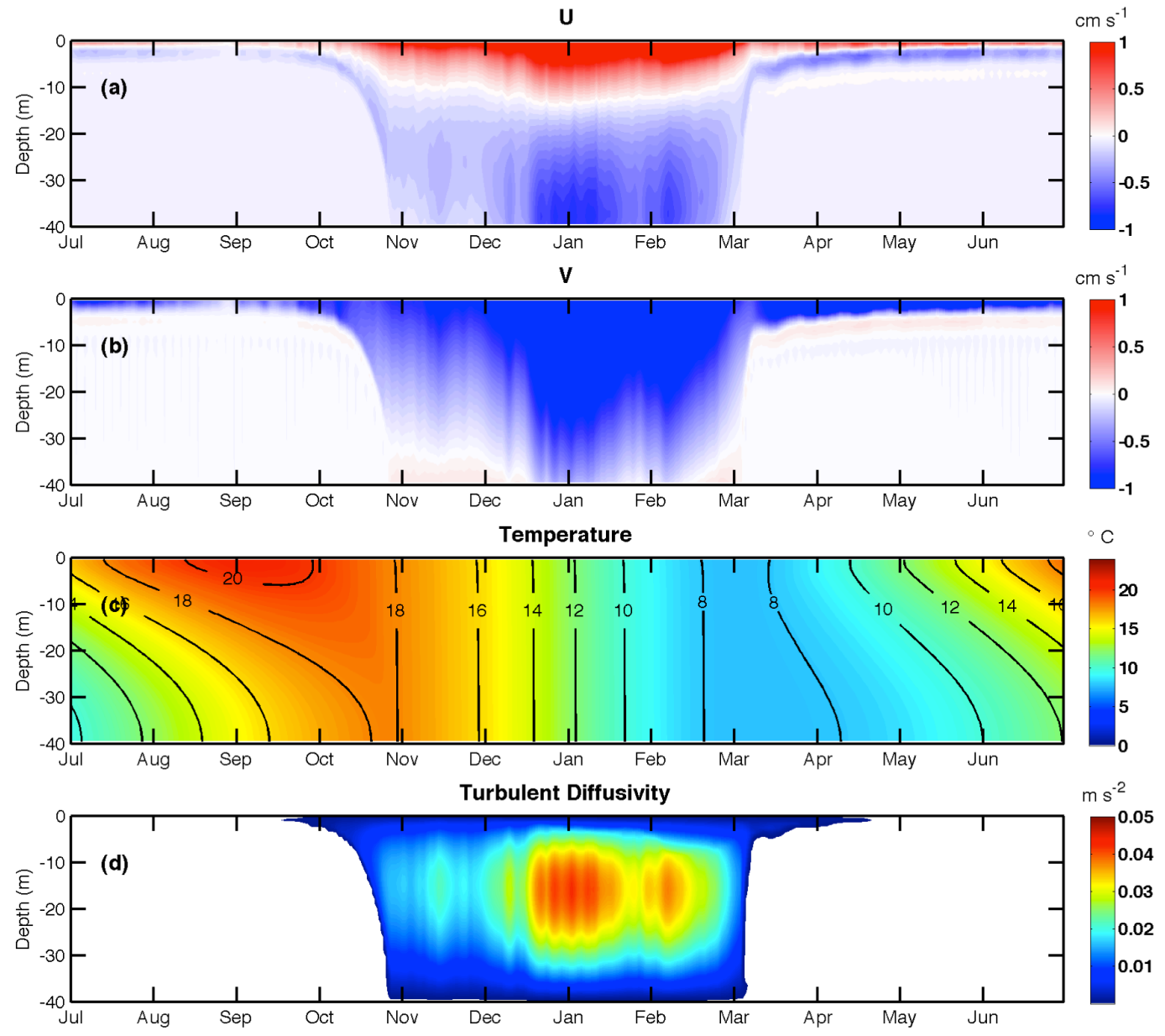

Figure 2-12 Time-depth distributions of (a) velocity along the wind direction; (b) velocity cross the wind direction; (c) temperature; (d) turbulent diffusivity coefficient during a climatological year. 

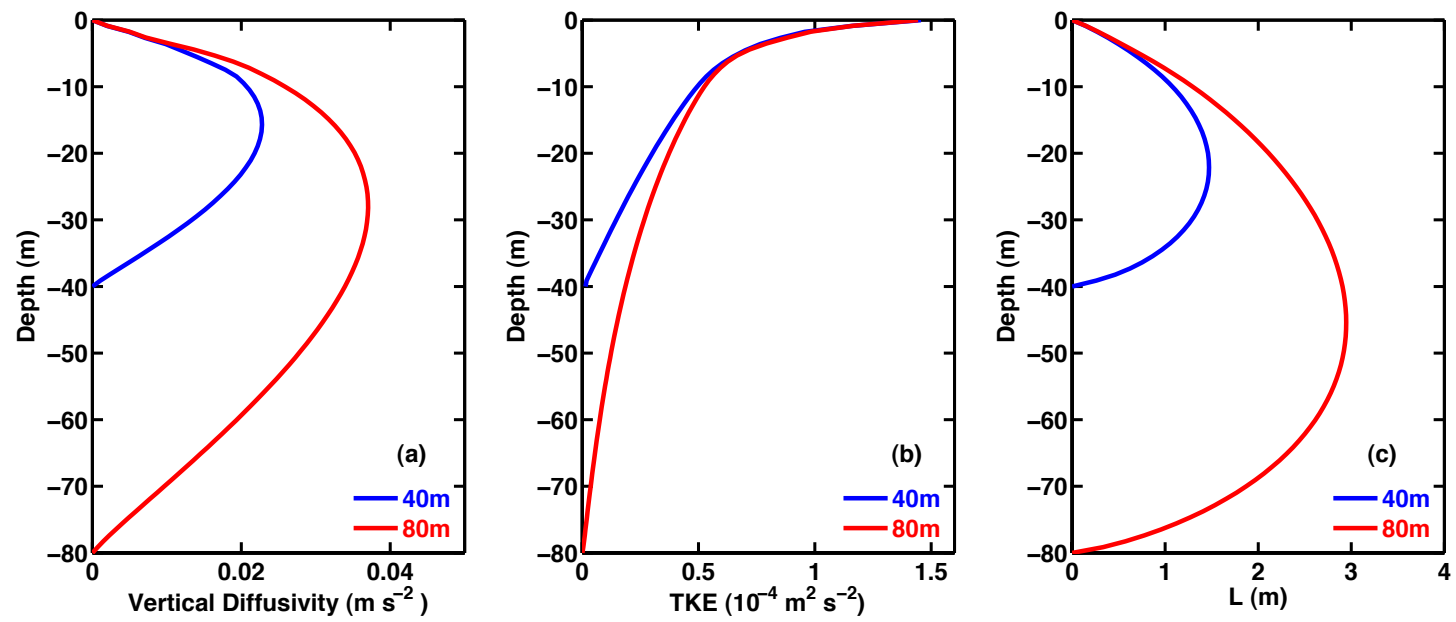

Figure 2-13 Winter-averaged (November-March) profiles of (a) turbulent diffusivity $\left(k_{v}\right)$, (b) turbulence kinetic energy (TKE), (c) turbulence length scale (l). 

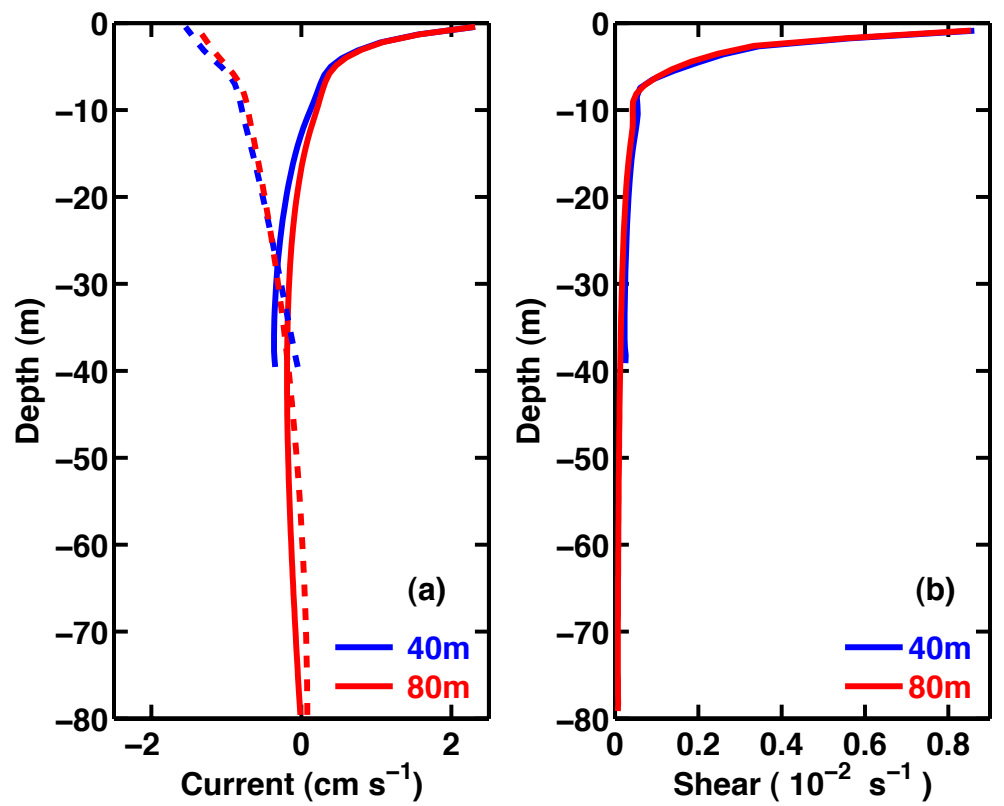

Figure 2-14 Time-averaged (November-March) profiles of (a) current velocities (sold the velocity along the surface wind direction; dashed - the velocity cross the surface wind direction) and (b) vertical shear. 


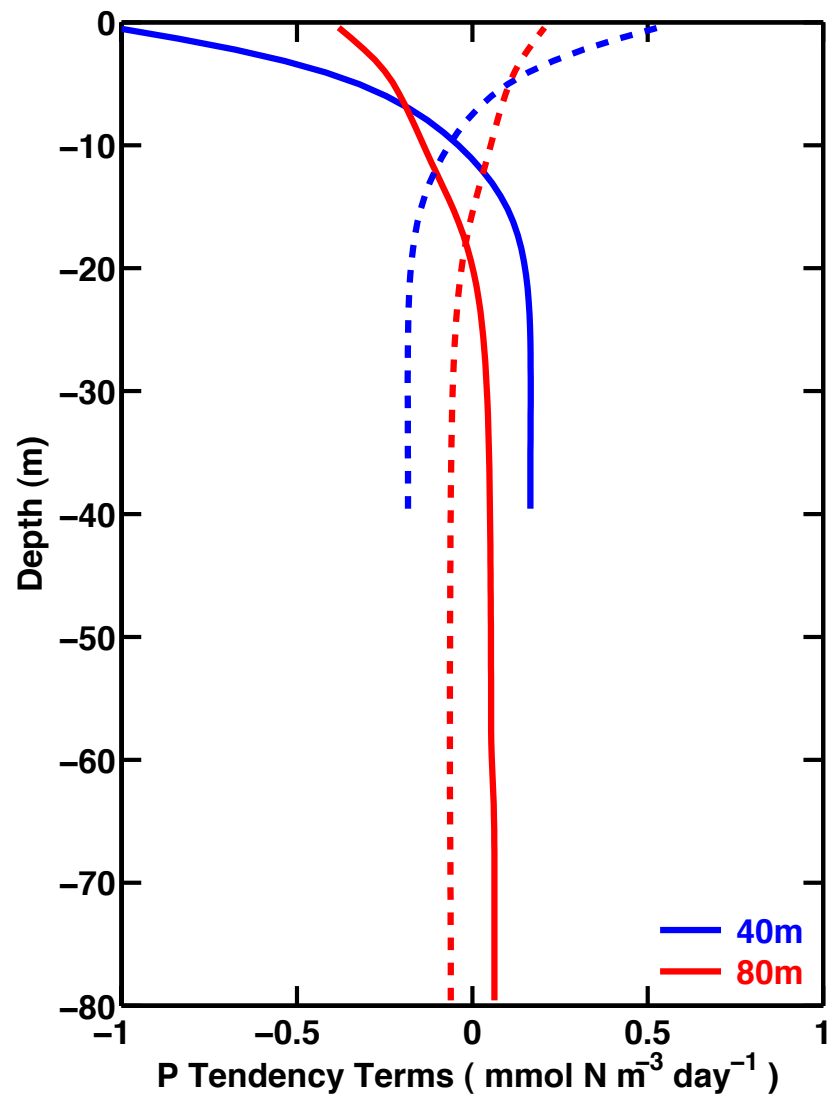

Figure 2-15 Time-averaged (November-March) profiles of the phytoplankton budget terms. The solid lines are the DIF terms and the dashed lines are the BIO terms (see Equation 2 in the text). 

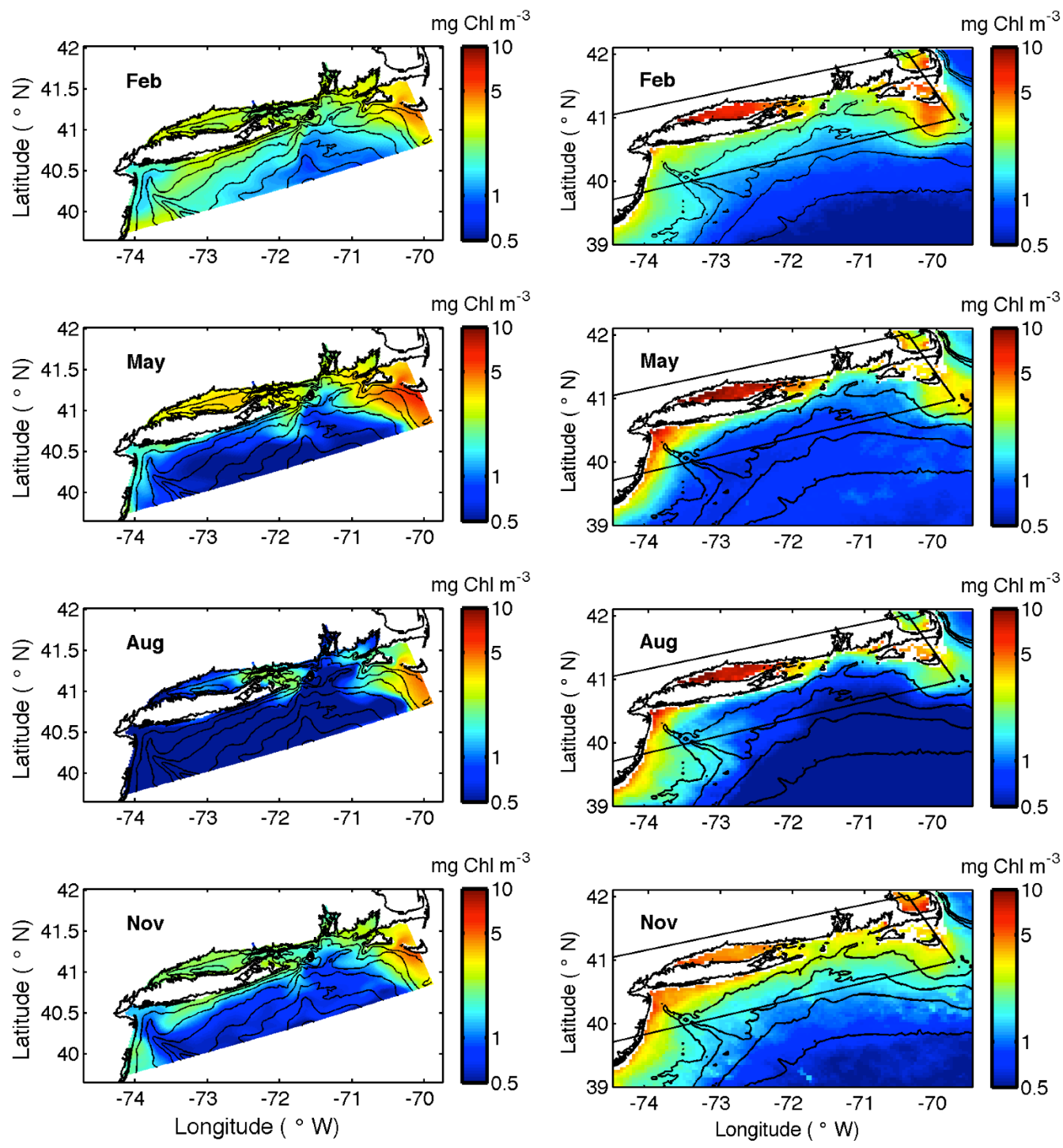

Figure 2-16 Surface chlorophyll fields in (left column) the three-dimensional model simulation and (right column) the MODIS observations for four typical months. The black box in the right column indicates the model domain. 

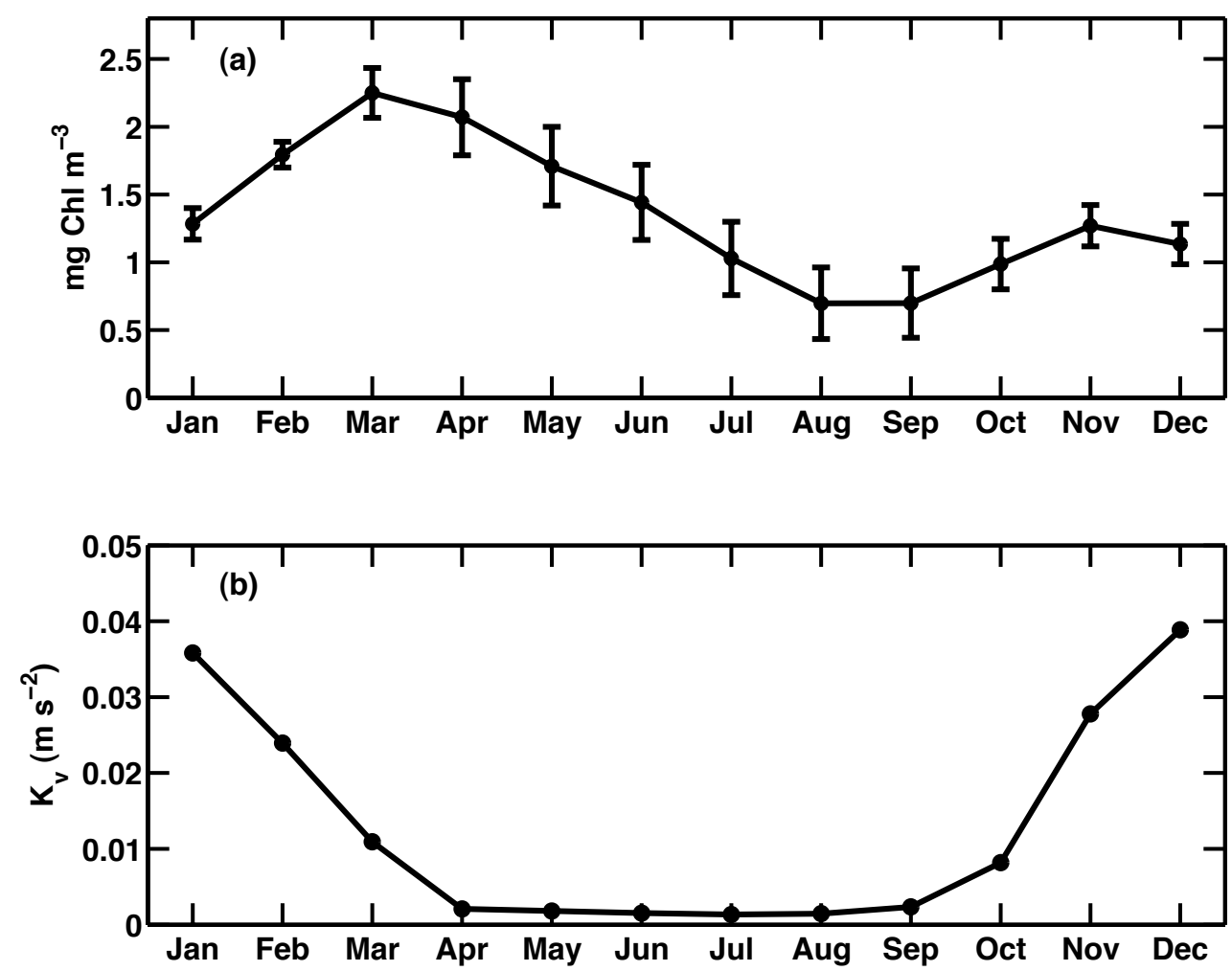

Figure 2-17 (a) Monthly mean and standard deviation of the surface chlorophyll and (b) monthly mean of the turbulent diffusivity at $15 \mathrm{~m}$ depth spatially averaged within the Rhode Island coastal region (indicated by the black box in Figure 2-5). 

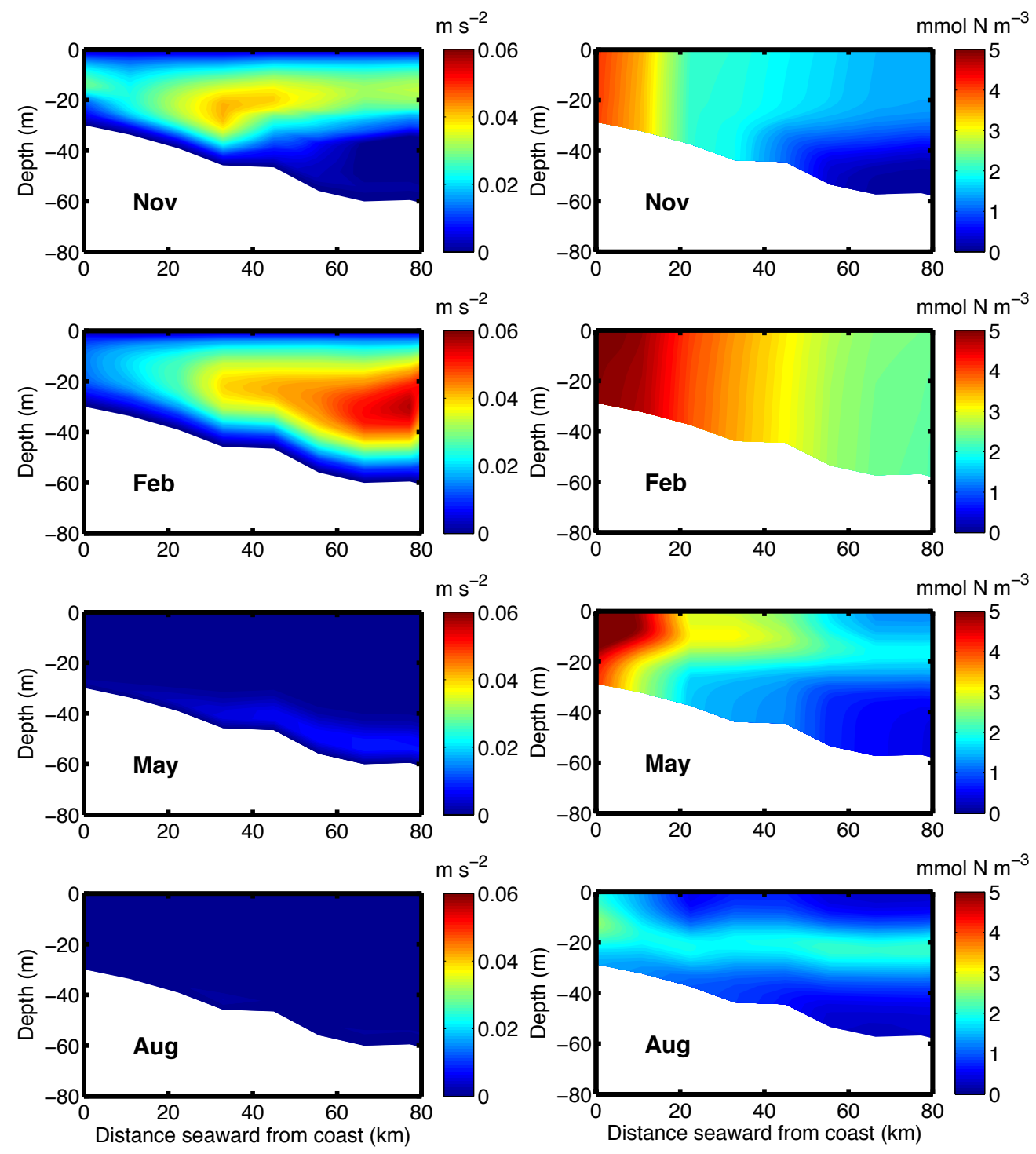

Figure 2-18 Cross-shelf distributions of (left column) the turbulent diffusivity and (right column) the phytoplankton biomass along the transect shown in Figure 2-5. 


\section{Appendix A: Model sensitivity to biological parameters}

As listed in Table 2-1, there are a number of biological parameters that need to be prescribed in the NPZD model, which can be divided into two categories: i) those that depend upon the local water optical property and are used by convention in coastal water modeling, i.e. the fraction of light available for photosynthesis $(\beta)$, and light attenuation coefficients for seawater $\left(\mathrm{k}_{\mathrm{z}}\right)$ and phytoplankton $\left(\mathrm{k}_{\mathrm{p}}\right)(\mathrm{Kirk}, 1983)$; and ii) those that relate to the intrinsic variability associated with biological processes (e.g., nutrient uptake, growth, grazing), and the inherent difficulties of measuring these rates in situ imply that these values used for parameterizations potentially carry significant uncertainty (Fiechter, 2012). Here, we assess the sensitivity of the model simulated phytoplankton biomass to the parameters in the second category by independently increasing and decreasing each parameter by $50 \%$. While other techniques, such as data assimilation (Friedrichs, 2002) and ensemble methods (Follows et al., 2007) are often used for either numerical prediction or diagnosing regimes undergoing biological variability and may be better suited for the purpose of parameter optimization our study, however, is process-oriented, i.e. we aim to explore the impact of physical environments on the temporal and spatial variations of the phytoplankton biomass in our study area. The numerical experiments were conducted to answer the questions we raised after analyzing the MODIS observations. Therefore, the sensitivity experiments we present here are used to support (or not) the robustness of our findings and also to explain the bases of some of the assumptions made in the main text.

For each sensitivity test, we calculate a normalized root-mean-square deviation (RMSD) between the new model solution and the model solution with the default 
parameters (i.e., control run). A large RMSD for a given solution indicates that changes in the associated parameter leads to significant variability in the NPZD model solution (Figure 2-A1). This sensitivity study suggests that the initial slope of the P-I curve $(\alpha)$ and the phytoplankton mortality rate $\left(\sigma_{\mathrm{d}}\right)$ are the main source of variability for phytoplankton parameters, especially when these values are decreased. Similarly, zooplankton growth rate coefficient $\left(\mathrm{R}_{\mathrm{m}}\right)$ and the quadratic zooplankton mortality rate $\left(\xi_{\mathrm{d}}\right)$ are the leading source of variability amongst zooplankton parameters.

The relatively weak variability relevant to the half-saturation concentration for uptake of nitrate $\left(\mathrm{k}_{\mathrm{N}}\right)$ and the uptake rate for nitrate $\left(\mathrm{V}_{\mathrm{m}}\right)$ could be explained by the fact that phytoplankton are considered as a single functional group within our NPZD model with similar nutrient requirements, while in reality the half-saturation constants for uptake of any nutrients vary approximately in proportion to cell size and is considered to be an important characteristic of organisms living in that kind of nutrient-limited environment. And $\mathrm{V}_{\mathrm{m}}$ is a variable imposed by external conditions, such as irradiance, day-length, temperature as well as species-specific properties of the organism (Eppley et al., 1969).

The weak impact of zooplankton assimilation efficiency $(\gamma)$ is due to the assumptions made by the NPZD model, i.e. that the zooplankton-phytoplankton link includes ingestion dependent upon prey abundance while $\gamma$ is invariant with prey abundance. This is a reasonable assumption as it is difficult to obtain unbiased responses for the relationship between $\gamma$ and phytoplankton abundance (e.g., Frangoulis et al., 2010; Landry et al., 1984; Miller, 2004), though there has been a recognition that varying $\gamma$ with prey abundance is an important aspect of multi-trophic level systems. 
The parameter used in the Ivlev (1955) formulation $(\Lambda)$ describes a saturation of the ingestion rate with high prey concentration (Holling, 1959), and a smaller value of $\Lambda$ indicates a slower approach to saturation. Our sensitivity experiments show that decreasing $\Lambda$ results in more fluctuations as compared with the control case.

The relative insensitivity of the model results to the variations of detritus remineralization $(\delta)$ and sinking rate $\left(\mathrm{w}_{\mathrm{d}}\right)$ could be attributed to the nitrate nudging that we imposed in the lower water column. The purpose of adding a detritus pool to the simplest three-component NPZ model takes into account the fact that remineralization is not instantaneous; in the control simulation $\mathrm{w}_{\mathrm{d}}=8 \mathrm{~m}_{\text {day }}{ }^{-1}$ and $\delta=0.1$ day $^{-1}$ yielding a remineralization length scale of $80 \mathrm{~m}$. Decreasing either $\mathrm{w}_{\mathrm{d}}$ or $\delta$ corresponds to a smaller remineralization length scale and removal of less detritus from the surface layer, however, a physical environment of strong mixing in coastal waters in relative shallow water depth diminishes this effect which requires a supplemental, near bottom nitrate source. This further justifies our imposing a nitrate nudging term.

So far, we have found the dynamics of the model are relatively sensitive to the parameters $\alpha, \sigma_{\mathrm{d}}, \mathrm{R}_{\mathrm{m}}$ and $\xi_{\mathrm{d}}$ among the ten biological parameters. We also present results of surface chlorophyll seasonality after varying each of those parameters (Figure 2-A2). Consistent with the above discussions, changing these four parameters $\left(\alpha, \sigma_{d}, R_{m}\right.$ and $\left.\xi_{d}\right)$ produces rather marked variations in the seasonal cycle of surface chlorophyll. The results are detailed below.

Increasing the initial slope of the photosynthesis versus irradiance (P-I) curve $(\alpha)$ results in increasing the efficiency of light utilization at a time when production is controlled by light-limitation. As a consequence, phytoplankton concentrations also 
increase in fall and winter. In the nutrient-limited conditions of the spring and summer, increasing $\alpha$ deepens the euphotic zone, which does not result in any surface variation. Nevertheless chlorophyll would accumulate in the subsurface, thereby enhancing the vertically integrated annual productivity.

Varying phytoplankton mortality rate $\left(\sigma_{\mathrm{d}}\right)$ alters chlorophyll concentration in all seasons, while the variations, in terms of peak abundance respond to decreasing $\sigma_{\mathrm{d}}$ by $50 \%$, e.g. the amplitude in March almost doubles compared with the control experiment. Due to the nonlinear predator-prey relationship in the biological process function, the weakened mortality contributes to an increase of phytoplankton biomass.

Increasing the zooplankton-grazing coefficient $\left(\mathrm{R}_{\mathrm{m}}\right)$ by $50 \%$ leads to an asymmetric variation compared with decreasing it by $50 \%$. Interestingly, this only happens during the fall-winter bloom, while the March peak is not altered. A similar asymmetry, but in the opposite sense, occurs when changing the coefficient of quadratic zooplankton mortality $\xi_{\mathrm{d}}$. The cause is an accumulation of zooplankton during the fallwinter period in the case of increasing $\mathrm{R}_{\mathrm{m}} /$ decreasing $\xi_{\mathrm{d}}$ (not shown here). This biological means that the phytoplankton bloom is consequently influenced by the abundance of a predator. Admittedly, in a lower trophic level model, zooplankton population has been the subject of some controversy especially when it comes to the zooplankton mortality function which behaves as a so-called closure term that maintains the stability of the model (Williams, 2006). 


\section{Appendix B: Choice of background turbulent diffusivity}

According to equation (8), the total vertical diffusivity is the sum of a turbulence contribution and a background constant $k_{b a c k}$. Since the strength of vertical mixing plays the main role in determining the timing of de-stratification, it is necessary to determine the best choice of $k_{\text {back }}$. Due to difficulty in directly measuring turbulence characteristics, we use vertical distributions of temperature as an indicator of the strength of turbulent mixing. The hydrographic observations we use were obtained at one location on the eastern side of Rhode Island Sound (Ullman et al. 2014). The temperature measurements are available from both climatology and an 11-month period from 2009 to 2010 at three depths: $1 \mathrm{~m}, 6 \mathrm{~m}$ and just above the bottom (Figure 2-A3(a)). To find the most reasonable background vertical diffusivity, we performed three 1-D simulations with $k_{\text {back }}$ varying from $1 \times 10^{-5}$ to $1 \times 10^{-3} \mathrm{~m}^{2} \mathrm{~s}^{-1}$. The water depth used in these simulations is the same as in the location where the temperature observations were obtained, and the surface atmospheric forcing is the same as described in Section 3. The time series of the temperature at the three different levels from these experiments are shown in Figure 2-A3 (b-d). Only the simulation with $k_{\text {back }}=1 \times 10^{-4} \mathrm{~m}^{2} \mathrm{~s}^{-1}$ captures a reasonable seasonal variation of temperature, in which the temperature is vertically uniform during October to February and the thermal stratification starts to develop from

late March and strengthens in summer. Therefore, $k_{\text {back }}=1 \times 10^{-4} \mathrm{~m}^{2} \mathrm{~s}^{-1}$ is used in all the experiments presented in the main text. 


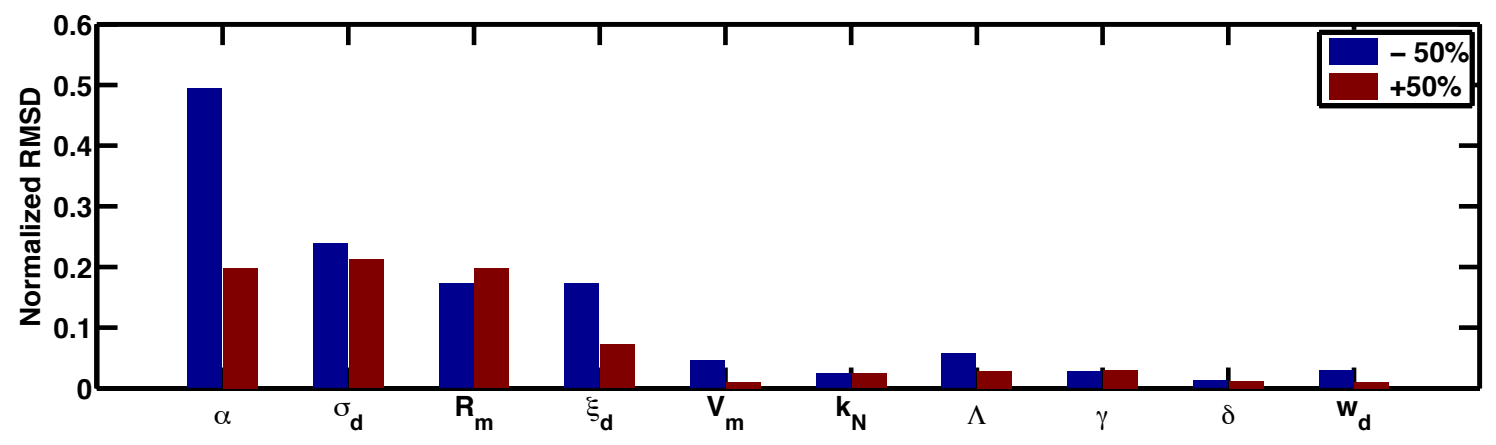

Figure 2-A1 Parameter sensitivity derived from a series of 1-D sensitivity experiments.

The histogram represents maximum normalized RMSD for each parameter with respect to the control simulation (experiment H40 in the main text; see Table 2-1 for parameter names, units and control values). For a given parameter, the blue/red bars indicate the maximum normalized RMSD after decreasing/increasing the control value by $50 \%$, respectively. 

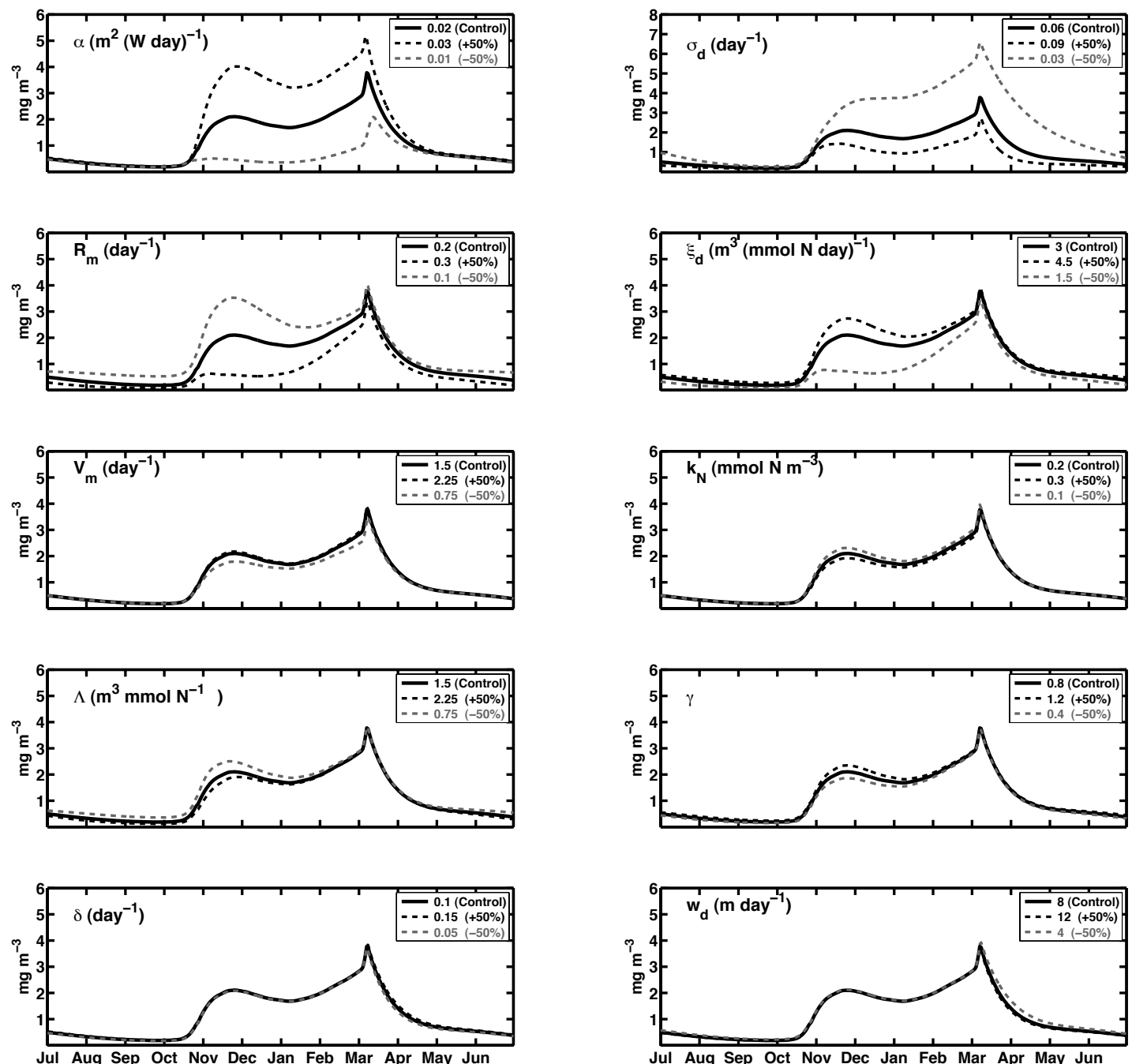

Figure 2-A2 Annual cycle of the surface chlorophyll concentrations in the sensitivity experiments. Black solid lines indicate the result from the control simulation; black/grey dashed lines are the results from the experiments in which the biological parameters are increased/decreased by $50 \%$, respectively. Note the $\mathrm{x}$-axis indicates one year from July 1st through June 30th. 

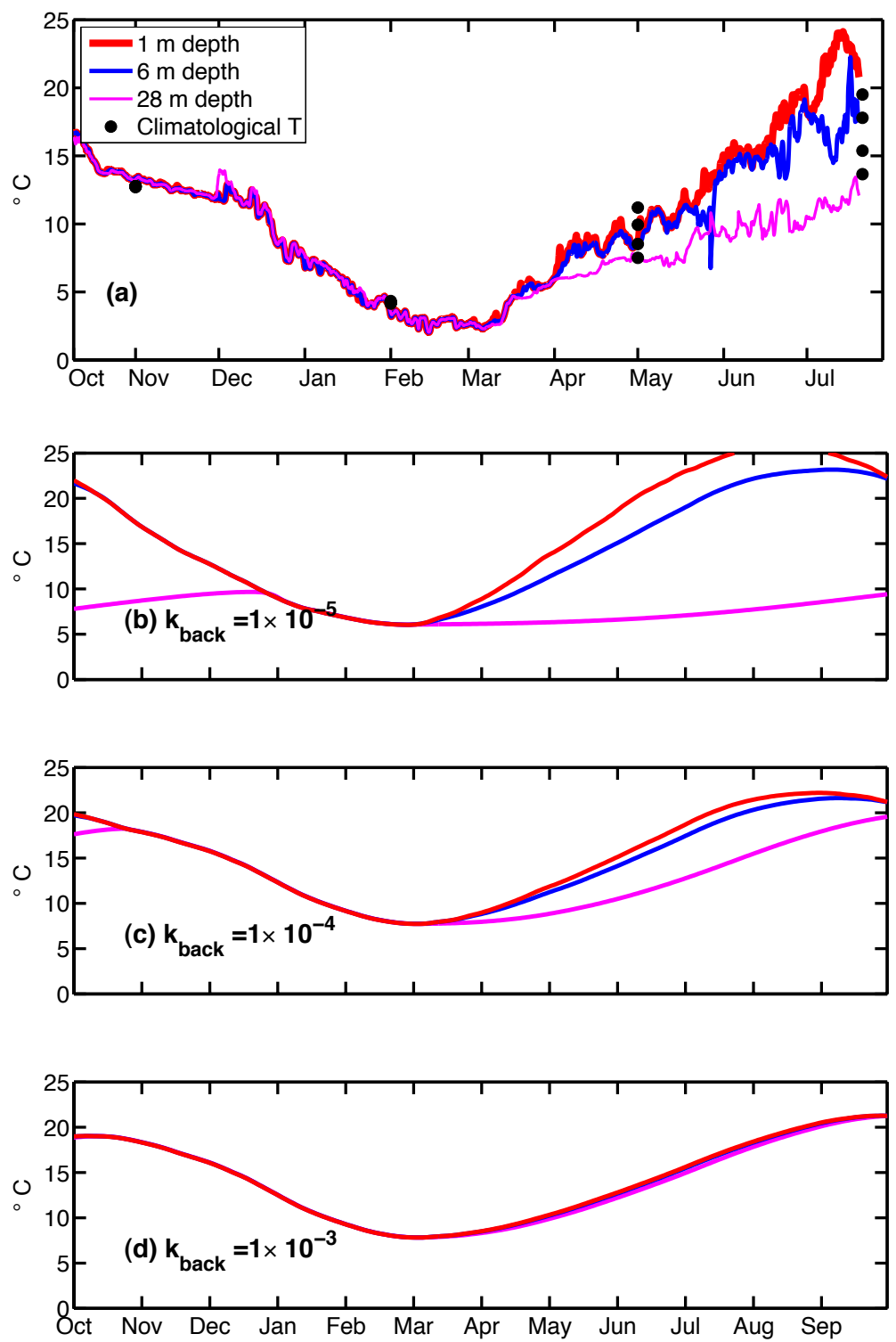

Figure 2-A3 Annual cycle of temperature at three depths (red 1m; blue 6m; magenta 28m) from: (a) one-year mooring dataset, black dots indicate historic observation at this location; (b) with $k_{\text {back }}=1 \times 10^{-5} \mathrm{~m}^{2} \mathrm{~s}^{-1}$; (c) with $k_{\text {back }}=1 \times 10^{-4} \mathrm{~m}^{2} \mathrm{~s}^{-1}$; (d) with $k_{\text {back }}=1 \times 10^{-3} \mathrm{~m}^{2} \mathrm{~s}^{-1}$. 